\title{
Problem -solving communication training and behavioral exchange for the treatment of parent -adolescent conflict
}

\author{
Ethan Sage Long \\ West Virginia University
}

Follow this and additional works at: https://researchrepository.wvu.edu/etd

\section{Recommended Citation}

Long, Ethan Sage, "Problem -solving communication training and behavioral exchange for the treatment of parent -adolescent conflict" (2001). Graduate Theses, Dissertations, and Problem Reports. 1382.

https://researchrepository.wvu.edu/etd/1382

This Dissertation is protected by copyright and/or related rights. It has been brought to you by the The Research Repository @ WVU with permission from the rights-holder(s). You are free to use this Dissertation in any way that is permitted by the copyright and related rights legislation that applies to your use. For other uses you must obtain permission from the rights-holder(s) directly, unless additional rights are indicated by a Creative Commons license in the record and/ or on the work itself. This Dissertation has been accepted for inclusion in WVU Graduate Theses, Dissertations, and Problem Reports collection by an authorized administrator of The Research Repository @ WVU.

For more information, please contact researchrepository@mail.wvu.edu. 
Problem-Solving Communication Training and Behavioral Exchange for the Treatment of Parent-Adolescent Conflict

Ethan S. Long

\author{
Dissertation submitted to the \\ Eberly College of Arts and Sciences \\ at West Virginia University \\ in partial fulfillment of the requirements \\ for the degree of
}
Doctor of Philosophy
in
Psychology
Christina Adams, Ph.D., Chair
Cynthia Anderson, Ph.D.
Cheryl McNeil, Ph.D.
Tracy Morris, Ph.D.
Linda Shuster, Ph.D.
Department of Psychology
Morgantown, West Virginia 2000

Keywords: Parent-adolescent conflict, Problem-Solving Communication Training

Copyright 2000 Ethan S. Long 


\author{
ABSTRACT \\ Problem-Solving Communication Training and \\ Behavioral Exchange for the Treatment of Parent-Adolescent Conflict
}

Ethan S. Long

Elevated levels of parent-adolescent conflict have been associated with a number of adolescent problem behaviors. One treatment that appears to be effective in reducing family conflict is Problem Solving Communication Training (PSCT). Research has indicated that PSCT appears to be an effective and acceptable treatment program for reducing parent-adolescent conflict. However, researchers have suggested some possible limitations associated with PSCT treatment. Many of the identified limitations of PSCT potentially may be addressed with the inclusion of a Behavioral Exchange (BE) treatment component. Evidence supporting this hypothesis is provided by the documented success of Behavioral Marital Therapy, a treatment package that uses a similar BE+PSCT procedure as that proposed by this study, for reducing distress experienced by couples. As a result, the purpose of this study was to examine if the combination of BE and PSCT treatment procedure would lead to effective reductions in parent-adolescent conflict. Four parent-adolescent dyads experiencing elevated levels of conflict participated in this investigation. A concurrent, multiple baselines across subjects design was utilized to assess session-by-session use of problem-solving skills, positive communication skills, and negative communication behaviors. Results suggest that the BE+PSCT treatment led to observable improvements in the use of problem-solving and communication skills for all four dyads during weekly discussions of issues frequently associated with parent-adolescent conflict. Furthermore, results indicate that three of the four parent participants and three of the four adolescent participants reported improvements at post-treatment and follow-up in their global distress, problem-solving, and communication skill use. In addition, three of the four families rated themselves satisfied to highly satisfied with the treatment. Unfortunately, the results are less conclusive when examining the discrepancies among participants' self-reports concerning general ratings of conflict and distress, use of problem-solving and communication skills at home, and adherence to irrational or distorted beliefs. Overall, the findings of this study provide preliminary evidence supporting the use of BE+PSCT for reducing parent-adolescent conflict. Directions for future research are suggested. 


\section{Acknowledgments}

I would like to thank those parents and adolescents who participated in this study, without whom this project would not have been possible. I would also like to recognize Tim Ash, Desiree Elmore, Sharon Kreuer, Angie Headlee, Amy Massey, Vicki Lumley, and Amy Herschell, all of whom have my utmost appreciation and gratitude for their help. Finally, I would like to thank Dr. Alisa Bahl, who has offered me much encouragement and support as a colleague and a friend. 


\section{Table of Contents}

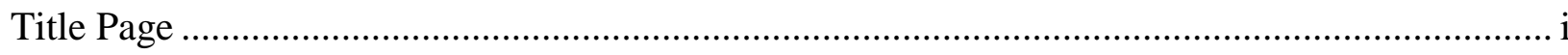

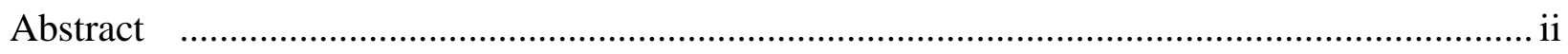

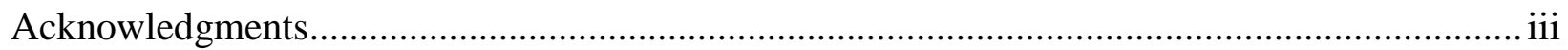

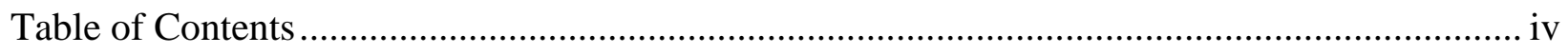

List of Tables and Figures........................................................................................ vi

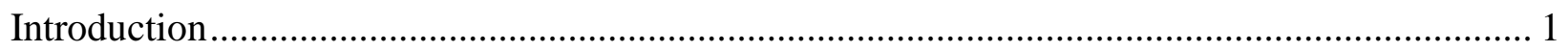

A Review of the PSCT Treatment Literature ............................................................... 5

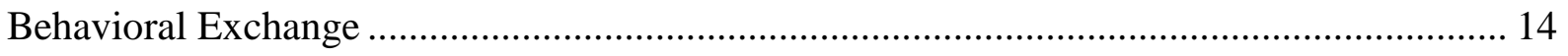

A Review of the BE plus PSCT Treatment Literature.................................................. 15

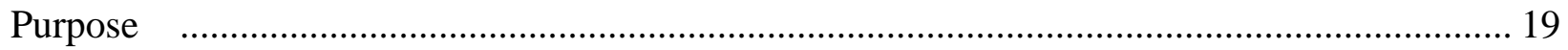

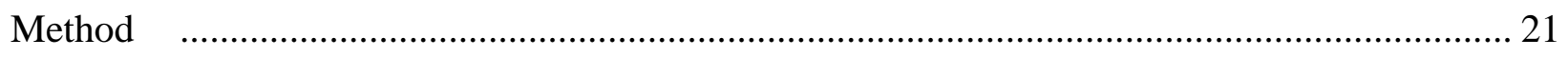

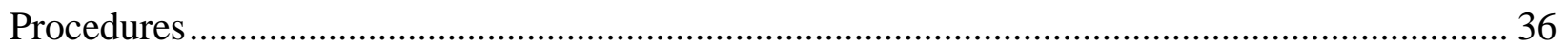

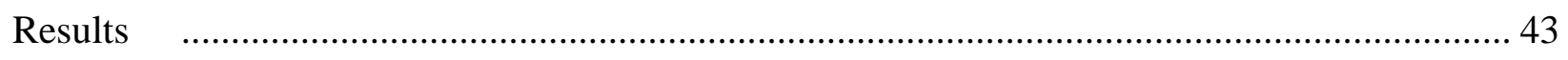

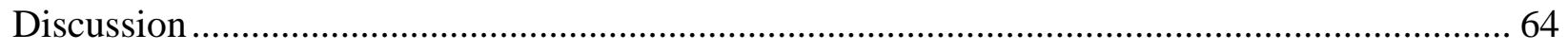

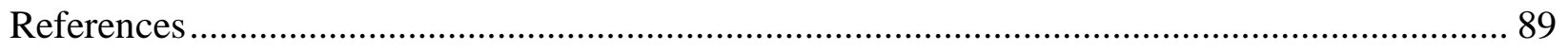

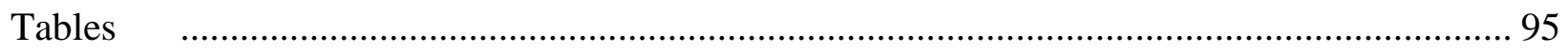

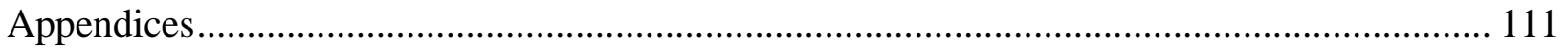

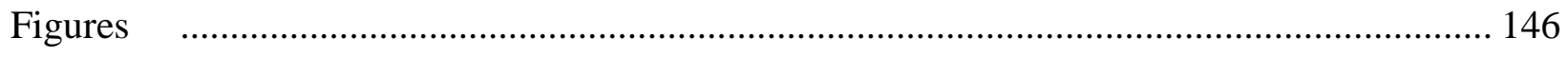




\section{List of Tables and Figures}

Table 1. Treatment Integrity Percentages for Each Therapist 95

Table 2. Percent Interobserver Agreement for Each Observers' Total PSBC Score and IBC Total Positive and Negative Scores on Test Videotapes 96

Table 3. Mean Percent Interobserver Agreement for Each Dyad's Total PSBC Score and IBC Positive and Negative Scores 97

Table 4. Pre, Post, and 2-Week Follow-up Data for Dyad 1 Parent (i.e., Rob) ........................ 98

Table 5. Pre, Post, and 2-Week Follow-up Data for Dyad 1 Adolescent (i.e., Jan)................... 99

Table 6. Therapist Rating of Family Cooperation (TRFC) Scores for Dyad 1....................... 100

Table 7. Pre, Post, and 2-Week Follow-up Data for Dyad 2 Parent (i.e., Nina)....................... 101

Table 8. Pre, Post, and 2-Week Follow-up Data for Dyad 2 Adolescent (i.e., Tom) ................ 102

Table 9. Therapist Rating of Family Cooperation (TRFC) Scores for Dyad 2........................ 103

Table 10. Pre, Post, and 2-Week Follow-up Data for Dyad 3 Parent (i.e., Donna) .................. 104

Table 11. Pre, Post, and 2-Week Follow-up Data for Dyad 3 Adolescent (i.e., Jon) ................ 105

Table 12. Therapist Rating of Family Cooperation (TRFC) Scores for Dyad 3...................... 106

Table 13. Pre, Post, and 2-Week Follow-up Data for Dyad 4 Parent (i.e., Sally).................... 107

Table 14. Pre, Post, and 2-Week Follow-up Data for Dyad 4 Adolescent (i.e., Don).............. 108

Table 15. Therapist Rating of Family Cooperation (TRFC) Scores for Dyad 4...................... 109

Table 16. Consumer Satisfaction Survey Average Item Scores obtained for Dyads 1-4

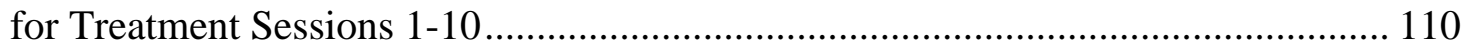

Figure 1. Problem-Solving Behavior Code Scores for Dyad 1 - 4 ...................................... 146

Figure 2. Interaction Behavior Code Scores for Dyad 1............................................... 147

Figure 3. Interaction Behavior Code Scores for Dyad 2 .............................................. 148 
Figure 4. Interaction Behavior Code Scores for Dyad 3................................................ 149

Figure 5. Interaction Behavior Code Scores for Dyad 4 ............................................... 150 


\section{Problem-Solving Communication Training and}

Behavioral Exchange for the Treatment of Parent-Adolescent Conflict

Adolescence is a period of transition during which many qualitative biological, psychological, and social changes occur (Conger, 1977). Adolescents typically begin to seek their independence and frequently challenge the family's established norms and boundaries, often resulting in family conflict. Parent-adolescent conflict has been defined as recurring verbal arguments and negative family interaction patterns between adolescents and their parents regarding multiple issues (e.g., curfew) that frequently go unresolved (Foster \& Robin, 1998). In fact, some conflict between parents and adolescents is considered developmentally characteristic and is to be expected (Montemayor, 1983). However, there may be serious ramifications for high levels of parent-adolescent conflict. Elevated levels of conflict and negative family communication has been associated with a number of adolescent problem behaviors, including drug use, higher rates of school drop out, and running away from home, suicide, and delinquency (Bachman, Green, \& Wirtanen, 1971; Gottlieb \& Chafetz, 1977; Montemayor, 1983). High degrees of parent-adolescent conflict have also been associated with adolescents with behavior disorders, such as Conduct Disorder (CD; Henggeler, Schoenwald, Borduin, Rowland, \& Cunningham, 1998), Oppositional Defiant Disorder (ODD; Robin, Koepke, \& Moye, 1990), and Attention-Deficit/Hyperactivity Disorder (ADHD; Barkley, Guevremont, Anastopoulos, \& Fletcher, 1992). Given the incidence of serious parent-adolescent conflict has been reported to be as high as $15-20 \%$ in all families living with an adolescent (Montemayor, 1983), treatment targeting parent-adolescent discord is warranted.

One treatment that appears effective in reducing family conflict is Problem Solving Communication Training (PSCT; Robin \& Foster, 1989). PSCT is based on a behavioral-family 
systems model of parent-adolescent conflict that hypothesizes that adolescent developmental factors, along with family skill deficits, structural difficulties, and functional interaction patterns potentiate family discord (Robin \& Foster). PSCT attempts to help families cope with adolescent developmental factors that may influence how parents and adolescents interact. A developmental factor that may contribute to family conflict includes adolescent adjustment to the physical and psychological changes occurring as a result of puberty and sexual maturity (Montemayor, 1983). In addition, adolescents frequently exhibit more independence-seeking behaviors such as arguing with their parents about curfew, dating, and chores (Conger, 1977). Furthermore, adolescents that once were responsive to parental consequences as children now may be influenced more by peer-mediated reinforcers (Robin \& Foster).

Along with these adolescent developmental changes, PSCT treatment take into account how the family reacts and copes with the adolescent's behavior changes (Robin \& Foster, 1989). Factors such as how competent the family is at solving problems and using communication skills may contribute to the severity of the parent-adolescent conflict (Robin \& Foster). In order to resolve specific disputes, the family needs to be proficient at following a logical sequence of skills to reach a solution to a given problem (D'Zurilla, 1988). Skill deficits may promote conflict because family disputes may not be resolved. In addition, family members must be able to demonstrate expressive and receptive communication abilities in order to successfully implement these problem solving skills. Negative communication styles are likely to impede problem solving by provoking anger and reciprocating negative statements. Deficits in communication skills may lead family members to become so angered that they do not listen to each other or accurately understand what is being said to them, consequently increasing the potential for parent-adolescent conflict (Robin \& Foster; Robin, Koepke, \& Nayar, 1986). 
Moreover, family members may possess unreasonable beliefs and misattributions regarding the behaviors and intentions of other family members. Both parent and adolescent cognitive distortions may exacerbate conflict because parents and adolescents may respond to environmental events related to developmentally appropriate adolescent independence seeking behaviors with excessive anger, thus inhibiting rational resolution of disagreements (Robin \& Foster). For example, consider a father who holds the extreme belief that if his daughter breaks her curfew, she will have unprotected sex, get pregnant, and ruin her life. Despite the fact that the daughter has never given the father any evidence that she would do these things, his extreme beliefs contribute to him becoming angry when she comes home late. As a result, he yells at his daughter and grounds her for three months as soon as she returns home, effectively inhibiting any rational resolution to her developmentally appropriate behavior. PSCT includes treatment components addressing each of these potential problem-solving, communication, and cognitive processing skill deficits.

PSCT intervention for parent-adolescent conflict is typically conducted in 8-12 sessions (Robin \& Foster, 1989). Families are taught a democratic approach to problem solving to resolve specific issues that family members disagree upon. Specific negative communication styles are identified and targeted for change to facilitate and enhance communication between family members. Cognitive restructuring techniques are employed to challenge and modify family members' rigid unreasonable beliefs and misattributions. Throughout the intervention, the therapist uses correction, modeling, behavior rehearsal, and feedback to teach problem solving skills and change negative communication patterns (Robin \& Foster). In addition, the therapist teaches family members to use reframing techniques and to conduct experiments designed to disconfirm unreasonable beliefs (Robin \& Foster). Furthermore, therapists attend to structural 
and functional interaction patterns by generating hypotheses about interlocking contingency arrangements and patterns of reinforcement that influence negative family interactions (Robin \& Foster). Skills learned in session are used to modify and reorganize problematic structural and functional arrangements. Successive sessions focus on increasingly severe family issues that result in the parent-adolescent conflict. Homework consisting of additional practice in the use of problem solving skills, communication skills, and cognitive restructuring techniques are assigned to program for generalization across time and settings (Robin \& Foster). Overall, the goals of PSCT are accomplished within the framework of three overriding treatment components: (a) problem solving, (b) communication training, and (c) cognitive restructuring (Robin \& Foster). In general, PSCT begins by teaching family members problem solving skills (Robin \& Foster, 1989). Problem solving skills training attempts to teach parents and adolescents four basic skills: (a) problem definition, (b) generation of alternative solutions, (c) decision making, and (d) planning solution implementation. First, family members are taught to operationally define the problem in a concise, nonaccusatory manner. Next, the family is taught to brainstorm and develop creative, novel ideas for evaluation. For the third skill, decision making, family members are taught to use a plus and minus rating system to independently evaluate the ideas generated in the previous step. The family members discuss the consequences for everyone involved and are prompted to compromise if a consensus cannot be reached. The fourth step consists of teaching the family to specify the details for putting the agreed-upon solution into practice. A final step, renegotiation, is utilized when implementation of the initial solution fails to resolve the conflict. Families are taught to problem solve why the initial plan did not work and to develop changes that may lead to successful problem resolution. 
The communication training component of PSCT generally takes place throughout all of the PSCT sessions. Generally, communication skill training is conducted in a more informal manner than problem solving training and is tailored to address specific communication deficits exhibited by the family. During the initial assessment sessions, particular deficits and excesses in positive and negative communication skills are identified for each family. The therapist then targets the deficits or excesses in session by stopping the discussions when the inappropriate verbal behaviors occur. The therapist provides feedback, instructions, modeling, and rehearsal to modify the negative communication patterns identified for treatment (Robin \& Foster, 1989).

The final component of PSCT is designed to teach family members cognitive restructuring techniques to change problematic perceptions, beliefs, and attributions. PSCT cognitive restructuring techniques are based on Ellis's rational-emotive approach and Beck's collaborative empiricism (Robin \& Foster, 1989). Family members are taught techniques such as relabeling and how to correct misattributions through verification. For more resistant cognitive distortions, family members are assigned homework in which they practice identifying and challenging absolutistic beliefs through didactic debate and experimental learning (Robin \& Foster).

\section{$\underline{\text { A Review of the PSCT Treatment Literature }}$}

Four published treatment-outcome studies have been conducted to evaluate the effectiveness of the PSCT treatment outlined by Robin and Foster (1989). An initial study conducted by Robin, Kent, O’Leary, Foster and Prinz (1977) evaluated the effectiveness of problem solving and communication training to reduce mother-adolescent conflict as compared to no treatment. Twenty-four mother-adolescent dyads were randomly assigned to either a problem solving and communication training condition or a wait-list control condition. The 
adolescents, half of whom were male, ranged in age from 11 to 14 years. Treatment consisted of the problem solving and communication training described above; however, no homework was assigned and the cognitive restructuring component was not implemented. Dependent measures included a communication questionnaire and pre- and post-intervention audio tapes of the dyads discussing hypothetical and real-life conflict issues for $10 \mathrm{~min}$. Trained observers recorded the frequency of four categories of verbal behaviors: problem definition, option listening, evaluation, and agreement. Results indicated that the treatment group demonstrated significant posttreatment improvement in their problem solving scores when discussing both the hypothetical and real-life conflict issues. The wait-list control group did not show significant changes in their use of problem solving skills when discussing the hypothetical or the real-life conflict issues. Interestingly, both the treatment and the wait-list control groups did not show significant changes on the communication checklist. Therefore, these results suggested that the problem solving and communication training program could enhance the problem solving skills of mother-adolescent dyads when discussing conflict issues in a controlled setting. However, there was no evidence that these skills generalized to the home environment. The absence generalization strategies for the home, along with the lack of a comprehensive, psychometrically sound assessment battery, limited the utility of this treatment as implemented in this study.

In a second study of problem solving and communication training, Foster, Prinz, and O'Leary (1983) attempted to improve on the original Robin et al. (1977) study in two ways. First, Foster et al. used a more complete assessment battery to better assess individual effects of treatment. Second, Foster et al. compared the PSCT originally used in the Robin et al. study to a similar PSCT treatment protocol that included an additional systematic set of homework procedures. These homework procedures were included in an attempt to enhance the 
generalization of the PSCT treatment. Twenty-eight families were randomly assigned to a PSCT condition, a PSCT plus generalization condition, or a wait-list control condition. Dependent variables included scores on the Issues Checklist (IC; Prinz, Foster, Kent, \& O’Leary, 1979, Robin \& Weiss, 1980), Conflict Behavior Questionnaire (CBQ; Prinz et al.), Daily Home Report, a consumer satisfaction survey, and 10-min audiotape discussion of mother-adolescent dyads discussing real-life conflict issues. Discussions were coded using the Interaction Behavior Code (Prinz \& Kent, 1978). Six-to eight-week follow-up data were collected on the two treatment groups.

Significant gains were found on the questionnaires at post-treatment for both treatment groups as well as on some of the measures for the wait-list control group. Furthermore, followup data regarding both treatment groups (follow up data were not collected on the wait-list control group) showed some improvements from pre-treatment scores on virtually all measures, indicating that some treatment effects were maintained. However, on some measures, the programmed generalization strategies treatment group gains deteriorated, thus raising questions regarding the utility of the homework sessions. Lastly, differences were not found among the coded audiotape discussions at post-treatment between the two treatment groups and the wait-list control group, as was evidenced in the original Robin et al. (1977) study. Taken together, the results from this study indicated that PSCT could potentially produce changes in conflict issues and communication over short follow-up periods; however, the effectiveness of generalization strategies was questionable. Furthermore, the extent to which PSCT could produce beneficial changes remained unclear, considering the surprising improvements found in the wait-list control group. 
A third study conducted to further evaluate the effects of PSCT and to clarify the therapeutic benefits of the PSCT treatment package was conducted by Robin (1981). This study compared PSCT, an Alternative Family Therapy (AFT) treatment group, and a wait-list control condition. The PSCT treatment package included a systematic set of homework procedures in an attempt to enhance generalization and the cognitive restructuring component described previously. Thirty-three families were randomly assigned to groups. The PSCT condition consisted of seven 1-hour sessions. The AFT therapy consisted of seven sessions of the typical treatments derived from psychodynamic, family systems, and eclectic orientations normally used in alleviating parent-adolescent conflict at the clinic where the study was conducted. Dependent measures included the CBQ, the IC, a Home Report, and the audiotape recording of two family discussions of real-life conflict issues pre and post treatment. The audiotape discussions were coded using the Parent-Adolescent Coding System (PAICS) (Robin). Follow-up data consisting of parent and adolescent reports on the CBQ and the IC were collected 10 weeks after the conclusion of treatment for both the PSCT and the AFT groups. Finally, families completed a survey which measured their satisfaction with therapy and their assigned therapist.

Both treatment groups improved significantly more than the wait-list control group on behavior observation measures of problem-solving communication skills and on self-report measures of conflict. PSCT was found to be superior to AFT treatment on the observational measures of problem solving behavior. Interestingly, parents and adolescents generally reported positive attitudes toward both therapies and their assigned therapist. The follow-up data suggested that gains on the questionnaires maintained after 10 weeks following the termination of both treatments. However only $60 \%$ of the families who completed therapy responded to the 
follow-up questionnaires, limiting the ability to interpret the maintenance of the treatment effects.

A fourth study, conducted by Barkley et al. (1992), examined the effects of PSCT for families with adolescents diagnosed with ADHD, a disorder often associated with parentadolescent conflict (Robin, 1998). Sixty-four families with adolescents were randomly assigned, within gender, to one of three possible treatment conditions: PSCT, behavioral management training (BMT), and structural family therapy (SFT). Eight to ten weekly, 1-hour treatment sessions were conducted, and follow-up data were collected three months after treatment termination. Dependent measures included, the mothers' and adolescents' scores on Family Beliefs Questionnaire (FBI; Vincent-Roehling \& Robin, 1986), IC, and the CBQ. In addition, 1015 min videotaped discussions of a neutral situation and a real-life conflict situation were coded using the Parent-Adolescent Interaction Coding System-Revised (PAICS-R; Robin \& Foster, 1989). Furthermore, the therapists completed rating scales following each session assessing family cooperation. Using a 7 -point Likert scale $(1=$ low, $7=$ high $)$, therapists rated items pertaining to how the family accepted the therapist, the quality of communication in therapy, the quality of effort by the family during problem solving, completion of homework, and achievement of session goals. In addition to the dependent measures, families completed consumer satisfaction surveys.

According to the self-report measures, the number of conflicts, the intensity of anger during discussions at home, as well as parent-adolescent communication significantly improved for all three treatment groups. In addition, these results were maintained at 3-month follow-up. However, results from the direct observations of problem solving behaviors, as measured by the PAICS-R, were mixed. Both positive problem solving behavior categories (e.g., 
Defines/evaluates) and negative behavior categories (e.g., Defends/complains) were found to increase significantly at post-treatment, thus the authors were unable to make definitive statements regarding the effectiveness of the PSCT treatment for enhancing problem solving skills during the videotaped discussions. In addition, PSCT treatment group mothers' ratings (as measured by the FBI) worsened in the degree of unreasonable beliefs regarding their adolescents' behavior. The mothers' ratings in the BMT and SFT treatment groups did not change. The authors speculated that this may be due to a heightened awareness due to the cognitive restructuring treatment component found in the PSCT treatment. Finally, the families in the PSCT group were rated as less cooperative with treatment than those in the BMT and SFT treatment groups. However, families in all three treatment groups rated themselves equally as highly satisfied with their respective treatments.

The treatment studies reviewed here highlight some potential benefits of PSCT treatment programs for parent-adolescent conflict. First, for three of the four studies, PSCT resulted in reducing parent-adolescent conflict and enhancing problem solving and communication skills at home as reported on the participant self-report measures. These studies employed questionnaires that have demonstrated sufficient psychometric properties (e.g., IC, CBQ; Robin \& Foster, 1989), further lending credibility to the reported effectiveness of PSCT for ameliorating conflict at home (Robin \& Foster, 1984). Second, for two of the four studies, PSCT resulted in significant, observable problem solving behavior change in videotape and audiotape discussion sessions. This suggests that PSCT can be used to teach parents and adolescents problem solving and communication skills effectively (Robin \& Foster, 1984). Third, for three of the four studies, follow-up data indicated that treatment gains made with PSCT were maintained for 6-12 weeks after treatment was terminated. Fourth, in the three studies that examined consumer satisfaction 
ratings, participants found PSCT to be an appropriate and acceptable treatment. Furthermore, a study conducted by Mittl and Robin (1987) examined how acceptable college students and their mothers found PSCT, behavioral contracting, paradox, and medication in the treatment of parentadolescent conflict. Results indicated that PSCT had higher acceptability ratings compared to the other treatments. Taken together, these conclusions tentatively support PSCT as an effective and acceptable treatment for parent-adolescent conflict.

Nonetheless, researchers have suggested some disadvantages that may result from using PSCT treatment with parents and adolescents experiencing conflict. One potential disadvantage suggested by Barkley et al. (1992) was that the therapists in the Barkley et al. study rated the families in the PSCT as less cooperative with treatment than families in the other treatment groups. Barkley et al. suggested that PSCT may require parents and adolescents to learn more novel and diverse skills when compared to other treatments. PSCT also incorporates multiple homework assignments designed to practice new skills that, in order to complete, require greater cooperation from the adolescent than compared to other therapies. Barkley et al. speculated that perhaps families found PSCT to be more demanding, and thus appeared to be less cooperative. Certainly, PSCT requires parents and adolescents to cooperate and work together to learn new skills, which may be difficult for families experiencing high levels of conflict. Thus, strategies designed to first reduce the hostilities between family members before requiring them to work together may potentially enhance the effectiveness of PSCT.

Another disadvantage raised by the Barkley et al. (1992) study includes the finding that the PSCT treatment group mothers' ratings worsened in their degree of negative attributions or cognitive distortions regarding their adolescents' behavior when compared to the mothers' ratings in the other treatment groups. Specifically, the mothers in the PSCT group reported more 
extreme beliefs about adolescent obedience and perfectionism after treatment than before treatment. One possible explanation for this finding suggested by Barkley et al. is that PSCT was the only treatment that required parents to specifically focus on and address their own negative attributions and beliefs. As a result, parents may have an increased awareness of their beliefs and attributions, rather than an actual worsening in the beliefs, that is being reflected in their posttreatment reports. Another explanation suggested by Barkley et al. was that the cognitive restructuring component of PSCT resulted in a negative side effect, in which the parents' extreme beliefs and negative attributions were exacerbated. In support of this theory, a study conducted by Alexander, Waldron, Barton, and Mas (1989) found that family therapies that initially emphasize and focus immediately on problems and negative attributions (e.g., PSCT) may actually create or exacerbate negative attributions that are highly resistant to change. The resulting negative attributions may produce a negative context within which the family members become highly resistant to learning new skills (e.g., cognitive restructuring) and cooperating in therapy (Alexander et al). Alexander et al. suggested that by initially focusing parents on the more positive, nonblaming, relational aspects of their adolescent's behavior, therapists may be able to decrease the levels of resistance often exhibited by parents and adolescents in therapy.

The results of the Alexander et al. (1989) study suggest another potential weakness in the PSCT treatment outlined by Robin and Foster (1989). PSCT treatment currently makes only a limited attempt in the initial phases of therapy to restore the parent-adolescent relationship before focusing on long term skill building. Other parent-child therapies (e.g., Parent-Child Interaction Therapy, PCIT; Hembree-Kigin \& McNeil, 1995) generally begin by focusing on establishing a more positive relationship between the parent and the child before teaching more complex skills (e.g., problem solving skills). In PCIT, therapy begins with child directed play sessions in which 
the parent is taught to recognize the child's positive qualities. Parents are instructed to follow the child's lead and provide high rates of reinforcement for appropriate behavior before learning how to implement the more complex discipline procedures. Consequently, a positive context is developed for the parents and child to interact, thus potentially de-escalating anger and coerciveness between the parent and child (Patterson, 1982). This potentially increases the likelihood that skills taught later in therapy will be acquired (Hembree-Kigin \& McNeil). Similarly, some marriage therapies (e.g., Behavioral Marital Therapy; Jacobson \& Margolin, 1979) also attempt to initially develop and enhance the relationship between partners first by focusing on nonconflictual issues. The expectation is that by developing or enhancing a positive relationship by first focusing on nonconflictual issues, the couple will experience some success in therapy, thus the potential for treatment resistance will be decreased (Jacobson \& Margolin). As a result, couples may increase their commitment to learning and using more difficult skills taught in the later stages in therapy at the beginning of treatment (Jacobson \& Margolin).

The lack of focus on developing a more positive context for therapy, in which the positive aspects of the parent-adolescent relationship are emphasized, suggests a final disadvantage of PSCT treatment. This specifically pertains to the developmental level of understanding that adolescents generally have regarding the effects of their behavior on others. Brigham (1989) has suggested that many adolescents do not understand the effects of their behavior on their environment. This failure to recognize the concept of reciprocity aggravates parent-adolescent conflict. By initially teaching adolescents the effects of their behaviors on the parent-adolescent relationship and the subsequent behavioral consequences that occur, adolescents can be taught to function more effectively within their environment (Brigham). Traditional PSCT fails to initially teach reciprocity skills to adolescents which potentially could 
develop a more positive relationship between the adolescent and the parent, thus addressing some of the potential weaknesses of PSCT suggested previously.

\section{Behavioral Exchange}

One treatment strategy that has been used to alleviate conflict between parents and adolescents, as well as conflict between spouses and couples in traditional marriage/couples therapy, is to teach reciprocity skills (Besalel \& Azrin, 1981; Lawrence, Eldridge, Christensen, \& Jacobson, 1999; Jacobson \& Margolin, 1979). Reciprocity skills training or Behavioral Exchange (BE) has been used separately (e.g., Besalel \& Azrin) or as part of a larger treatment package, known as Behavioral Marital Therapy (BMT; Jacobson \& Margolin) that combines BE and PSCT treatment components. Initially beginning therapy with a BE component may potentially address some of the disadvantages resulting from traditional PSCT treatment. BE treatment attempts to alleviate conflict at home by having both parties focus on nonconflictual issues in the participants' natural environments (Besalel \& Azrin; Jacobson \& Margolin; Lawrence et al.). Generally, BE treatment packages are comprised of five components. First, the participants are taught to identify and list existing reciprocity of reinforcement. Next, behavioral goals are established to escalate the number of positive behaviors, independent of other types of negative interactions. The third component consists of teaching participants some form of behavioral contracting whereby the participants write and sign agreements regarding the positive changes they intend to make in their behavior (Besalel \& Azrin; Jacobson \& Margolin). The fourth component teaches participants to increase the amount of time they engage in preferred activities with each other (Besalel \& Azrin; Jacobson \& Margolin). The final component generally consists of some form of positive communication training for the participants (Besalel \& Azrin; Jacobson \& Margolin; Lawrence et al). As a result of introducing a BE treatment early in therapy, it is 
hoped that families and spouses first experience success in therapy and learn that relationship improvement is possible. In addition, the likelihood for treatment resistance is decreased and the stage is set for teaching complex, long-term skills such as those taught in PSCT (Jacobson \& Margolin).

\section{$\underline{\text { A Review of the BE plus PSCT Treatment Literature }}$}

Unfortunately, there has been only two treatment studies that have examined the effects of the BE treatment to reduce parent-adolescent conflict. Besalel and Azrin (1981) and Raue and Spence (1985) conducted studies which applied the BE procedures reviewed previously. Besalel and Azrin examined the effects of BE initially for twenty-nine families consisting of parents and youths which reported experiencing conflict. The youths ranged from 6 to 16 years of age with a mean age of 11 years old. Families were randomly assigned to either a BE treatment or a delayed wait-list control group. The BE treatment was implemented in four 1.5 hour sessions. Assessment measures consisted of experimenter-developed parent and child problem checklists.

Following BE treatment, results indicated significant reductions in both the parents' and the childrens' perceived problems, as indicated by the checklists. Treatment gains were reportedly maintained at 6-month follow-up. However, given the lack of established psychometric properties for the outcome measures used in this study, these results should be viewed tentatively.

A second study evaluating the effects of BE treatment for alleviating parent-adolescent conflict was conducted by Raue and Spence (1985). Raue and Spence's BE treatment consisted of similar procedures as those used in the Besalel and Azrin (1981) study, however they employed standardized assessment measures and observational data. In addition, Raue and Spence evaluated the benefits of BE treatment applied in a family group-based program. Thirty 
families with youths ranging in age from 10 to 16 years of age were randomly assigned to one of three conditions; a individual-family based BE program, a group-based BE program, and a waitlist control group. The group-based BE program consisted of 3 groups of 3 families attending similar sessions to those in the individual-based BE training program. Standardized outcome measures for this study included the Achenbach Child Behavior Problem Checklist (CBPC; Achenbach, 1978), the Parent Attitude Survey (PAS; Hereford, 1963), and the Family Environment Scale (FES; Moos, Insel \& Humphrey, 1974). Additional measures developed specifically for this study included parent collected youth observations and the Child Perception of Parent Behavior Questionnaire (CPPBQ; Raue \& Spence, 1985).

Results indicated that the group training and individual training BE treatment groups improved as measured by the CBPC Aggressiveness factor and parent collected observations. Both the group and individual BE training groups were superior to the wait-list control condition, and no statistically significant differences were found between the two BE training groups. Results were maintained at a 2-month follow-up. Unfortunately, statistically significant differences between the two BE training groups and the wait-list control group were not obtained on the PAS, the FES, or on the CPPBQ. Taken together, the results of these two treatment outcome studies suggest that $\mathrm{BE}$ treatment programs alone may produce some immediate benefits for parents and adolescents experiencing conflict. Unfortunately, the limited number of treatment studies evaluating BE treatment for parent-adolescent conflict allow for tentative conclusions at best. As a result, it may be advantageous to examine studies assessing the effects of BE and PSCT treatment programs for other populations.

Traditional behavioral marital therapy (BMT; Jacobson \& Margolin, 1979) calls for the combination of the five BE components described previously with PSCT procedures similar to 
those described by Robin and Foster (1989). In a series of studies evaluating the various components of BMT, Jacobson (1984), Jacobson et al. (1985), and Jacobson, Schmaling, and Hotzworth-Munroe (1987) conducted a 2-year, longitudinal component analysis. These studies compared the effects of the traditional BMT with the two components (i.e., a BE treatment and a PSCT treatment) each presented in isolation. The study attempted to determine if there were any advantages to using BE plus PSCT, or if either of the individual treatments would suffice to alleviate conflict experienced by couples.

Sixty couples experiencing conflict were randomly assigned to one of three treatment groups (i.e., BE, PSCT, BMT) or a wait-list control group. All treatment groups were scheduled to attend one 60 -to 90 -min treatment session each week for 12 weeks. The BE treatment consisted of only the five components outlined in the previous section. The PSCT treatment adhered to only the components reviewed previously as outlined by Robin and Foster (1989). The BMT treatment combined key elements of both the BE and the PSCT treatments. The first four sessions were devoted to implementing BE procedures, and the following sessions concentrated on teaching the couple problem-solving and communication skills. Outcome measures included the couples' self-report of marital satisfaction as measured by the Dyadic Adjustment Scale (DAS; Spanier, 1976). In addition, the couples presenting complaints were assessed by the Areas of Change Questionnaire (AC; Weiss \& Perry, 1979). Finally, each spouse completed the Spouse Observation Checklist (SOC; Weiss \& Perry) which tallied the frequency of positive, neutral, and negative events that occurred at home. Follow-up data consisting of the DAS and the AC were collected at 6-month (Jacobson, 1984), 1-year (Jacobson et al., 1985), and 2-years (Jacobson et. al, 1987). 
Couples in all three treatment groups showed significant improvement relative to the wait-list control group on the three outcome measures administered immediately following treatment (Jacobson, 1984; Jacobson et al., 1985). All three treatments were equally effective in enhancing marital satisfaction and reducing the frequency of presenting complaints. However, only the BE couples showed significantly greater increases in positive behavior exchanges. The BMT couples produced a greater number of positive behavior exchanges than the PSCT couples at post-treatment. However, statistically significant differences between BMT pre-treatment and BMT post-treatment were not found.

Because $\mathrm{BE}$ focuses on the immediate alleviation of marital distress, if follows that this group demonstrated desirable outcomes at the immediate end of treatment. It is important to note, however, that the BE couples reversed their treatment gains at 6-month follow-up, whereas the PSCT and the BMT couples actually maintained or continued to improve (Jacobson, 1984; Jacobson et al., 1985). Therefore, including both BE and PSCT components in a treatment package may have complementary advantages. The immediate increases in positive behavioral exchanges attained with the BE component may help to provide a positive context for couples to begin to learn new skills to prevent future conflict. In addition, the problem solving and communication skills learned in the PSCT component may be beneficial in maintaining treatment effects for 6 months (Jacobson, 1984; Jacobson et al., 1985). Furthermore, some couples in the PSCT and the BMT treatments actually improved from post-treatment to 6-month follow-up, suggesting that teaching PSCT skills could enhance treatment effects that occur after the termination of therapy (Jacobson, 1984; Jacobson et al., 1985). Unfortunately, 1-year and 2year follow-up data showed no statistical differences on the outcome measures between the three treatment groups, thus suggesting that after 6 months therapy gains may start to diminish. 
However, couples in the BMT treatment group reported being more happily married and were least likely to be separated or divorced at both the 1- and 2-year follow-up when compared to the other treatment groups, despite the findings on the outcome measures (Jacobson, 1984; Jacobson et al., 1985).

The results of the BMT studies reviewed here and in other BMT literature reviews (e.g., Baucom \& Hoffman, 1986; Hahlweg \& Markman, 1988) suggest that the combination of the BE treatment component with the PSCT treatment component can effectively decrease the amount of conflict experienced by couples (Baucom \& Hoffman; Hahlweg \& Markman; Jacobson, 1984). BMT is one of the most widely tested and empirically supported interventions for couples experiencing conflict (Christensen, Jacobson, \& Babcock, 1995; Lawrence et al., 1999). In fact, it is the only form of couples therapy that meets the criteria of an "empirically validated treatment," as determined by the clinical psychology division of the American Psychological Association (Crits-Christoph, Frank, Chambless, Brody, \& Karp, 1995). Given the success of BMT, it seems likely that a BE treatment component combined with Robin and Foster's (1989) PSCT treatment may enhance therapy for reducing parent-adolescent conflict.

\section{$\underline{\text { Purpose }}$}

Research has indicated that Robin and Foster's (1989) PSCT treatment appears to be an effective and acceptable treatment program for reducing parent-adolescent conflict. However, researchers have suggested some possible limitations associated with PSCT treatment (Barkley et al., 1992). PSCT places immediate focus on the alleviating the problems reported by the family and the negative behaviors and attributions associated with those problems. However, the PSCT model fails to guide the therapist to develop initially a positive context for future therapy sessions. As a result, treatment resistance may be increased and family members' initial 
involvement in therapy is less likely to occur. Because PSCT focuses on teaching difficult skills to parents and adolescents to reduce conflict issues at the onset of treatment, lack of initial involvement may be quite detrimental to the effectiveness of treatment. PSCT may require greater commitment and cooperation on behalf of family members early in treatment in order to learn these difficult skills (Barkley et al.). In addition, PSCT does not include a treatment component that addresses younger adolescents lack of reciprocity skills. As a result, some adolescents may not understand the effects that their behaviors have on other family members, thus exacerbating conflict (Brigham, 1989).

Many of the identified limitations of PSCT potentially may be addressed with the inclusion of a BE treatment component. BE emphasizes improving the immediate relationship by first focusing on increasing the reciprocity of reinforcement between all participants. Participants are taught to reinforce already existing, appropriate communication skills while attending to nonconflictual issues. Family members increase the amount of time they engage in preferred activities, as well as rates of verbal praise they provide for each others' behaviors non-contingent upon inappropriate behavior. In doing so, a positive context for therapy is developed. As the family experiences some immediate alleviation of conflict and some improvement in their relationships, they learn that relationship improvement is possible. This positive context potentially lessens the likelihood for treatment resistance and likely increases family members' commitment and cooperation. Increased commitment and cooperation may be important for teaching the more difficult, long-term prevention skills included in PSCT. In addition, early success in treatment may heighten the family's compliance with the multiple homework tasks assigned later in PSCT treatment. As a result, the family may benefit more from treatment by maintaining and generalizing treatment gains to novel conflict situations. Although the number 
of studies examining the effects of BE used in isolation for alleviating parent-adolescent conflict is limited, those that have been conducted have been relatively successful. Considering these results, along with the documented success of BMT treatment for reducing distress experienced by couples, it appears that combining a BE component with traditional PSCT to alleviate parentadolescent conflict is warranted. As a result, the purpose of this study will be to examine if the combination of BE and PSCT treatment procedures will lead to effective reductions in parentadolescent conflict. Specific hypotheses to be tested include:

1. A BE+PSCT treatment program will result in observable behavior change in the use of problem solving skills and increases in positive and decreases in negative communication patterns during discussions of common problems associated with parent-adolescent conflict.

2. A BE+PSCT treatment program will reduce conflict at home and enhance problem solving and communication skills as reported by parents and adolescents on pre- and post-treatment self-report measures.

3. A BE+PSCT treatment program will be an appropriate and acceptable form of treatment for parents and adolescents experiencing conflict as measured by their consumer satisfaction ratings.

\section{Method}

\section{$\underline{\text { Participants }}$}

Initially, five parent and adolescent dyads participated in the study. However, one family withdrew participation due to time constraints associated with project activities. To be eligible, dyads had to meet the following criteria: (a) the adolescent had to be at least 12 years of age and have no immediate, ongoing legal proceedings against them for criminal offenses, (b) both members of the dyad had to report significant distress due to disagreements concerning rules and 
responsibilities during the initial interview, (c) both family members had to be willing to attend sessions together, (d) both members agreed to the constraints of the research design (waiting to begin therapy due to multiple baselines, videotaping of the assessment sessions, completing questionnaires, submitting a \$10 tape recorder deposit to be returned upon completion of the program), and (d) both members of the dyad had to exhibit the absence of mental retardation, psychosis, or known organic brain damage. In addition, adolescents and parents had to endorse arguing about at least 5 issues frequently found to be the subject of parent-adolescent conflicts, as measured by the Issues Checklist.

Four dyads (including the family who withdrew participation )were recruited through announcements made at local area schools and one dyad was referred by the Quin Curtis Center, the West Virginia University Psychology Department's mental health clinic. The primary investigator initially met individually with each dyad to discuss reasons for the referral, purposes and logistics of the study, and to assess whether the family was appropriate for treatment. It should be noted that six additional families expressed interest in participating in the study, but after hearing the logistics of the study, opted not to participate. If both the adolescent and parent agreed to participate, they signed the informed assent or consent forms. Next, participants completed structured interviews and paper-and-pencil measures consisting of rating scales of behavioral adjustment, family conflict, and parental self-report measures of adolescent psychological symptoms and overall adjustment. All of the participants who met the selection criteria were admitted into the study on a first come first serve basis. Each adolescent was paid $\$ 10$ upon completion of the pre-treatment measures and another $\$ 10$ upon completion of the post-treatment measures. In addition, each adolescent participant was entered into a $\$ 100$ lottery 
for participating in the study. The lottery winner was chosen after all of the families had completed their 2-week follow-up assessment session.

Dyad 1. Dyad 1 consisted of a 38-year-old father, Rob, and his 12-year-old female adolescent, Jan. Rob and Jan lived at home with Jan's step-mother, age 30, and Jan's half-sister, age 2. Rob was employed as a dispatcher at a local university and the step-mother was employed as a nurse. Both father and step-mother had been married and living together for approximately 3 years at the time when Rob and Jan participated in the study. Two years prior to Rob's second marriage, Jan lived with her father and her biological mother, along with her older sister, aged 16. Rob reported that Jan's biological mother had a severe alcohol and drug problem that led to his filing for a divorce. As a result, Jan saw her biological mother on a limited basis. Furthermore, her sister Tina was living with her biological mother at the time of the study due to her repeated disagreements with Rob and her step-mother regarding the rules in the house.

Both father and step-mother reported fighting with Jan "all of the time about everything." The most frequently reported issues that resulted in conflict with Jan were talking on the telephone, completing chores, going to places without adult supervision, and poor school performance. Both parents reported that Jan was having behavior and academic problems at school as evidenced by recent report cards and discussions with the teacher. Rob stated that Jan's teachers have reported that she frequently does not turn in her homework and she talks and socializes with her friends at times when it is inappropriate. In addition, Rob reported that Jan is frequently disrespectful, noncompliant, and angry whenever asked to do something for them at home. He stated that Jan frequently would talk back and yell at both her parents and her halfsister. He reported that, at times, Jan damaged both her telephone and desk when she was angry. Rob's attempts to discipline Jan in the past included removing her stereo or her CDs contingent 
upon unsatisfactory grades and noncompliant behavior, however he reported that this was not successful in changing her behavior.

Jan reported arguing daily with both her father and her step-mother. She stated that both her parents were unreasonable in their expectations of her. She stated that they frequently did not listen to her and that her step-mother did not care for her. Furthermore, she reported frequently being blamed by her parents and her teachers for things she did not do. Similar to both of her parents, Jan reported that the most frequent issues that resulted in family conflict included time spent talking on the telephone, going places without adult supervision, and cleaning up her bedroom. In addition, she reported disliking school work but enjoying her friends.

According to results obtained solely from the initial structured interview conducted with Rob, Jan met 8 of the 8 symptoms for Oppositional Defiant Disorder (ODD), 4 of the 8 symptoms for Conduct Disorder (CD), and 4 of the 9 symptoms that comprise the inattention component and 6 of the 9 symptoms that comprise the hyperactivity-impulsivity component of Attention Deficit/Hyperactivity Disorder (ADHD). Furthermore, her father reported that Jan had exhibited some symptoms congruent with a mood disorder diagnosis in the past, although both he and Jan reported that she was not exhibiting those symptoms at the time of the study. Both Rob and Jan currently were not seeking any outside medical or psychological treatment for their family conflict. Although invited, Jan's step-mother declined to participate in the treatment sessions because she was pregnant and suspected she would not have the time to consistently attend sessions.

Dyad 2. Dyad 2 consisted of a 42-year-old mother, Nina, and her 12-year-old male adolescent, Tom. Nina and Tom lived at home with Tom's father, age 45, and Tom's 2-year-old 
sister. Nina was not employed and Tom's father was employed as a coal miner. Tom's father did not participate in any aspect of the study because of conflicts with his work schedule.

According to Nina, the issues that resulted in the most distressing conflict included fighting with sibling, talking back to parents, and making too much noise at home. Nina's major concern was the aggressive and destructive behavior her son exhibited towards her and his younger sister when he was not allowed to do something he preferred. She reported that this occurred on a daily basis and that the intensity of his tantrums was increasing. Tom frequently would throw things, rip posters off of his bedroom walls, break games and toys, and push his sister to the floor. She reported that on occasion, Tom had punched and kicked both her and her husband during his tantrums. Furthermore, Nina was concerned with the way Tom blamed others for his mistakes and would not take responsibility for his actions. Past attempts to discipline Tom included repeating instructions, taking away his television and videogame privileges, and not allowing him to play with his friends. However, these strategies generally were unsuccessful.

Tom reported arguing most with his mother about doing his homework. In addition, he reported arguing about what time he should go to bed and fighting with his sister. Although Tom reported during the structured interview that he argued frequently with both his mother and father, he reported that he enjoyed spending some time with both of his parents. In addition, he denied acting aggressively towards either his sister or mother.

According solely to the initial interview completed by Nina, Tom met 8 of the 8 symptoms for ODD and 6 of 9 symptoms that comprise inattention and 9 of the 9 symptoms that comprise hyperactivity-impulsivity that comprise ADHD. Nina and Tom reported no other symptoms or behavioral problems. Prior to the start of the study, the family was not participating in any outside medical or psychological treatment for their family conflict. 
Dyad 3. Dyad 3 consisted of a 38-year-old mother, Donna, and her 12-year old son, Jon. Donna had separated from her husband 6 months prior to participating in the study. At the time of the study, she lived at home with Jon and his two siblings, ages 7 and 9. Donna was employed as a secretary at a local business. Donna was legally blind, thus all materials used in the study were modified to accommodate her condition (e.g., handouts were transcribed into Braille, homework instructions were recorded on audiotape). Materials were transcribed to Braille on a voluntary basis by a local area agency serving individuals with disabilities. Jon was diagnosed with Marfan's syndrome and ADHD. At the time of the study, he was not taking medication for ADHD due to potential medication complications with the Marfan's yndrome. Marfan's syndrome is a genetic connective tissue disorder that affects the heart, eyes, and skeletal system. Individuals affected with Marfan's syndrome are frequently prohibited from playing sports due to potential medical complications that may arise from their condition. Jon's desire to play sports and his mother's wishes that he not participate in sports, served as an issue between them that added to their level of conflict. Both Donna and Jon previously had been to counseling in an attempt to manage his inattentive and impulsive behaviors. However, throughout the course of the study, Donna and Jon did not seek any other medical or psychological treatment for their family conflict.

Both Donna and Jon reported arguing frequently about his taking care of things (e.g., bike, pets, etc.), fighting with siblings, and getting in trouble at school. In addition, Donna reported that she and Jon argued daily about Jon making too much noise at home, talking back to his mother, and getting up in the morning on time to go to school. Donna stated that she particularly was worried about her and Jon's relationship deteriorating as he became older. Furthermore, she was worried about Jon's poor school performance. She reported that he was 
getting in trouble for talking back to his teachers, failing to complete his homework, and fighting on a weekly basis. She reported that Jon always had been difficult, however the level of conflict between them had escalated after she had separated from his father.

Jon reported being "nagged" by his mother daily about getting up in the morning, fighting with his brother and sister, helping out around the house, and his selection of friends. He stated that he thought he had more responsibilities than other adolescents his age, due to his father's departure from the home and his mother's disability. Jon stated that he would participate in the study, but he did not think it would help him and his mother.

According solely to the initial structured interview, Jon exhibited 5 of 8 of the symptoms that comprise ODD, 3 of the 11 symptoms that comprise CD, and 9 of the 9 symptoms that comprise inattention and 9 of the 9 symptoms that comprise hyperactivity-impulsivity that comprise ADHD. Donna stated that past parenting practices consisted of removing privileges, implementing time-out from activities upon noncompliance, and attempting to use a point system. However, she reported that these strategies were unsuccessful in changing Jon's behaviors.

Dyad 4. Dyad 4 consisted of a 44-year-old mother, Sally, and her 14-year-old son, Don. Sally and Don lived at home with Don's younger brothers, ages 6 and 12. Sally divorced Don's biological father approximately 1.5 years prior to participating in the study. At the time of the study, Don visited his father every other weekend but primarily lived at home with his mother. Sally was employed as a research assistant on an animal farm.

According solely to the initial interview completed by Sally, Don exhibited 4 of the 8 of the symptoms that comprise ODD, 3 of the 11 symptoms that comprise $\mathrm{CD}$, and 2 of the 9 symptoms that comprise the inattention component and 0 of the 9 symptoms that comprise the 
hyperactivity-impulsivity component that encompass the diagnosis of ADHD. The major issues that lead to conflict between Sally and Don included his taking care of things around the house, doing chores, and his use of the telephone. Sally reported that, prior to the study, Don had become unwilling to be "part of the family" and to "do his part." Sally was most concerned, however, with the increasingly frequent and violent manner in which Don fought with his brothers. She reported that Don had become excessively "bossy" when interacting with his brothers, and the fights that resulted ended with Don physically hurting them. When she confronted Don about these issues, he became argumentative and sarcastic when responding to her. Sally reported that past parenting practices consisted of grounding, occasionally removing privileges, repeating instructions, and using verbal reprimands. However, she reported that these practices were becoming less successful in modifying Don's behavior. Prior to participating in the study, the family was not seeking any outside medical or psychological treatment for their family conflict.

Don reported similar issues that led to conflict between him and his mother (e.g., doing chores, fighting with brothers and sisters, etc.). Don also reported arguing about allowance, how to spend his money, what he should do during his free time, and his curfew time. He reported that the conflict between he and his mother and siblings had increased in frequency, but he attributed this to his mother's strict rules and his brothers "not leaving him alone." Therapists

Three Masters-level graduate students (one male, two females) in the clinical psychology doctoral program at West Virginia University served as therapists. All therapists had previous experience providing treatment to parents and adolescents experiencing conflict. Each therapist received a detailed treatment manual outlining therapy session procedures, objectives, and 
homework assignments. Additional training included receiving didactic instruction, reviewing videotapes of therapy sessions, practicing procedures, and discussing impending therapy sessions outlined in the treatment manual. All therapists received weekly 1-hr group supervision throughout the study from a licensed clinical psychologist with experience in the area of parentadolescent relationships. The primary investigator was assigned to the family that initially met treatment criteria. Thereafter, families were randomly assigned to each of the therapists. Therapist-family matching was not based on participant gender, age, and presenting concerns.

\section{Experimental Design}

A concurrent, multiple baselines across subjects design was utilized to assess session-bysession use of problem-solving and positive communication skills and negative communication behaviors. Dyads were selected to be in treatment consecutively as they met the baseline criterion for treatment. The criteria for treatment was based on inspection of weekly Problem Solving Behavior Code (PSBC) scores. Problem Solving Behavior Code scores from videotape assessment sessions served as the dependent measures that guided the multiple baselines. An a priori decision was made to use the PSBC rather than the Interaction Behavior Code (IBC) to guide the multiple baselines for two reasons. First, although no triads participated in the study, the PSBC accounts for both dyads and triads (allowing for two parents to potentially participate) whereas the IBC does not. Second, by using the PSBC rather than the IBC, it is easier to compare families with greater skill discrepancies due to the smaller scale on the PSBC y-axis (16 compared to 45). Treatment criteria consisted of a minimum of 3 consecutive data points demonstrating no notable upward trend. One week after the initial family began treatment, the next family whose PSBC scores met the no upward trend criteria began treatment. Each subsequent week, one family began treatment. Families met with their therapist for ten 1-hour 
weekly sessions. Missed appointments were rescheduled for the following week until families completed all ten sessions. Generalization probes occurred prior to beginning treatment and after completion of the final treatment session (i.e., Session 10). Follow-up data were collected for each dyad 2 weeks after completing the final treatment session.

\section{$\underline{\text { Dependent Measures }}$}

\section{Child Behavior Checklist (CBCL; Achenbach \& Edelbrock, 1991a).The CBCL is a} parent-report measure of general adolescent psychopathology. The CBCL contains 112 items consisting of common childhood and adolescent behavior problems. Parents indicate on a 3-point scale the extent to which each item describes the child's behavior within the past 6 months. Ratings are combined to yield eight subscales, each representing a different area of behavior. Three of these subscales are further combined to form an Internalizing scale (Anxious/Depressed, Withdrawn, and Somatic Complaints) and two form an Externalizing scale (Delinquent Behaviors and Aggressive Behaviors). The other subscales (Social Problems, Thought Problems, and Attention Problems) are considered individually. A Total Problem score also is obtained by combining all subscales. Scores are compared to those of a national sample of children and adolescents of the same age and gender. The CBCL has been demonstrated to have satisfactory psychometric properties (Achenbach \& Edelbrock, 1991a; Achenbach \& Edelbrock, 1991b).

\section{Child Behavior Checklist - Youth Self-Report (CBCL-YSR; Achenbach \& Edelbrock,} 1991b). The CBCL-YSR is a self-report measure of general psychopathology for adolescents between the ages of 11 and 18 years of age. The questionnaire contains 112 items and yields two broadband factors and eight subscale scores similar to those found on the CBCL. A Total Score also is obtained. Adolescents indicate the extent to which each item describes their behavior in 
the past 6 months. The measure has demonstrated reliability and validity with an adolescent population (Achenbach \& Edelbrock, 1991b).

Conflict Behavior Questionnaire-20 (CBQ-20; Robin \& Foster, 1989). The CBQ-20 is a 20-item true-false rating scale assessing communication and conflict in parent-adolescent interactions. Items reflect statements that attempt to examine respondents perceptions of the other person's behavior and perceptions of the dyadic interaction (e.g., "My child acts impatiently when I talk to him" or "My mother and I joke around often," etc.). Both the parent and the adolescent completed this form and a single score was obtained for each respondent. Higher scores represented more negative communications in the interactions. The CBQ-20 has been found to be a reliable and valid measure (Long, Adams, \& Ruggiero, 2000; Robin \& Foster). Furthermore, the CBQ has demonstrated adequate sensitivity to treatment effects (Robin \& Foster).

Family Beliefs Inventory (FBI; Vincent-Roehling \& Robin, 1986). This questionnaire was used to assess the parents' and adolescents' distorted cognitions and unreasonable beliefs that may have contributed to their conflict. The questionnaire assesses 10 types of unreasonable beliefs, 4 for the adolescent and 6 for the parent. For the adolescent, these unreasonable beliefs are approval, autonomy, ruination, and unfairness. For the parents, these are approval, obedience, malicious intent, perfectionism, self-blame, and ruination. The FBI presents 10 vignettes describing common parent-adolescent conflicts (e.g., curfew, allowance, etc.). After each vignette, a series of statements are provided, one for each type of unreasonable belief or distorted cognition described previously. Respondents rated each belief on a 7-point Likert scale reflecting how much the respondent agreed with the belief. Two responses that reflected more rational, less extreme, beliefs were intermingled with the other beliefs to reduce response bias, but these were 
not scored. Scores for each belief were obtained by summing the responses across all 10 vignettes (range 10-70). Higher scores indicated more extreme beliefs. The FBI has been shown to be a reliable and valid instrument for assessing distorted cognitions exhibited by parents and adolescents (e.g., Vincent-Roehling \& Robin). The FBI has shown some evidence for PSCT treatment sensitivity (e.g., Nayar, 1985). At the present time normative data are limited, therefore family beliefs scores were discussed within each individual.

Issues Checklist (IC; Prinz, Foster, Kent, O'Leary, 1979). The IC provides information regarding the frequency and content of disputes between parents and adolescents and the perceived anger-intensity level of these disputes. The IC consists of 44 items about which parents and adolescents frequently disagree (e.g., doing homework, curfew, talking on the telephone). Respondents rate if the topic was discussed in the last four weeks, and, if so, how many times and with what degree or intensity of anger (on a 5-point scale). Parents independently completed IC regarding their relationship with their adolescent, while the adolescent completed a separate IC for each participating parent. The IC yields three scores: number of conflicts, average anger-intensity level of the endorsed issues, and the weighted average of the frequency and anger-intensity level of the endorsed issues (WF/I). The WF/I score is computed by summing the cross-products of the anger-intensity ratings and the number of times the issue was reported as having occurred, then dividing by the number of issues for which discussions had been reported. The average anger-intensity score reflects the average anger per issue, regardless of the number of issues endorsed, whereas the WF/I score gives an estimate of anger per discussion (Robin \& Foster, 1989). Higher average anger-intensity scores and WF/I scores both are indicative of angry arguments, while low scores are indicative of calm discussions (Robin, 1981). The IC frequency score should not be examined without the average 
anger-intensity score and the $\mathrm{WF} / \mathrm{I}$ score, because it cannot be assumed that by endorsing a higher number of issues discussed, higher levels of conflict are occurring. On the contrary, a greater number of issues discussed with little or no anger would be indicative of better communication between the parent and adolescent (Robin). Thus, all three scores are presented in this study. The IC has been found to be a reliable and valid measure (Robin \& Foster). In addition, the IC has been shown to be sensitive to treatment effects (Robin \& Foster).

Parent-Adolescent Relationship Questionnaire (PARQ; Robin, Koepke, \& Moye, 1990). The PARQ is a multidimensional measure consisting of 250 and 285 true-false items, for parents and adolescents, respectively. The PARQ is divided into 16 scales tapping three broader dimensions of family functioning: 1) skill deficits/overt conflict (global distress, communication, problem solving, warmth/hostility, cohesion, school conflict, sibling conflict, conventionalization), 2) faulty belief systems/distorted cognitions (parents: ruination, obedience, perfectionism, self-blame, malicious intent; adolescents: ruination, unfairness, autonomy, perfectionism, approval), and 3) family structure problems (coalitions, triangulation, somatic concerns, hierarchy reversal). Parents and adolescents completed the questionnaire independently. Raw scores were obtained and compared relative to each other for 11 of the 16 categories in order to assess family functioning. The PARQ has been found to have good reliability and validity (Robin, 1998). In addition, the PARQ has been shown to be sensitive to treatment changes produced by behavioral family systems therapy (Robin, Siegel, \& Moye, 1995).

Therapist Rating of Family Cooperation (TRFC). The TRFC (see Appendix A) was developed by the primary investigator for the purpose of this study. The TRFC is a rating scale of five items assessing family cooperation. The scale was completed by the therapist at the end 
of each session. Items include acceptance of therapist, quality of communication in therapy, quality of effort in participating in therapy, completion of homework, and achievement of session goals. The therapist rated each item on a 7-point Likert scale with scores ranging from 1 (low) to 7 (high). The total score was derived by summing the ratings across each item and then across all sessions. In addition, each dyad's average item scores were computed by summing the total ratings for each item and dividing by the total number of sessions (10). For the homework completion item, the sum of the ratings for each session was divided by 9 , due to no homework being assigned for treatment Session 10.

Consumer Satisfaction Survey (CSS). The primary investigator developed the CSS (see Appendix B) for the purpose of this study. The CSS is a 10-item consumer satisfaction survey that was given to both the parent and the adolescent at the end of each treatment session. The survey assessed participants' thoughts regarding the acceptability of the treatment and the procedures used, as well as their feelings regarding their therapist. The participants rated each item on a 5-point Likert scale, ranging from 1 (strongly disagree) to 5 (strongly agree). Total scores ranged from 10 to 50, with high scores indicating more satisfaction and low scores indicating less satisfaction with the treatment and therapist. Total scores are derived by summing the ratings across items. The total score is then divided by the total number of items (i.e., 10) to yield an average item score that can be contrasted against the anchor descriptions for interpretation purposes. After each therapy session, therapists left the participants alone to complete the CSS. Participants were instructed to place their completed CSSs in an envelope and sign along the seal. This was done to ensure that the therapist would not see the ratings and to reduce socially desirable responding by the participants. 
Interaction Behavior Code (IBC; Prinz \& Kent, 1978). The IBC (see Appendix C) is a global-inferential coding system for assessing parent-adolescent negative and positive communication skills and interactions. The IBC consists of 31 categories of negative communication patterns and 7 categories of positive communication patterns, all accompanied by a brief definition. Seven of the positive communication categories and 22 of the negative communication patterns are rated "yes" (1-point) if they occur at all during the discussion or "no" (given a 0-point value) if they do not occur. The nine remaining negative communication categories are rated as occurring "a lot" (1-point), "a little" (.5-point), or "absent" (0-point). Points were totaled separately for positive and negative items to yield positive and negative interaction scores for each participant. The IBC has been shown to discriminate between families with and without conflict and to be sensitive to PSCT treatment (Foster et al., 1983; Robin \& Foster, 1989).

Problem-Solving Behavior Code (PSBC). The primary investigator developed the PSBC (see Appendix D) for the purpose of this study. The PSBC is a behavior code used for assessing problem-solving behaviors exhibited by the family during the weekly videotaped problemsolving discussions and during the pre- and post-generalization probes. The PSBC consists of 16 operationally defined problem-solving behaviors identified as being critical for successful problem resolution (Robin \& Foster, 1989). Problem-solving behaviors were scored as either "not occurring" (0-point) or "occurring" (1-point). The PSCT yields a single total score (computed by summing the total number of points) for the parent-adolescent dyad. Weekly total scores on the PSBC guided decisions on initiating the first treatment session. 


\section{$\underline{\text { Procedures }}$}

Assessment Procedures. After the initial screening, parents and adolescents completed the paper-and-pencil dependent measures once at pre-treatment and again at post-treatment. In addition, the issue identified as being of greatest concern to the parent (because it was associated with the highest frequency and intensity of conflict, as identified by the parent's IC score) was discussed once at pre-treatment and again at post-treatment. Parent selected issues were chosen rather than adolescent selected issues because it was thought that the parent would have a more valid and reliable opinion as to what issue was associated with the highest level of conflict. Dyad members were told to discuss and solve the specific issue the parent had identified. Participants were videotaped for 10 min discussing the issue. The IBC and the PSBC coding systems were used to assess problem-solving and communication skills exhibited by family members in the discussions. These discussions served as generalization probes to assess problem-solving and communication skill acquisition and generalization to "true" conflict situations.

In addition, dyads were videotaped once a week throughout the baseline and treatment phases of the study. The weekly video assessments were used to assess problem-solving and communication skill acquisition as therapy progressed. Dyads were videotaped in their home discussing an issue commonly associated with parent-adolescent conflict for $10 \mathrm{~min}$. Issues were selected at random without replacement from a pool of 20 issues commonly associated with parent-adolescent conflict. The discussion topics, developed by the primary investigator, were based on the items found on the IC, an empirically validated measure of parent-adolescent conflict. The topics, along with instructions for the family and the investigator to follow, are outlined in Appendix E. Throughout all of the assessment sessions, dyads discussed an issue only once and did not discuss the issue if it was used in the generalization probe discussion. 
Treatment Procedures. Families met with their therapist at the departmental psychology clinic or after hours at a local school for ten 1-hour weekly sessions. Nine of the treatment sessions concluded with the assignment of homework activities designed to help participants practice using skills learned in session at home. In addition, each family was assigned a tape recorder to record homework activities that subsequently were reviewed in the next session. At the first therapy session, dyads were required to deposit $\$ 10$ for a tape recorder, which was returned after completing treatment upon return of the tape recorder. The treatment sessions are summarized here, but are provided in their entirety in Appendix F.

Treatment Sessions 1-3 comprised the BE component and used procedures outlined in Besalel and Azrin (1981), Raue and Spence (1985), and Jacobson and Margolin (1979). In Session 1, the participants listed and identified existing sources of reciprocity and reinforcement. That is, each participant listed what each family member did for them and what they enjoyed about that person. Participants then discussed how their immediate behavior may affect subsequent family interactions. In addition, participants were instructed to increase the amount of verbal praise and time engaged in preferred activities together by scheduling $10 \mathrm{~min}$ of positive one-to-one time at home daily. During these one-to-one times, parents and adolescents were instructed to not discuss conflict issues. Instead, they were to spend time doing activities and discussing topics they both identify as enjoying. Session 2 was devoted to teaching parents and adolescents how to set behavioral goals based on reciprocity of reinforcing behaviors at home. Participants were taught how to establish behavioral contracts for positive changes in the behavior of both the adolescent and parent. In addition, participants learned basic positive communication skills. For example, participants were taught to provide non-contingent verbal reinforcers (e.g., compliments) and contingent verbal reinforcers (e.g., statements of appreciation 
based on appropriate behavior exhibited by the other person) to each other. Session 3 was devoted to reviewing and practicing the material presented in the first two sessions and emphasized enhancing specific skill deficits exhibited by the dyad.

The PSCT treatment component began in Session 4. Treatment Sessions 4-10 were based on Steps 10 through 18 in the treatment manual "Defiant Teens" (Barkley, Edwards, \& Robin, 1999). In Sessions 4 and 5, family members were taught a four-step model of problem solving that included the following: (a) define the problem concisely and without accusations, (b) brainstorm and generate multiple alternative solutions, (c) decide upon a mutually satisfactory solution by projecting positive and negative consequences, assigning solutions positive or negative ratings, adopting one or more solutions rated positively by everyone, and (d) specify the details for implementing the agreement. In addition, family members practiced using the fourstep model first with a hypothetical family problem and then with a low-level problem identified by the family as frequently resulting in conflict. Training in this process continued throughout the remaining treatment sessions. In the beginning sessions, the therapist guided discussions and frequently modeled, prompted, and provided corrective feedback to family members during discussions. As the family demonstrated skill acquisition in session and during videotaped assessment sessions, the therapist's level of participation during discussions was faded and families were encouraged to work more independently.

During Sessions 6 and 7, family members were instructed to use the four-step model while discussing additional low-level issues that resulted in conflict in their homes. In addition, dyads participated in further communication training. This training involved specific feedback, modeling, and behavior rehearsal to correct negative communication habits exhibited in previous sessions and during videotaped assessment sessions. Examples of negative communication 
targeted for change included accusations, interruptions, lectures, put-downs, and inattentive postures. Participants were taught positive communication skills such as how to verify meaning, use I-messages, exhibit appropriate eye contact, and display appropriate nonverbal postures. First, the therapist, and eventually family members, took turns stopping problem-solving discussions when negative communication deficits where exhibited. Then family members were instructed to generate and use alternative positive communication skills before continuing the problem-solving discussions.

In Sessions 7 and 8, family members continued to practice using the four-step model while discussing issues identified by the family as resulting in medium-levels of conflict. In addition, a cognitive restructuring component of treatment was tailored to the cognitive distortions and unreasonable beliefs exhibited by each family member. Family members were taught how to detect and restructure irrational, extreme, or rigid beliefs held by parents and adolescents about their own or others' conduct. Family members were taught to compare and contrast their own rules and beliefs with those held by other adolescents and parents, in order to develop more age-appropriate rules and more normative beliefs. Family members practiced identifying specific rules or their own beliefs that frequently were associated with conflict during discussions. Participants were then instructed to develop alternative rules or statements that aided in reducing levels or anger and conflict during problem discussions.

Sessions 9 and 10 were devoted to practicing, reviewing, and providing feedback regarding all of the procedures covered throughout therapy. Problem-solving discussions focused on the issues that the family had identified as most difficult to resolve. These sessions focused on applying skills that had been particularly difficult for participants to learn to apply to "real-life" 
issues. In addition, preparations were made for therapy termination and how family members would deal with future issues that could potentially result in conflict.

Upon finishing therapy, the dyad completed the post-treatment dependent paper-andpencil measures. In addition, the dyad was videotaped discussing the same issue identified for use as the generalization probe at pre-treatment. Families were provided with the phone numbers of local health service providers; however, none of the families sought additional services at the 2-week follow-up.

Treatment Integrity

Weekly supervision sessions in which the therapists reviewed and discussed treatment session content and correct therapy implementation were conducted to enhance treatment integrity. In addition, to ensure that treatment was implemented in the manner outlined in the treatment manual, $30 \%$ of the therapy sessions conducted with each dyad were randomly selected to be videotaped. A psychology graduate student, not serving as a therapist in this study, and an advanced undergraduate psychology student assisted as videotape reviewers. The reviewers independently watched the treatment sessions with a copy of the treatment manual and noted the number of outlined session steps the therapist appropriately completed. Percentages of session steps appropriately implemented per session were calculated for each therapist by dividing the number of session steps appropriately completed by the total number of session steps possible and multiplying by 100 . Table 1 illustrates the percent of session steps implemented appropriately by each therapist for each of the videotaped therapy sessions. The number of session steps implemented appropriately across all three therapists ranged from 92$100 \%$, suggesting that all of the therapists generally implemented the treatment as outlined in the treatment manual. 


\section{$\underline{\text { Interobserver Agreement and Response Measurement }}$}

Training Observers. Four undergraduate psychology students served as the observers who scored the weekly assessment and generalization probe videotapes to derive PSBC scores and IBC scores. Prior to observing participant tapes, observers met for 4 hours per week over the course of 10 weeks for extensive training. Initially, training consisted of didactic instruction in both observation code scoring procedures and code definitions, followed by 8 weeks of practice coding sample videotaped parent-adolescent problem discussions. Initial practice tapes consisted of the therapists role-playing parent and adolescent dyads participating in problem-solving discussions. Observers watched the videotapes in a group and then discussed how they derived PSBC and IBC scores. Throughout the group training, the primary investigator provided instruction and feedback on troublesome behavioral categories. Group training progressed until all of the observers met $80 \%$ interobserver agreement for the PSBC total score for the dyad and the IBC total positive and negative scores for both the parent and the adolescent.

Subsequently, individual training sessions with the primary investigator and each observer occurred. Practice videotapes were developed consisting of local area parent and adolescent dyads who volunteered to discuss similar problem scenarios to those used in the weekly assessment and generalization probes. Volunteers in the practice videotapes did not participate in the study. Observers independently viewed and scored the videotapes and then met to compare their PSBC and IBC scores with those derived by the primary investigator. The primary investigator provided additional corrective feedback and training as needed. One-to-one training continued until each observer obtained a minimum of $80 \%$ interobserver agreement with the primary investigator's PSBC and IBC total scores. 
Finally, three new "test" videotapes were developed consisting of parent and adolescent volunteers discussing issues that were problematic for them. Observers independently watched and scored the test videotapes. Percentages of interobserver agreement were calculated by dividing the number of occurrences of behaviors agreed upon by the total number of possible occurrences of behavior and multiplying this number by 100. For the 9 behavioral categories on the IBC in which observers were asked to rate the occurrence of behavior as not occurring (0), occurring a little (.5), or occurring a lot (1), agreed upon occurrences were scored only if observers had exact matches. Thus, an agreement would not be counted for a particular behavioral category if one observer scored it a ".5" and the other observer scored it a " 1 ". Table 2 illustrates the percent interobserver agreement between the primary investigator and each of the observers' PSBC total scores for the dyads and IBC positive and negative total scores for both the parent and the adolescent on the test videotapes. All observers tested above the $80 \%$ criteria with percent agreements ranging from $81.3-100 \%$ across all observers.

Interobserver Agreement. For each dyad, a minimum of 53\% of the weekly videotaped assessment discussions for each family were randomly selected across all treatment phases and independently scored yielding PSBC total scores. In addition, a minimum of $33 \%$ of the videotaped assessment discussions were randomly selected across all treatment phases and independently scored by observers to yield negative and positive IBC scores for parents and adolescents. Percentages of interobserver agreement were calculated in a manner similar to that previously described. Table 3 illustrates the mean and range percent agreement across all phases of treatment for each dyad's PSBC total score and positive and negative IBC scores. For all dyads, average interobserver agreement on PSBC total scores ranged from $87.5 \%$ to $93.0 \%$. Average interobserver agreement for parent and adolescent negative IBC scores ranged from 
$87.7 \%$ to $94.9 \%$ and $91.0 \%$ to $96.8 \%$, respectively. The average interobserver agreement for parent and adolescent IBC positive scores ranged from $80.0 \%$ to $94.3 \%$ and $87.7 \%$ to $94.3 \%$, respectively.

\section{Results}

It was hypothesized that the BE+PSCT treatment program would result in observable behavior changes in the dyads' use of problem solving skills and communication patterns. Therefore, weekly problem-solving discussions were observed and coded using the PSBC and the IBC. PSBC total scores across baseline and treatment phases for all dyads are shown in Figure 1. Negative and positive IBC scores for the parents and adolescents in Dyad 1, 2, 3, and 4 are shown in Figures 2, 3, 4, and 5, respectively. It was further hypothesized that the BE+PSCT treatment program would reduce conflict at home and enhance problem solving and communication skills as reported by parents and adolescents on pre- and post-treatment selfreport measures. Parent and adolescent self-report measures are found in Tables 4-15.

\section{Dyad 1}

\section{$\underline{\text { Behavior Observations }}$}

PSBC. Dyad 1's (i.e., Rob $=$ Parent 1, Jan = Adolescent 1) PSBC total scores derived from the 10 min weekly assessment sessions are illustrated in Figure 1. Weekly treatment Sessions 5 and 6 were rescheduled due to canceled appointments, thus no data points were portrayed for Weeks 8 and 10. During baseline, no distinct upward trend was evidenced in PSBC total scores, and the mean PSBC total score equaled 4.3. With the implementation of the behavioral exchange phase of the treatment program, there were no notable increases in PSBC total scores. In fact, the mean of the total PSBC scores in this phase was 4.3, equaling the baseline phase mean. In treatment Session 4 the PSCT phase of the treatment package began. 
Appreciable increases were noted in PSBC total scores after treatment Session 7 and treatment Session 9, with PSBC total scores equaling 15 and 14, respectively. The PSBC total score mean for the PSCT phase equaled 7.7.

Generalization probe PSBC total scores also are illustrated in Figure 1. For Dyad 1, the discussion topic, "going places without parent supervision" was chosen as the generalization probe. The first probe occurred prior to treatment in Week 3, and Dyad 1 achieved a PSBC total score of 1. After completing treatment, the same topic was discussed and the Dyad obtained a total PSBC score of 13. At 2-weeks follow-up, a new discussion topic was chosen based on the parent's highest weighted IC item score. For Dyad 1, the 2-week follow-up discussion was "helping out around the house." Dyad 1 obtained a PSBC total score of 15.

IBC. Negative and positive IBC scores for both Dyad 1 are illustrated in Figure 2. For Dyad 1, negative behavior IBC scores in baseline decreased slightly for the parent and increased slightly for the adolescent prior to treatment. Mean IBC negative behavior scores for the baseline phase equaled 6.8 for the parent and 7.5 for the adolescent. With the implementation of the behavioral exchange phase of treatment, minimal decreases were found in IBC negative scores for both dyad members. Mean IBC negative scores equaled 5 for the parent and 7.2 for the adolescent. With the implementation of the PSCT phase of treatment, negative IBC scores increased for the adolescent in the Weeks 7 and 11. Overall, however, the adolescent's negative IBC scores remained relatively unchanged (phase $\underline{\mathrm{M}}=7.9$ ) when compared to the baseline and behavioral exchange phases. For the parent, negative IBC scores decreased to zero during Weeks 7 and 15 , with an overall phase mean decrease to 3.1 .

Positive IBC scores for both the adolescent and the parent remained stable throughout baseline with phase means of 1 and 2, respectively. With the implementation of the BE phase, 
both the adolescent's and the parent's positive scores remained relatively unchanged, with the phase means equaling .66 and 2.3, respectively. With the implementation of the PSCT component, the adolescent's positive scores increased during Week 7, decreased in Week 9, and then increased in Weeks 11 and 12 before stabilizing for the remaining three weeks. The PSCT phase mean equaled 1.4. For the parent, minor increases occurred for Weeks 12 through 15 . The overall phase mean equaled 3.4.

Generalization probes also were scored for negative and positive IBC scores. Prior to treatment, the adolescent obtained a negative IBC score of 10 and a positive IBC score of 1 . The parent obtained a negative IBC score of 7.5 and a positive IBC score of 2 in baseline. After treatment, the adolescent's negative IBC decreased to a 4.5 , however her positive score remained unchanged at a 1 . The parent's negative IBC decreased to 0 and his positive IBC increased to 4 .

At 2-weeks follow-up the adolescent's negative and positive IBC scores remained relatively unchanged (negative $=5$; positive $=2$ ) compared to her scores in the baseline and treatment phases. However, compared to his baseline scores, improvements in the 2-week follow-up scores were noted for the parent. The parent obtained a negative IBC score of 0 and a positive IBC score of 3.

\section{$\underline{\text { Parent Report }}$}

The results from Parent 1's self-report assessment measures completed at pre-treatment, post-treatment, and 2-week follow-up are illustrated in Table 4. General profile results for Adolescent 1 from the pre-treatment CBCL completed by Parent 1 indicated that 7 of the 8 subscale scores fell within the Normal range. The only exception, the attention problems subscale score, fell within the Borderline range $(\mathrm{T}-\mathrm{Score}=67)$. Results at post-treatment indicated that all of the subscale scores were within normal limits. On the measures specifically 
intended to assess parent-adolescent conflict, notable reductions from pre-treatment to posttreatment were reported by Parent 1 on the CBQ-20, on the IC quantity of issues discussed score, and on the PARQ global distress, communication, problem-solving, and hierarchy reversal subscale scores. In addition, his IC average anger-intensity scores and WF/I scores at all three assessment periods indicated that he was experiencing little to no anger, regardless of the issue or how many times it was discussed. Taken together, these results suggest that Parent 1 perceived less conflict and perhaps some improved communication with his daughter at post-treatment.

The FBI and the PARQ belief scales assessed parental beliefs and cognitions about their adolescents at pre-and post-treatment. Both measures contain the Ruination, Perfectionism, SelfBlame, Malicious Intent, and Obedience scales. The FBI contains an additional Approval scale. Results for Parent 1 appear contradictory. On the FBI, post-treatment scores increased relative to pre-treatment scores for all of the scales except Obedience. In fact, the Perfection and Approval scales increased by 8 and 9 points, respectively. This was congruent with the relative increase found on the PARQ Perfection scale from a score of 2 at baseline to a score of 5 at posttreatment, suggesting a worsening in the Parent 1's ratings regarding his beliefs. The only reductions found at post-treatment, were on the PARQ Ruination and Self-Blame scales.

At 2-weeks follow-up, his CBQ-20 score decreased further from pre-treatment and posttreatment levels. In addition, the reduction found at post-treatment in the number of issues argued about, as measured on the IC, was maintained at 2-week follow-up. As mentioned previously, the IC anger-intensity level score and WF/I score at 2-weeek follow-up remained comparable to those found in pre-and post-treatment. As a result, it appears that some treatment effects maintained at 2-week follow-up as per his report. 


\section{$\underline{\text { Adolescent Report }}$}

The results from Adolescent 1's paper-and-pencil assessment measures completed at pretreatment, post-treatment, and 2-week follow-up are presented in Table 5. According to Adolescent 1's CBCL-YSR at pre-and post-treatment, all subscale scores fell within the Normal range. On the measures designed to assess overall conflict, communication, and problemsolving, Adolescent 1's scores appear contradictory. She had an extremely high CBQ-20 score of 20 at post-treatment. In addition, her IC scores at post-treatment increased from the pre-treatment assessment, suggesting a worsening in communication and conflict between her and her father. Similarly, her PARQ global distress, communication with mother, and communication with father scale scores remained relatively high. In addition, her PARQ problem-solving with mother, hierarchy reversal rating both parents, and her conventionalization subscale scale scores increased. Higher PARQ scores on these scales represent more negative interactions. However, her PARQ problem-solving rating father scale score decreased from a 13 at pre-treatment assessment to a 5 at post-treatment, indicating she perceived improved problem-solving discussions with her father.

Adolescent 1's scores on the FBI and PARQ ruination and autonomy scales both decreased from baseline assessment, representing weaker adherence to these beliefs at the end of treatment. However, increases were noted in her FBI fairness and approval scale scores at posttreatment, perhaps representing stronger adherence to these beliefs. PARQ pre-treatment perfectionism and fairness scale scores remained the same at post-treatment.

At 2-weeks follow-up, Adolescent 1 continued to report extremely high levels of conflict and anger based on her CBQ-20 and IC scores. Her CBQ-20 score of 20 was the highest possible obtainable score. In addition, the average intensity/issue and WF/I scores both increased by 1 
point from post-treatment, suggesting she was experiencing relatively higher levels of anger and arguments.

Therapist's Ratings of Family Cooperation

Table 6 illustrates Dyad 1's TRFC total score and average item scores. Overall, Dyad 1 obtained average ratings from the therapist on items concerning how accepting the dyad was of the therapist and how the family was able to achieve the session's goals. The therapist rated the overall quality of communication and problem-solving displayed by the family within sessions as slightly below average. The lowest average score was obtained on the completion of homework item, due to the family's not doing any homework for 4 of the 9 sessions (i.e. Sessions 2, 5, 6, and 8).

\section{$\underline{\text { Dyad } 2}$}

\section{$\underline{\text { Behavior Observations }}$}

PSBC. Dyad 2's (i.e., Nina = Parent 2, Tom = Adolescent 2) PSBC total scores derived from the weekly assessment sessions are shown in Figure 1. During baseline, PSCT total scores varied from a high of 14 to a low of 2 with a phase mean equaling 6. After week two, PSCT total scores decreased to 2 for Weeks 3 and 4 and no upward trend was demonstrated. During the BE phase of treatment, PSCT total scores remained low, with a phase mean equaling 3.7. Treatment Sessions 2 and 3 were rescheduled due to missed sessions, resulting in no assessment data being collected for Weeks 6 and 8. At Week 10, the PSCT component of treatment was implemented. Treatment Session 6 also had to be rescheduled; consequently, no assessment data were collected for Week 12. Notable increases in PSBC total scores occurred in Week 11 and 12. During Week 14, PSBC total scores decreased to 3. This low score may have been due to a reported argument between the parent and adolescent that occurred before the assessment session. Regardless, 
PSBC total scores returned to high levels in Weeks 15, 16, and 17. The PSCT phase mean equaled 9.1.

The generalization probe topic "fighting with your sibling," was discussed by Dyad 2 prior to treatment and again at treatment completion. Prior to treatment, Dyad 2 received a PSBC total score of 2. After treatment, Dyad 2 received a score of 13. At 2-weeks follow-up, Dyad 2 discussed the issue "talking back to parents" which was rated by the parent as the highest frequency x intensity IC score. Dyad 2 received a PSBC total score of 15.

IBC. For Dyad 2, negative and positive IBC behavior scores are shown in Figure 3. During baseline, the parent averaged a negative IBC score of 4.1, whereas the adolescent averaged a negative IBC score of 5.6. Both Parent 2's and Adolescent 2's negative scores remained relatively stable within the $\mathrm{BE}$ treatment phase, with an increase occurring in Adolescent 2's Week 9 negative IBC score to 8.5. Parent 2's BE phase mean equaled 3.8, whereas Adolescent 2's BE phase mean equaled 6.5. During the PSCT phase, Parent 2's scores continually decreased until a score of 0 was reached at week 14 . Slight increases occurred in her scores during week 15, 16, and 17. Overall, her PSCT phase mean decreased to 2.1. Adolescent 2's negative IBC scores in the PSCT phase ranged from 2.5 to 6 , with an overall phase mean equaling 4.6.

Baseline positive IBC scores for Parent 2 and Adolescent 2 ranged between 1 and 3, with Parent 2's mean IBC positive score equaling 2.5, and Adolescent 2's equaling 2. With the implementation of the BE phase, initially positive scores increased in week 5. However, scores for both Parent 2 and Adolescent 2 subsequently decreased as treatment progressed in the BE phase. Mean BE phase IBC positive scores for Parent 2 and Adolescent 2 equaled 2 and 1.3, respectively. Positive IBC scores slightly increased with the implementation of the PSCT phase 
of treatment. Notable increases occurred for both Parent 2 and Adolescent 2 during weeks 13 and 14. Parent 2' higher scores maintained in weeks 16 and 17, while Adolescent 2's returned to baseline levels. Mean positive IBC scores for the PSCT phase of treatment for Parent 2 and Adolescent 2 equaled 4.1 and 2.7, respectively.

Negative and positive IBC scores were generated for the generalization probes, as well. During baseline, Parent 2 obtained a negative IBC score of 12.5 and a positive IBC score of 3 . Adolescent 2 obtained a negative IBC score of 10.5 and a positive IBC score of 2 in baseline. After treatment, the Parent 2's negative IBC decreased to a 4.5, and her positive score remained unchanged at 3 . Adolescent 2's negative IBC decreased to a 3 and his positive IBC increased to 3.

At 2-weeks follow-up, Parent 2's negative IBC score decreased to .5. In addition, her positive IBC score remained at 3. Adolescent 2's negative score decreased to 1.5 , but his positive IBC score increased to a 3 .

\section{$\underline{\text { Parent Report }}$}

The results from the Parent 2's paper-and-pencil assessment measures completed at pretreatment, post-treatment, and 2-week follow-up are illustrated in Table 7. Parent 2's pretreatment CBCL profile indicates that for Adolescent 2, 7 of 8 subscale scores fell within the Normal range. Adolescent 2's aggressive behavior subscale score however, fell within the clinical range $(\mathrm{T}-\mathrm{Score}=70)$. At post-treatment, the same 7 subscales remained within the Normal range. However, his aggressive behavior subscale score decreased to the Borderline range (TScore $=69)$. On the measures assessing conflict, substantial decreases occurred at post-treatment on the CBQ-20 score, for all three of the IC scores, and the PARQ global distress, communication, problem-solving, and cohesion scale scores. Taken together, these results 
suggest that Parent 2 was reporting overall decreases in the level of conflict occurring between her and Adolescent 2 at post-treatment. In addition, she reported decreases in negative communication patterns and increases in her and Adolescent 2's use of problem-solving skills.

Compared to baseline, a number of scores obtained at post-treatment on both the FBI and PARQ belief subscales decreased. A relatively large reductions was found in Parent 2's FBI and PARQ perfection subscale, suggesting that Parent 2 adhered less to the belief that with too much freedom, teenagers will ruin their futures. Furthermore, relatively larger decreases were noted in her post-treatment self-blame subscale scores on both the FBI and the PARQ, suggesting that she was less likely to believe that parents were responsible for their adolescent's inappropriate behavior.

At 2-weeks follow-up, Parent 2's CBQ-20 score of a 6 remained relatively low compared to her pre-treatment score (i.e., 17). In addition, the number of issues she identified as having discussed with Adolescent 2 remained at 8, similar to her post-treatment score. Considered alone, these scores would suggest that treatment effects had maintained. However, even though the number of issues she identified at follow-up was similar to the number in post-treatment, her average anger-intensity score and her WF/I score at follow-up had increased to pre-treatment levels. This suggests that although Parent 2 reported discussing less issues with Adolescent 2, she was experiencing higher levels of anger than she reported at pre-treatment during those discussions.

\section{$\underline{\text { Adolescent Report }}$}

The results from Adolescent 2's paper-and-pencil assessment measures completed at pretreatment, post-treatment, and 2-week follow-up are presented in Table 8. Adolescent 2's CBCLYSR scores at both pre-treatment and post-treatment all were found to be in the Normal range. 
With regard to Adolescent 2's pre-treatment scores on the measures assessing family conflict, it is important to note how low his CBQ-20, IC, and PARQ scores were. Accordingly, these low scores suggest that Adolescent 2 did not perceive high levels of conflict within his family or problems in family communication or problem-solving with his mother prior to beginning treatment. Due to low scores on pre-treatment measures, post-treatment changes were relatively minor. His CBQ-20 score at post-treatment decreased from a 6 at pre-treatment to a 2 at posttreatment. Similarly, a reduction was noted in the number of issues discussed as measured by the IC. However, little to no changes in scores occurred on the IC average anger-intensity score or the WF/I score from pre-treatment to post-treatment. Likewise, PARQ global distress and communication with father scale scores remained the same. Only PARQ cohesion and conventionalization scale score, increased at post-treatment, suggesting that Adolescent 2 may have felt more positive about family interactions and support.

Adolescent 2's post-treatment FBI ruination, fairness, and autonomy subscale scores increased significantly relative to his pre-treatment scores. Based on these scores, Adolescent 2 endorsed a stronger adherence to these beliefs after completing treatment. Only his FBI approval subscale score decreased at post-treatment. His PARQ belief subscale scores remained relatively unchanged, with only his approval subscale increasing, contrary to his FBI approval score.

At 2-weeks follow-up, Adolescent 2's CBQ-20 score decreased to 1, suggesting little to no conflict and communication problems with his mother. His IC number of issues score increased slightly to an 8 , suggesting he was discussing fewer issues than at pre-treatment. However, his IC average anger-intensity score and WF/I score remained relatively unchanged from his pre- and post-treatment scores, implying that he was experiencing approximately the same amount of anger when discussing issues with his mother. 


\section{Therapist's Ratings of Family Cooperation}

Dyad 2's TRFC total score and average item scores are presented in Table 9. Dyad 2's average rating on the item concerning how accepting the dyad was of the therapist was high at a 6.0. For the items assessing the therapist's ratings of the quality communication and problemsolving displayed by the family, as well as the family's ability to achieve the session's goals, Dyad 2 obtained mean scores just slightly above average. Finally, the therapist rated the family's completion of the assigned homework as below average. This was due to Dyad 2's failure to complete 4 of the 9 homework assignments. Homework assigned in treatment Sessions 2, 4, 5 , and 6 reportedly was not attempted, and homework assigned in treatment Session 8 was only partially completed.

\section{Dyad 3}

\section{$\underline{\text { Behavior Observations }}$}

$$
\text { PSBC. Dyad 3's (i.e., Donna }=\text { Parent 3, Adolescent } 3=\text { Adolescent 3) PSBC total }
$$
scores derived from the weekly assessment sessions are shown in Figure 1. During baseline, Dyad 3's PSBC total scores ranged from a high of 9 to a low of 2. The baseline phase mean equaled 5.4. Treatment began after a score of 2 was obtained in Week 5 and no upward trend in the data was present. With the implementation of the BE component of treatment, PSCT total scores increased by 1 point weekly. The BE phase mean equaled 7. With the implementation of the PSCT component of treatment, PSBC total scores increased above the average BE phase mean beginning in week 12 . No data were obtained for Week 11 due to rescheduling treatment Session 6. Increases over Baseline and BE treatment phase averages continued until Week 15, when the family scored a 10. However, in Week 16 Dyad 3 scored a 16 . The overall PSCT phase mean equaled 12. 
The generalization probe topic "taking care of CDs, games, bikes, pets, and other things," was discussed by Dyad 3 prior to treatment and at treatment completion. Prior to treatment, Dyad 3 received a PSBC total score of 4 . After treatment, Dyad 3 received a score of 16, indicating that both Parent 3 and Adolescent 3 exhibited all of the problem-solving skills measured by PSBC. At 2-weeks follow-up, Dyad 3 discussed the issue "playing the stereo or radio too loudly" which was rated at that time as the highest frequency $\mathrm{x}$ intensity IC score. Dyad 3 again received a PSBC total score of 16 , suggesting that problem-solving skills had maintained over the 2-week period.

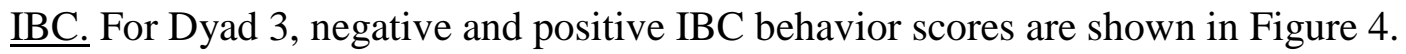
During baseline, both Parent 3 and Adolescent 3 exhibited higher negative behavior IBC scores in the first 3 weeks of assessment. However, for the last two weeks, both exhibited a downward trend in negative IBC scores. Parent 3's baseline phase mean equaled 6.2 and Adolescent 3's baseline phase mean equaled 11.6. Throughout the BE phase of treatment, scores gradually increased. However, both Parent 3's and Adolescent 3's BE phase means slightly decreased. Parent 3's average IBC negative score for the BE phase equaled 5.3, whereas Adolescent 3 average score equaled 9. With the implementation of the PSCT component of treatment, scores for both Parent 3 and Adolescent 3 decreased. No data are presented for Week 11 because treatment session 6 was rescheduled. Negative IBC scores for both Parent 3 and Adolescent 3 remained at near zero levels. Parent 3's PSCT phase mean equaled 1.3, whereas Adolescent 3's equaled 3.9.

Baseline positive IBC scores for both Parent 3 and Adolescent 3 exhibited a downward trend prior to treatment, as well. Particularly noticeable was Adolescent 3's low positive scores. Baseline phase mean positive IBC scores for Parent 3 and Adolescent 3 were a 2.8 and a .8, 
respectively. With the implementation of the BE phase, scores initially increased in Week 6. However, scores for both Parent 3 and Adolescent 3 decreased in Week 7, before increasing again in Week 8. BE treatment phase means equaled 3 for Parent 3 and 1.7 for Adolescent 3. Observable increases occurred in both Parent 3 and Adolescent 3's positive IBC scores with the implementation of the PSCT phase of treatment. Parent 3's scores ranged from 3 to 6, with only Weeks 12 and 15 decreasing to a 3. Adolescent 3's scores increased as well, with only one week's score (i.e., Week 12) equaling a 0. The lower scores obtained in Week 12 may have reflected a recent argument between Parent 3 and Adolescent 3 that occurred prior to the assessment session. The PSCT phase means for both Parent 3 and Adolescent 3 increased to a 4.4 and a 2.4 , respectively.

Likewise, negative and positive IBC scores were generated for the generalization probes. During baseline, Parent 3 obtained a negative IBC score of 2.5 and a positive IBC score of 2 . Adolescent 3 obtained a negative IBC score of 8.5 and a positive IBC score of 0 . Following BE+PSCT treatment, Parent 3's negative IBC decreased to 0, and her positive score increased to 4. Adolescent 3's negative IBC score decreased to a 2 and his positive IBC score increased to a 3.

At 2-weeks follow-up, Parent 3's negative IBC score remained below her baseline mean score, but increased to a 3 . Her positive score of a 4 was relatively higher than most of her baseline scores. Adolescent 3's negative score of 6.5 remained lower than his baseline average negative score, as well. Adolescent 3's positive IBC score at follow-up was a 3.

\section{$\underline{\text { Parent Report }}$}

The results from Parent 3's paper-and-pencil assessment measures completed at pretreatment, post-treatment, and 2-week follow-up are presented in Table 10. Parent 3's CBCL 
scores completed at pre-treatment regarding Adolescent 3 place his attention problems and delinquent behavior subscale scores in the Borderline range (T-Scores=67 and 69, respectively). His aggressive behavior subscale score fell within the Clinical range $($ T-Score $=81)$. All other subscale scores were in the Normal range. At post-treatment, Adolescent 3's delinquent behavior and aggressive behavior subscale scores fell within the Clinical range (T-Scores $=72$ and 75 , respectively). His attention problems subscale and all other subscales were found to be in the Normal Range. On the measures assessing conflict, Parent 3 reported relatively few improvements from pre-treatment as measured by her post-treatment CBQ-20, IC, and PARQ subscale scores, despite the improvements demonstrated by the PSBC total scores and IBC positive and negative scores. Her CBQ-20 score decreased from an 8 to a 7 at post-treatment. In addition, the number of issues she discussed with Adolescent 3 increased to 28, although the intensity in which they discussed those issues decreased slightly, as measured by her IC scores. However, PARQ global distress, communication, and cohesion subscale scores were identical at post-treatment to the pre-treatment scores. In addition, the PARQ problem-solving, conventionalization, and hierarchy reversal subscale scores only changed by a point from the pre-treatment assessment, suggesting little or no change.

Regarding Parent 3's beliefs, increases were noted on her post-treatment FBI perfection and obedience subscale scores, whereas decreases were noted on the FBI approval, self-blame, and malicious intent subscales. This was congruent with decreases noted in her post-treatment PARQ self-blame and malicious intent subscale scores. However, contradictory findings were obtained regarding her PARQ ruination and obedience subscale scores. Scores for these PARQ subscales decreased or stayed the same at post-treatment, whereas FBI subscale scores increased. 
As a result, interpretations regarding changes in Parent 3's adherence to certain beliefs are difficult to establish.

At the 2-week follow-up, a small decrease from pre-and post-treatment was observed in Parent 3's CBQ-20 score. In addition, the number of issues discussed as measured by the IC remained the same as the number at post-treatment. The average anger-intensity score returned to a near pre-treatment level, however the WF/I remained near the post-treatment level. This suggests that although Parent 3 was experiencing similar levels of anger in general, the average anger per discussion about specific issues she was discussing with Adolescent 3 remained lower than pre-treatment levels.

\section{$\underline{\text { Adolescent Report }}$}

Pre-treatment, post-treatment, and 2-week follow-up questionnaire data for Adolescent 3 are presented in Table 11. According to Adolescent 3's CBCL-YSR pre-treatment scores, his somatic complaints and aggressive behavior subscale scores were in the Clinical range (T-Scores $=70$ and 82, respectively). All other subscale scores fell within Normal range. At post-treatment Adolescent 3's CBCL-YSR delinquent behavior and aggressive behavior subscale scores fell within the Borderline range (T-Scores $=70$ and 69, respectively). All other subscale scores fell within the Normal range. Regarding the measures assessing conflict, relatively small decreases from pre-treatment were obtained at post-treatment on Adolescent 3's CBQ-20 and PARQ global distress and communication subscale scores, suggesting he experienced limited benefits from treatment. A noticeable decrease was reported in the number of issues discussed by Adolescent 3 and his mother, as measured by the IC. However, an increase in Adolescent 3's IC average anger-intensity score suggests he was experiencing relatively more anger in general with his mother. Adolescent 3's PARQ problem-solving rating mother subscale increased from a 5 to a 6 
at post-treatment, congruent with his other scores suggesting little treatment effect. Furthermore, his problem-solving rating father subscale increased from a 4 to a 10 , suggesting a worsening in problem-solving with his father. In addition, his PARQ cohesion, conventionalization, and hierarchy reversal rating father subscale scores all increased slightly at post-treatment.

Score increases at post-treatment were evident on the FBI ruination, fairness, and approval subscales. Increases in scores also were noted on the PARQ ruination and perfectionism subscales. Relatively larger increases occurred on both the FBI and PARQ ruination subscale scores, suggesting that Adolescent 3 adhered more strongly to the belief that parental rules and restrictions will ruin teenagers' lives.

At 2-weeks follow-up, Adolescent 3 obtained a CBQ-20 score of 11. This was the same score he obtained at post-treatment, both of which were slightly lower than his pre-treatment score. The number of issues he discussed with his mother decreased to 4 , as measured by the IC. In addition, his average anger-intensity level score returned to pre-treatment levels. However, his WF/I score slightly increased above pre-and post-treatment levels, indicating a worsening in parent-adolescent conflict.

Therapist's Ratings of Family Cooperation

Table 12 shows Dyad 3's TRFC total score and average item scores. The therapist's rating of Dyad 3 on the item concerning how accepting the dyad was of the therapist was in the above average to high range with a mean score of 5.7. For the items assessing the therapist's ratings of the quality communication and problem-solving displayed by the family, as well as the family's ability to achieve the session's goals, Dyad 3 obtained mean scores just slightly above average (range $=4.5-4.9$ ). The therapist rated the family's completion of the assigned homework as slightly below average with a mean score of 3.2. This was due to Dyad 3's failure to complete 
any part of the homework in treatment Session 5, 6, 7, and 8. As a result, Dyad 3 obtained ratings of 1 for those four assignments. However, the assignments Dyad 3 did complete resulted in high ratings from the therapist, indicating thorough and accurate completion.

\section{Dyad 4}

\section{$\underline{\text { Behavior Observations }}$}

PSBC. Dyad 4's (i.e., Sally = Parent 4, Don = Adolescent 4) PSBC total scores are shown in Figure 1. During baseline, PSBC total scores for Dyad 4 initially increased to 10 during Week 2. However, PSBC total scores subsequently decreased to a 5 in Week 6. Dyad 4's PSBC total score baseline mean equaled 7.2. With the implementation of the BE component, PSBC scores remained stable for Weeks 7 and 8, however increased to a 12 during Week 9. The BE phase mean was 7.3. With the implementation of the PSCT phase of treatment, scores initially decreased. However, scores gradually increased, with scores of 14 and higher obtained in Weeks 13, 15, and 17. No data were collected for Week 16 due to Dyad 4's rescheduling of treatment Session 10. The PSCT phase mean was 12.

Dyad 4 discussed the generalization probe topic "fighting with your siblings," prior to treatment and obtained a PSBC total score of 4. The topic was discussed again after treatment and Dyad 4 scored a 15. At 2-weeks follow-up, Dyad 4 discussed the issue "helping out around the house," which had the highest frequency x intensity IC score. Dyad 4 received a PSBC total score of 14 , suggesting that the dyad continued to exhibit problem solving skills during their discussion two weeks after treatment.

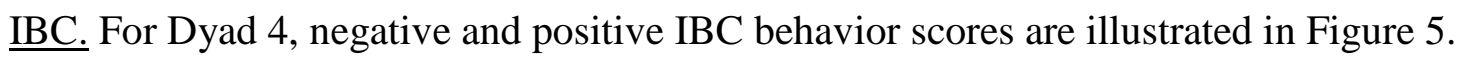
During baseline, Parent 4's negative IBC behavior scores ranged between 2 and 11 with a phase mean of 5. Adolescent 4's negative IBC scores ranged between 4.5 and 9 with an average phase 
score of 6.9. With the implementation of the BE phase of treatment, both Parent 4's and Adolescent 4's IBC negative scores remained relatively stable. In fact, Parent 4's mean BE phase score was 5, which was the same as her baseline mean. The BE phase mean for Adolescent 4 was 6.7. The PSCT component of treatment began in Week 10 for Dyad 4. During this treatment phase, Parent 4's negative IBC scores decreased to near zero or zero during Weeks 10, 12, 15, and 17. Parent 4's PSCT treatment phase mean equaled 1.2. For Adolescent 4, his negative IBC scores decreased gradually, with decreases to near zero or zero occurring during Weeks 12 and 15. His PSCT phase mean equaled 3.2.

Baseline positive IBC scores for both Parent 4 and Adolescent 4 were similar. Parent 4 ranged from a 2 to a 5 , with a mean score of 2.8. Adolescent 4's positive IBC scores ranged from a 1 to a 3, with a mean phase score of 2.3. During the BE phase, both Parent 4's and Adolescent 4's positive IBC scores were similar to those scores found in baseline. Parent 4's BE phase mean was 2.7 and Adolescent 4's was a 2. With the implementation of the PSCT phase of treatment, Parent 4's scores initially increased during Week 10. However, during Week 14 her score decreased to a zero. Her later scores were similar to those found in baseline and treatment, with an overall PSCT phase mean of 3. Similar results were found with Adolescent 4's positive IBC scores during the PSCT phase of treatment. Adolescent 4 also obtained a positive IBC score of zero for Week 14. However, his Week 15 and 17 scores increased to a 4. His overall PSCT phase mean was 2.7.

Negative and positive IBC scores were generated for the generalization probes. Prior to beginning treatment, Parent 4 obtained a negative IBC score of 9 and a positive IBC score of 3 . Adolescent 4 obtained a negative IBC score of 7 and a positive IBC score of a 1. After treatment, 
Parent 4's negative IBC decreased to 2.5, and her positive score increased to 4. Adolescent 4's negative score decreased to a 2.5 and his positive IBC score increased to a 4 .

At 2-weeks follow-up, Parent 4's negative IBC score was a 2 and her positive score was a 4. Adolescent 4's IBC scores at 2-weeks follow-up included a negative IBC score of an 8 and a positive score of a 3 . These scores indicated that Parent 4 continued to exhibit appropriate communication behaviors during the discussion at 2-weeks follow-up. However, Adolescent 4's scores indicated that he exhibited a higher number of negative communication behaviors relative to post-treatment during the discussion at follow-up.

\section{Parent Report}

The results from Parent 4's paper-and-pencil assessment measures completed at pretreatment, post-treatment, and 2-week follow-up are presented in Table 13. Parent 4's CBCL subscale scores regarding Adolescent 4 all fell within the Normal range at both pre-treatment and post-treatment. As to the measures assessing conflict, Parent 4's CBQ-20 score at pre-treatment was considerably low, suggesting she was not perceiving high levels of conflict and negative communication with Adolescent 4 at home. However, her pre-treatment PARQ global distress raw score of 11 (out of a possible 15) suggests that she was dissatisfied with her and Adolescent 4's relationship, and she was experiencing conflict between her and Adolescent 4. As a result, Parent 4's reports of the overall degree of conflict experienced with Adolescent 4 are conflicting. Her post-treatment CBQ-20 score was identical to her pre-treatment score. However, her PARQ global distress score decreased to a 3, suggesting she was reporting improvements at home. Minimal decreases also were found in post-treatment communication, problem-solving, and cohesion scores. In addition, the number of issues and the level of anger she experienced when discussing those issues, as measured by the IC, decreased slightly at post-treatment. However, 
given the low scores at pre-treatment (excluding the PARQ global distress subscale score), Parent 4's results suggest minimal improvement from baseline.

Parent 4's adherence to beliefs measured by the FBI and PARQ subscales at posttreatment generally did not vary much from pre-treatment. Conflicting results were obtained on these measures as well. At post-treatment, Increases were noted on the FBI perfection and obedience subscales, however decreases were found on the PARQ perfection and obedience subscales. Only the self-blame subscale scores on both measures decreased slightly from pretreatment to post-treatment.

At the 2-week follow-up, Parent 4's CBQ-20 score of a 3 was the same at pre- and posttreatment. The number of issues discussed as measured by the IC at follow-up (i.e.,7) remained nearly the same as the number at post-treatment (i.e., 8). However, the average anger-intensity score and the WF/I score were elevated above baseline pre-treatment levels. Suggesting that although Parent 4 was reporting discussing fewer issues with Adolescent 4 she was experiencing higher levels of anger in general and higher levels of anger per discussion about specific issues she was discussing with Adolescent 4

\section{$\underline{\text { Adolescent Report }}$}

Adolescent 4's pre-treatment, post-treatment, and follow-up data are shown in Table 14. Adolescent 4's CBCL-YSR subscale scores at pre-treatment and post-treatment all fell within the Normal range. Concerning the measures assessing conflict, Adolescent 4 reported low levels of conflict at pre-treatment as evidenced by his CBQ-20 total score and PARQ global distress, communication rating mother and father, and problem-solving rating mother and father subscale scores. Both low scores at pre-treatment suggested Adolescent 4 was not experiencing high levels of conflict overall. Adolescent 4's CBQ-20 score and PARQ global distress subscale 
scores at post-treatment decreased to 0. In addition, the number of issues Adolescent 4 reported discussing with his mother decreased from 14 at pre-treatment to 7 at post-treatment. However, the average anger intensity score and the $\mathrm{WF} / \mathrm{I}$ score remained relatively similar, suggesting that prior to and after treatment, Adolescent 4 was reporting low levels of anger regarding issues and discussions he had with his mother.

Minimal changes from pre-treatment to post-treatment were found on Adolescent 4's FBI beliefs subscale scores and his PARQ beliefs subscale scores. His PARQ ruination, fairness, and autonomy subscale scores remained at zero at post-treatment. In addition, his PARQ perfectionism and approval subscales decreased to zero. However, it should be noted that relative to the other adolescent participants, Adolescent 4's PARQ belief subscale scores were somewhat lower at pre-treatment. In addition, his FBI subscale scores all decreased from pre-treatment to post-treatment.

At 2-weeks follow-up, Adolescent 4 continued to report low levels of conflict based on his CBQ-20 scores. His IC score indicated that he continued to discuss fewer issues with his mother than at pre-treatment. In addition, the average intensity/issue and WF/I scores both increased from post-treatment, suggesting he was experiencing relatively higher levels of anger and arguments during specific discussions.

\section{Therapist's Ratings of Family Cooperation}

Table 15 shows Dyad 4's TRFC total score and average item scores. The therapist's rating of Dyad 4 on the item concerning how accepting the dyad was of the therapist was in the high range with a mean score of 6.1 . For the items assessing the therapist's ratings of the quality of communication and problem-solving displayed by the family, as well as the family's ability to achieve the session's goals, Dyad 4 obtained mean scores slightly above average (range=5.0- 
5.8). The therapist rated the family's completion of the assigned homework as slightly below average with a mean score of 3.0. This was due to Dyad 4's failure to complete the homework assigned in treatment Session 5, 7, 8, and 9. Thus, 4 of the 9 homework assignments were not completed, resulting in therapist ratings of 1.

\section{$\underline{\text { Consumer Satisfaction Survey }}$}

An additional hypothesis examined by this study was whether the BE+PSCT treatment program would be an appropriate and acceptable form of treatment, as measured by consumer satisfaction ratings, for parents and adolescents experiencing conflict. Average item scores obtained for each participant per session are shown in Table 16. Average item scores for Dyad 1 were below those found for Dyads 2, 3, and 4. The Dyad 1 parent's scores ranged from 3.0 to 3.8 across sessions, suggesting he generally felt neutral with regard to how satisfied he was with the treatment. Similarly, Dyad 1 adolescent's average item ratings were somewhat below those of the other adolescents. Her average item score ranged from 3.4 to 4.5 across sessions, suggesting that after some sessions she felt neutral to satisfied with the BE+PSCT treatment. In general, parents and adolescents in Dyads 2, 3, and 4 average item scores ranged from 4.0 to 5.0 across all sessions, suggesting that these participants were satisfied to very satisfied with each treatment session.

\section{Discussion}

It was hypothesized that many of the identified limitations of PSCT (e.g., PSCT requires more family cooperation than other treatments, the initial stages of PSCT do not focus on enhancing participant's relationships) for parent-adolescent conflict could be addressed with the inclusion of a BE treatment component. The literature regarding Behavioral Marital Therapy documents the success of a combination BE+PSCT treatment for couples. In addition, a limited 
number of studies have employed a BE component in isolation to alleviate parent-adolescent conflict successfully. As a result, the examination of a BE+PSCT treatment package for parents and adolescents is warranted. Hence, the reasons for conducting this investigation were threefold. The first goal was to evaluate if the BE+PSCT treatment would result in observable behavior change in the dyads' use of problem-solving skills, positive communication skills, and negative communication patterns during discussions of common topics associated with parentadolescent conflict. The second goal was to evaluate if the BE+PSCT treatment program would reduce conflict at home and enhance problem solving and communication skills as reported by parents and adolescents on pre-and post-treatment self-report measures. The final goal was to evaluate if the BE+PSCT treatment program would be considered an acceptable form of treatment for parents and adolescents experiencing conflict as measured by the participants' consumer satisfaction ratings.

\section{Observable Behavior Changes}

Problem-Solving Skills. The results of this study suggest that the BE+PSCT treatment led to observable increases in all four dyads' use of problem-solving skills identified to be instrumental in the resolution of specific disputes related to elevated levels of parent-adolescent conflict. By the end of treatment, all four dyads were exhibiting a high number of skills during the assessment discussions. In fact, all four dyads exhibited all of the skills identified by the PSBC at least once during their assessment discussion sessions. Thus, all of the families demonstrated skill acquisition by the completion of treatment. It should be noted however, that the topics discussed in the assessment sessions were thought to be associated with higher levels of conflict for "typical" parents and adolescents, but some of the topics may not have been problematic for certain dyads. As a result, some of the variability in PSBC scores obtained 
throughout baseline and treatment may be due to either how problematic or unproblematic the "pretend" topic discussed was for the family. Furthermore, although all of the families met baseline criteria in that their PSBC scores were not on an upward trend prior to implementing treatment, longer baselines allowing for further examination of pre-treatment problem-solving skill use would have been preferable. However, a clinical decision to begin treatment with the shortest baselines that met criteria was made in an effort to potentially help troubled families as soon as possible.

The question of problem-solving skill acquisition is irrelevant for families experiencing conflict if they do not use the skills in "real" conflict situations, however. Generalization probes were utilized in this study in an attempt to observe the use of skills while the participants discussed specific issues that they had identified as leading to conflict. All four families demonstrated notable improvements as compared to their initial performance at pre-treatment in their use of a number of problem-solving skills, as measured by the PSBC, when discussing these issues at the end of treatment. Although these findings are promising, they should be considered with caution. One limitation of this study is the amount of time between generalization probes because topics discussed prior to treatment may have lost some of the emotional intensity associated with them when being discussed a second time 10 weeks later. Another limitation with the generalization probes used in this study was that families discussed the same issue during the post-treatment probe as they had discussed at the pre-treatment probe. Families may have resolved the particular issue they had discussed in the first probe by the time they discussed it a second time.

To address the possibility that probes no longer were salient or anger-producing, families identified new, "current" issues that led to conflict for their 2-week follow-up assessment 
discussion. Follow-up PSBC scores across families suggested that skill acquisition maintained for a 2-week period, and perhaps more interestingly, high rates of problem-solving skills were exhibited by all of the families when they discussed the new issue. This finding further implies that the families had acquired the problem-solving skills and could apply them when asked to discuss and develop a solution for a new problem that currently was causing conflict.

Positive Communication Skills and Negative Communication Behaviors. In addition to problem-solving skills, families were taught to identify negative communication behaviors that frequently were associated with higher levels of conflict during discussions. In order to decrease anger and arguments, families also were taught to use positive communication skills when discussing issues associated with conflict. Both higher levels of positive communication skills and lower levels of negative behaviors during discussions have been shown to be associated with lower levels of conflict and anger (Robin \& Weiss, 1980). Results obtained from the IBC for both the parent and adolescent participants in this study indicate that levels of negative communication behaviors remained stable or slightly decreased from baseline to treatment during assessment discussion sessions. For example, negative IBC scores for the adolescent in Dyad 1 and the parent and adolescent in Dyad 2 remained relatively stable from baseline throughout the end of treatment, whereas negative IBC scores for the parent in Dyad 1 and both the parents and adolescents in Dyad 3 and Dyad 4 decreased slightly from baseline to the end of treatment. Furthermore, levels of positive communication behaviors generally remained stable or increased from baseline to treatment. Specifically, notable increases in the use of positive communication skills from baseline across treatment were noted for the parents in Dyads 1,2, and 3 and for the adolescent in Dyad 3. Overall, the majority of parents and adolescents demonstrated improvements in communication skills. 
It should be noted, however, that overall changes in some of the participants' positive and negative IBC scores were relatively minor from baseline to post-treatment. These minor changes may have been a result of the fact that the current BE+PSCT treatment program did not effectively teach some of the participants to identify negative communication behaviors or to use positive communication skills adequately. Although the BE+PSCT treatment attempted to address idiosyncratic communication patterns of dyad members, the current program may not have devoted the time necessary to facilitate decreases in the use of negative communication behaviors and increases in positive communication behaviors. The current program devoted 3 sessions to communication training, whereas 6 sessions were devoted to teaching problemsolving skills. Other researchers have lamented the difficulties associated with trying to teach parents and adolescents to identify and change specific target verbal behaviors and communication patterns exhibited during disputes (Foster, 1987; Robin \& Foster, 1989). Perhaps with more time devoted in treatment to changing communication patterns, greater gains would have been obtained.

Related to the possibility of insufficient time devoted to communication skill instruction, it also may have been the case that the limited changes occurring in positive and negative IBC scores were due to difficulties associated with changing negative and positive communication patterns. It may be that patterns of communication established between family members are less susceptible to change, thus, more difficult to change, than problem-solving skills. This difficulty may be due to longer learning histories associated with family communication patterns. As a result, prior reinforcement and punishment histories may influence the ability of parents and adolescents to exhibit newly learned communication behaviors and patterns during times of conflict. Family members may resort to past negative verbal behaviors and communication 
patterns that have an established history of reinforcement, limiting the use of new behaviors. For example, in the absence of structure provided by the therapy session, it may be easier for the adolescent to simply interrupt the parent, instead of listening to something that the adolescent does not like to hear. If the parent reinforces interrupting by ceasing to speak of the topic that the adolescent found undesirable, the adolescent may be more likely to continue to interrupt in the future. Unfortunately, not only is the negative behavior of interrupting likely to persist, the adolescent may subsequently terminate any chance of using positive communication behaviors during the discussion by both the adolescent and the parent due to the reciprocal nature of verbal behavior.

Similarly, verbal and nonverbal positive and negative communication behaviors may be more difficult than problem-solving skills to target for treatment given their "subtle" nature. It may have been difficult for both members of the dyad to identify and subsequently change some negative communication behaviors (e.g., a smirk or a sarcastic statement). In addition, complex positive communication behaviors, such as "appropriate listening," may be comprised of a number of smaller behaviors (e.g., head nods and statements of reflection) that need not only to be exhibited by the speaker, but acknowledged by the listener. All of these "subtle" communication behaviors are difficult to target for change, whereas problem-solving behaviors such as defining the problem or listing possible solutions may be more overt and obvious to identify and subsequently change. Further study of how best to teach communication skills should include examination of the time devoted to training, examination of past reinforcement histories of the speaker and listener, and how best to identify and subsequently target "subtle" communication behaviors and their function. 


\section{$\underline{\text { Self-Report Behavior Changes }}$}

$\underline{\text { Parent Self-Report of Conflict, Problem-Solving, and Communication. In addition to }}$ direct observation measures, this study also relied upon self-report measures to evaluate the extent to which participants reported reductions in conflict, along with increased problemsolving and communication skill use, outside of assessment situations. It was hypothesized that if the participants independently used the problem-solving and communication skills taught throughout the treatment sessions, they would report lower levels of conflict after concluding the program. Researchers have cautioned about conclusions derived from parent and adolescent selfreport measures as family members' reports of communication patterns frequently vary from what the therapist observes in session (Foster \& Robin, 1998; Robin \& Foster, 1989). In addition, family members frequently define and label interactions and communication patterns differently from each other, resulting in discrepancies and inaccurate reporting (Foster \& Robin). Finally, researchers have suggested that many family members are not aware of the day-to-day molecular interaction patterns that occur, leading to further inaccurate reporting (Foster \& Robin). Thus, the self-report data presented in this section and the adolescent self-report section of this manuscript should be interpreted with caution.

General measures of conflict for this study included scores on the CBQ-20, IC, and the Global Distress scale score on the PARQ. Results at post-treatment indicated reductions on all of these measures for the parents in Dyad 1 and Dyad 2 (i.e., Parent 1 and Parent 2), reductions on the IC and PARQ Global Distress scale for the parent in Dyad 4, and for the most part, no changes were found for the parent in Dyad 3. A similar pattern of results for each participant was obtained at follow-up, with Parent 1's, Parent 2's, and Parent 4's reported lower levels of conflict (as measured by the CBQ-20 and IC) maintaining and with minimal improvements in Parent 3's 
report. In addition to the global measures of conflict, more specific self-report measures examining problem-solving used in this study included the PARQ Problem-solving scale scores. Parent 2 reported a relatively large increase in problem-solving at home, whereas Parent 1 and Parent 4 reported relatively smaller increases. Parent 3 actually reported a slight worsening in the use of problem-solving skills at home. Finally, specific self-report measures of communication included the PARQ Communication scale score. Parent 1, Parent 2, and Parent 4 all reported improvements in the use of communication behaviors at home, whereas Parent 3 reported no change from pre-treatment to post-treatment.

Taken together, results from the self-report measures indicate that two of the four parents (i.e., Parent 1 and Parent 2) reported improvement, one parent (i.e., Parent 3) did not report improvements, and one (i.e., Parent 4) reported minimal gains. Both Parent 1 and Parent 2 reported improvements in the overall level of conflict at home. For both, their self-reported changes in problem-solving skill use coincide with observable problem-solving skill use (as measured by the PSBC) found in their weekly assessments and generalization probes. However, their self-report of communication skill use did not coincide with observable behavior changes (as measured by the IBC) in their weekly assessment sessions and generalization probes. The discrepancy between the self-report and observable behavior change in communication scores suggest a number of possible interpretations. First, it is possible that the parents were using the communication skills outside of the assessment sessions and generalization probes, and they simply did not exhibit them during assessment sessions. It also may be the case that in general conversations not related to conflictual issues, parents felt that their communication patterns improved with their adolescents. Thus, they reported improvements in communication skill use, although these improvements were not related to discussing specific issues associate with 
conflict. However, when considering the possibility of inaccurate reporting by parents and adolescents, another interpretation of the discrepancy between self-report and observable behavior change may be demand characteristics, in that these parents now were aware of target behaviors (i.e., positive communication skills and negative communication behaviors) and inaccurately reported changes.

For Parent 3, the fact that she did not report improvements in levels of conflict and problem-solving and communication skill use may have been due to the fact that she and her son, Adolescent 3, were experiencing greater levels of conflict relative to the other dyads at the beginning of treatment. Her scores on the IC and the PARQ Global Distress scale were the highest when compared to the other families. Furthermore, she reported that she and Adolescent 3 faced significant new stressors throughout therapy, such as losing their source of transportation due to her marital separation, her having to take off time from work due to a 3-day suspension Adolescent 3 received from school, and complications involving symptoms related to Adolescent 3's Marfan's syndrome. It may have been the case that, despite demonstrating observable problem-solving and positive communication skill acquisition in assessment sessions, Parent 3 reported higher levels of conflict at post-treatment and follow-up because she and her son experienced more significant stressors than the other families, potentially increasing the number or issues in which conflict occurred. Perhaps the limited number of training opportunities, the length of time practicing new skills, and the intensity of the current treatment was not adequate for those new skills to generalize to the abundance of stressful issues and situations the family experienced at home.

Overall, results for Parent 4 were somewhat mixed, with some measures showing minimal improvements and others showing greater improvement. Some of the minimal gains 
reported by Parent 4 potentially could be explained by her pre-treatment report of relatively lower levels of conflict in her home. Parent 4's reporting of very low levels of conflict on the CBQ-20 and the PARQ Communication and Problem-solving scales created a ceiling effect in which there was only a small range in which scores could improve at post-treatment and followup. However, her PARQ Global Distress scale score decreased substantially from pre-treatment to post-treatment, suggesting that she did report some improvement. As a result, conclusions regarding Parent 4 self-report scores should be interpreted with caution, given the lack of range in which some of her scores could improve.

Adolescent Self-Report of Conflict, Problem-Solving, and Communication. Similar to the parents, adolescent self-report measures included general measures of conflict (i.e., the CBQ-20, IC, and the PARQ Global Distress scale scores), measures of their perceived use of problemsolving skills (i.e., PARQ Problem-solving rating mother and father scale scores), and communication skills (i.e., PARQ Communication rating mother and father scale scores) In general, the adolescents in Dyad 2, Dyad 3, and Dyad 4 reported minimal improvements in overall conflict and problem-solving and communication skill use at post-treatment and followup. The adolescent in Dyad 1 reported a slight worsening in overall levels of conflict, and minor improvements in problem-solving and communication with her father.

For Adolescent 2 and Adolescent 4, minimal improvements in self-report scores may be attributed to the high scores both reported at pre-treatment, leaving little room for score improvement at post-treatment. It may be the case that these participants simply did not perceive or experience much conflict or difficulties with problem-solving and communication skill use at pre-treatment. Another possibility may be that their initial high scores reflect the phenomenon that some teens tend to report relatively fewer problems than other informants (Hinshaw, 1994), 
particularly in the realm of externalizing behaviors (Barkley, Fischer, Edelbrock, \& Smallish, 1991). Hence, these adolescents might have under-reported distress at pre-treatment. Finally, an additional interpretation may be that prior to treatment, when these adolescents and their parents argued, disputes resulted in outcomes favorable to the adolescent. This pattern of consequences may explain the low levels of distress reported at pre-treatment.

Adolescent 3's reports of global distress, as measured by the CBQ-20 and PARQ Global Distress scale scores, demonstrated minimal improvements at post-treatment. Furthermore, his CBQ-20 scores demonstrated no improvement at follow-up. In addition, his IC scores suggested that the number of issues he reported discussing with his mother at post-treatment and follow-up decreased; however, the anger associated with discussing those issues increased. Adolescent 3's lack of improvement on his self-report measures may be attributed to increased levels of stress experienced by his mother and him during treatment. Some of this stress was related to his ADHD and Marfan's syndrome symptoms. During the course of treatment, Adolescent 3 was suspended from school for excessive disruptions in the classroom. In addition, he was told that he no longer could participate in his favorite sporting events due to complications resulting from Marfan's syndrome. These events potentially increased the frequency and intensity of issues Adolescent 3 and his mother discussed throughout the course of therapy. Perhaps more intensive treatment or more time addressing specific issues related to Adolescent 3's condition would have facilitated greater improvements on self-report measures.

Adolescent 1 reported an overall worsening in the levels of conflict she experienced from pre-treatment to post-treatment. In addition, she reported only minimal improvements in communication and greater improvements in problem-solving skill use with her father at posttreatment. These results suggest that although treatment resulted in observable problem-solving 
skill acquisition that was congruent with her self-report, the treatment did not lead to reports of improvement of family conflict. This discrepancy may be attributed to a number of factors, including elevated levels of conflict with her step-mother that she felt were not addressed by her father, a perception that her father did not provide her with enough attention due to the birth of her half-sister during the course of treatment, and possible depressive symptoms (e.g., extreme mood swings and withdrawal from conversations) that she exhibited on occasion in treatment sessions.

\section{$\underline{\text { Self-Report of Beliefs and Cognitive Distortions }}$}

One justification for combining a BE treatment component with a PSCT treatment package was to decrease parent and adolescent treatment resistance by focusing on the more positive, nonblaming relational aspects of their behavior. Alexander et al. (1989) suggested that this may in turn promote more therapeutic benefits. Recall that the Barkley et al. (1992) study of PSCT found that the PSCT treatment group mothers' ratings worsened in their degree of negative attributions or cognitive distortions regarding their adolescents' behavior when compared to the mothers' ratings in the other treatment groups. Specifically, the mothers in the PSCT group reported more extreme beliefs about adolescent obedience and perfectionism after treatment than before treatment. Thus, one important aspect of this study was to examine parents' and adolescents' beliefs, as measured by the FBI and the PARQ scale scores, to see if the cognitive restructuring component of PSCT resulted in negative side effects (e.g., stronger adherence to irrational beliefs, higher frequency of negative attributions).

Both the FBI and the PARQ Belief scales measured the parents and adolescents adherence to distorted cognitions and unreasonable beliefs that may have contributed to their conflict. For both measures, higher scores indicate more extreme beliefs. Of interest is that only 
one parent (i.e., Parent 2) reported congruent pre-treatment and post-treatment FBI and PARQ scale scores. The other three parents had incongruent results between the FBI and the PARQ scale scores from pre-treatment to post-treatment. For example, Parent 1 endorsed having stronger adherence to the ruination and self-blame beliefs as measured by the FBI scale scores from pre- to post-treatment, whereas he endorsed having less adherence to the same scale scores as measured by the PARQ from pre- to post-treatment. Likewise, only one adolescent (i.e., Adolescent 4) reported congruent pre- and post-treatment FBI and PARQ scale scores. The discrepant results may be due to differences in the two questionnaires even though both measures defined each belief in a similar manner and were constructed in part by the same author. The FBI scales ask parents and teens to rate how much they endorse each of 6 types of irrational beliefs (e.g., ruination, approval) in response to 10 hypothetical situations. The PARQ scales have 8 true-false items for each of 6 irrational beliefs for parents (e.g., self-blame, malicious intent) and 4 irrational beliefs for teens (e.g., fairness, autonomy). Given the discrepancies, a conservative interpretation of only the beliefs that were congruent on both scales is provided in the section to follow.

For the parents, Parent 2 reported less extreme adherence to all beliefs from pre-treatment to post-treatment. Parent 3 and Parent 4 both reported less adherence to the self-blame belief from pre-treatment at post-treatment. Furthermore, Parent 3 reported a reduction in adherence to the malicious intent belief from pre-treatment to post-treatment. Only Parent 1's adherence to the perfectionism belief increased from pre-treatment to post-treatment. For the adolescents, Adolescent 4 reported less extreme adherence to all categories of beliefs from pre-treatment to post-treatment. Furthermore, Adolescent 1's adherence to the ruination and autonomy beliefs decreased from pre-treatment to post-treatment. Only Adolescent 2's adherence to the fairness 
belief and Adolescent 3's adherence to the ruination belief increased from pre-treatment to posttreatment.

Taken together, these results do not support the findings of the Barkley et al. (1992) study that found that mothers who had received PSCT appeared to worsen in their ratings of their degree of extreme beliefs about their adolescents' conduct. On the contrary, the results of this study tentatively suggest that in general, the BE+PSCT package slightly decreased parents' and adolescents' ratings of their adherence to distorted or irrational beliefs. However, given the discrepancies in findings between the two measures, any interpretations may be suspect. It is interesting to note that the Barkley et al. study did not incorporate the PARQ belief scales. Future investigations are needed to examine the convergent validity between the two questionnaires. In addition, further examination is necessary to determine what, if any, effect the addition of the $\mathrm{BE}$ component may have had in reducing adherence to irrational or rigid beliefs.

\section{Consumer Satisfaction}

The importance of measuring consumer satisfaction has been well documented in the literature (e.g., Hawkins, 1991). Consumer satisfaction data, when evaluated in combination with other types of data, can be used to not only assess comprehensiveness of treatment effects, but also to predict or detect undesired effects of treatment (Hawkins, 1991). As a result, participants' ratings of how satisfied they were with the BE+PSCT treatment and the therapist were assessed at the end of every treatment session throughout this study. Results indicated that in addition to some of the treatment gains, there was evidence of consumer satisfaction with the procedures, format, treatment content, and therapists. The average item score for all sessions ranged from satisfied to very satisfied for the participants in Dyads 2, 3, and 4. Both parents and adolescents in these dyads rated their reactions to the treatment and therapist positively. 
Of interest is the average item scores obtained for the parent and adolescent in Dyad 1. Parent 1's average item scores across sessions were lower than the other parents' scores. Upon closer inspection, lower ratings were obtained across all sessions on the items pertaining to treatment, but not items pertaining to the therapist. In fact, the parent did not rate items 7-10 (i.e., the items targeting the therapist) lower than a 4 at anytime during the treatment, suggesting that he was satisfied with the therapist throughout treatment. In addition, Parent 1 overwhelmingly endorsed the "neutral" category for items assessing satisfaction with treatment across all sessions, suggesting that he was neither satisfied nor dissatisfied with any particular treatment session. A lack of opinion of how satisfied he was with treatment may reflect his assumption that nothing would help his daughter. Parent 1 reported in the initial interview and throughout treatment that he did not believe his daughter would improve, regardless of what was tried. His reported feelings of helplessness, particularly given a number of issues that occurred throughout the treatment (e.g., birth of his daughter, lack of support from his wife) may have contributed to his neutral ratings. Perhaps Parent 1's neutral ratings reflect his lack of enthusiasm and motivation, but not a general dislike for the treatment.

Similar to the father, Dyad 1's adolescent's scores on all of the items assessing the therapist across all of the sessions indicated that she felt "satisfied" to "very satisfied" with the therapist. Her scores on the items assessing the treatment, however, decreased in Sessions 5-10. The adolescent's scores indicated that she was "dissatisfied" or "neutral" in her opinion of how effective the treatment was and the procedures utilized in the treatment. Her lower ratings for these items in later sessions may be a reflection of her dislike for the PSCT component of treatment, which was implemented in session 4. The PSCT component of treatment required the family members to focus on issues and topics that resulted in conflict. Solutions to problems 
were generated, consequences for failing to abide by the agreement were stated explicitly, and both participants were instructed to implement the consequences. Perhaps Adolescent 1's lower average satisfaction ratings with treatment resulted from her perceptions of a failure on behalf of her and her father to successfully implement PSCT procedures. Alternatively, her lower ratings may have coincided with her having, at times, negative consequences placed on her for failure to comply with problem solutions generated in therapy sessions or for inappropriate behaviors exhibited at home. In contrast, she may have perceived favorable outcomes to conflict episodes prior to treatment. However, when she failed to meet expectations and negative consequences were implemented, she may have perceived the treatment as less desirable, leading to her lower ratings. Also, the lower ratings in the last 5 sessions may reflect a growing disinterest or dislike for treatment as the time involved grew. Finally, she may have been anticipating certain changes throughout treatment, but did not perceive them in the later sessions.

Despite the lower ratings from Dyad 1, the remaining three dyads indicated that they were "satisfied" to "highly satisfied" with the treatment and therapists, providing initial evidence that the BE+PSCT was found to be an acceptable treatment for parents and adolescents experiencing conflict. It should be noted that all of the items of the CSS were positively worded which could have resulted in a socially desirable response format. However, procedural steps (e.g., completing CSS in the absence of therapist, placing results in sealed and signed envelope, all forms being coded by number as opposed to by name) were taken to reduce responding in a socially desirable manner. Dyad 1's findings suggest that future evaluation of the treatment may be necessary to ensure that the procedures and format used in this treatment are found to be acceptable to parents and adolescents. However, the overall satisfaction ratings across the four dyads suggest consumer satisfaction with the BE+PSCT treatment package. 


\section{$\underline{\text { Additional Considerations and Future Directions }}$}

Results of this study suggest that the BE+PSCT treatment led to observable improvements in the use of problem-solving and communication skills for all four dyads during weekly discussions of issues frequently associated with parent-adolescent conflict. Also, results indicated that three of four parent participants and three of four adolescent participants reported improvements at post-treatment and follow-up in their global distress, problem-solving, and communication skill use. In addition, three of the four families rated themselves satisfied to highly satisfied with the treatment. This study employed observational measures to assess behavior change in the participants' homes, allowing for comparisons between observations of participant behavior change and their self-reports of behavior change. Finally, this study conducted weekly assessment sessions to track participants' progress throughout treatment, allowing for the week-by-week assessment of skill acquisition. Given the initial successes of the treatment for reducing parent-adolescent conflict, several strengths of this study should be noted and suggest further investigation of BE+PSCT.

For example, the finding that the combination of BE+PSCT can reduce conflict adds to the existing research investigating PSCT for parents and adolescents experiencing conflict. It is interesting to note that the four published PSCT treatment outcome studies have been conducted by only two research groups, both with commercial PSCT treatment manuals for sale. The results of this study, obtained by a researcher not associated with the other two research groups, provides additional empirical support for the success of PSCT. Future research evaluating PSCT by other independent research groups is needed to further document the effects of the treatment for parents and adolescents. 
Furthermore, this study lead to the development and piloting of the PSBC, a measure that was used to identify those skills thought to be critical to problem solving. The PSBC served as an effective measure of problem-solving skill use between parent and adolescent dyads discussing issues associated with conflict. In addition, the PSBC was found to be sensitive to treatment effects as families progressed through the treatment. The PSBC allowed for the identification of specific skills not being used by participants during problem-solving discussions, potentially allowing the therapist to direct future training efforts in order to enhance skill acquisition and usage. Future studies should examine the utility and psychometric properties of PSBC with various populations of individuals attempting to learn problem-solving skills.

An additional strength of this initial evaluation of BE+PSCT includes the single subject experimental design, which allowed for the inclusion of four heterogeneous families exhibiting different levels of distress. By employing a single subject design, individual parent and adolescent dyads' prior levels of functioning and subsequent responses to treatment were assessed in detail. Thus, effectiveness of BE+PSCT for a variety of participants functioning at various levels of distress were evaluated. As a result, variability found in the data could be examined in detail, an important factor when attempting to evaluate a treatment package. Despite the strengths of this investigation, additional limitations and factors that need to be considered and addressed by future research are presented in the following sections.

Component Analysis of Behavioral Exchange. A limitation of the current study is that a specific assessment of the effects of the BE component was not conducted. Although this study provides initial evidence that a combined BE+PSCT can reduce conflict for some parents and adolescents, the extent to which BE enhances or limits PSCT remains to be examined. Future studies should attempt to explore what, if any, benefits arise from the addition of the $\mathrm{BE}$ 
component. One of the hypothesized reasons for the inclusion of the BE component in the current investigation was the possibility that the BE component would decrease treatment resistance and enhance possible homework completion, and in turn improve skill building. Yet, the current study did not employ a design that allowed for an examination of the additive effects of BE. Other studies have compared components of treatment packages so as to isolate the effects of each component in order to further evaluate the benefits of a treatment package (e.g., Eisenstadt, Eyberg, McNeil, Newcomb, \& Funderburk, 1993). Future component analysis research examining the effects of the two components in isolation, as well as the combined effects of BE+PSCT, should be conducted.

Training Skills to Criterion. This study was conducted according to a schedule based on a predetermined 10-week program, modeled after the 7-week PSCT programs (e.g., Foster et al., 1983; Robin, 1981) and 3-4 week BE programs (e.g., Besalel \& Azrin , 1981) previously reported to be successful in reducing parent-adolescent conflict. Families met approximately once per week for 1 hour, based on the participants' and therapists' availability. Although this enabled families to keep a consistent schedule, thus potentially helping families to attend sessions, a more powerful treatment would have trained skills to specified criteria. Thus, families would have continued with training until they demonstrated specific skill acquisition by meeting predetermined mastery criteria, enhancing the likelihood that they would have learned all of the skills taught in treatment. As it were, many of the participants did not exhibit substantial changes in their use of communication skills. If a criterion-based treatment had been employed, families would have been taught communication skills until they demonstrated acquisition by meeting criteria before treatment progressed. As a result, families would have remained in treatment until demonstrating behavior change. Future studies attempting to teach problem-solving and 
communication skills may want to treat to specified criteria, in which behavioral objectives and mastery criteria are developed, in order to further facilitate skill acquisition.

Communication Skills \& Global Distress. One assumption of this study was that problem-solving skills were an essential component necessary for reductions in reported overall levels of conflict and global distress. Problem-solving verbal behaviors were hypothesized to facilitate discussion and subsequent problem resolution satisfactory to both parents and adolescents. However, these skills alone may not lead to reductions in global distress. For example, all of the participants were able to exhibit problem-solving skills during the weekly assessment sessions. However, not all of the participants reported lower levels of general distress. One potential explanation for this effect could be that problem-solving skills are unique to specific disagreements. Thus, they are utilized only in specific situations when working to solve a problem. Communication skills, however, are exhibited and applied across a greater range of situations and contexts (Foster \& Robin, 1998). Communication skills (or deficits) are exhibited not only when attempts are made to resolve problems, but frequently facilitate the exchange of information in daily interactions not related to specific disputes. As a result, it may be necessary for treatment to impact communication behaviors in order for participants to experience reductions in overall conflict levels. Further study examining the relationship between communication behaviors and self-reports of global distress is necessary to establish future intervention objectives.

In addition, this study employed communication training techniques which targeted communication behaviors that have been shown to discriminate groups of distressed from nondistressed parents and adolescents (Robin \& Foster, 1989). Although efforts were made to individualize communication training for each participant, communication impairments in this 
study were defined at a group level. Thus, one limitation of this study was the lack of examination of the functional relations between specific communication behaviors in particular environmental contexts, and the subsequent lack of intervention goals based on the determination of those functional relations. Future research examining functional relations between specific communication behaviors in distinct environmental contexts is needed to develop more effective targets for communication training programs.

Programmatic vs. Individualized Treatment. Despite evidence that parents and adolescents exhibiting high levels of conflict have displayed more negative communication styles and fewer problem-solving behaviors than nondistressed families (Robin \& Foster, 1989), results from this study suggest that communication and problem-solving skill acquisition alone may not be enough to change self-report of conflict for some of the participants. As a result, more functionally based, individualized treatment interventions may be beneficial in the reduction of parent-adolescent conflict. Conducting a functional assessment of specific responses and response classes exhibited by family members may help identify specific variables maintaining the conflict. As a result, interventions based on functional assessment results could be developed to address those antecedents and consequences associated with the discord.

Despite the documented efficacy of interventions developed from functional assessment results for a number of populations with diverse presenting problems (Repp \& Horner, 1999), practical questions remain regarding how best to conduct functional assessments with parents and adolescents experiencing conflict. Analyses of the functions of various communication and interaction patterns exhibited during conflictual exchanges can be examined on both molecular and molar levels, thus complicating intervention targets. For example, in a molecular analysis the immediate consequence for an adolescent's noncompliance may be to escape from a task, 
suggesting that the noncompliance is maintained by escape. However, in a more molar analysis, the consequences over time for noncompliance may be increased parental attention, suggesting that attention maintains the noncompliance. As a result, future research examining how best to conduct functional assessments of conflictual behaviors exhibited by parents and adolescents is needed. Furthermore, treatment programs focused on teaching multiple communication and problem-solving skills, as well as attempting to address hypothesized determinants and maintaining conditions related to negative family interaction patterns, are needed.

Comorbidity and Contextual Issues. This study employed a treatment package designed under the assumption that the conflict experienced by the parents and adolescents was the primary cause of the families' difficulties. However, another possibility may have been that the conflict was a consequence resulting from other parent and adolescent factors. Given the frequent comorbidity between family conflict, adolescent psychopathology, and family dysfunction, it is possible that the treatment outcomes resulting from this study may have been influenced by a number of specific participant characteristics (Barkley et al., 1999).

Consequently, the BE+PSCT treatment may have taught problem-solving skills effectively, but more idiographic treatment may be necessary for optimal treatment success.

Take, for example, the adolescents in Dyads 2 and 3 who both met criteria for ADHD at the beginning of this study. This treatment was not designed to directly address some of the behaviors associated with this comorbid disorder. Researchers have suggested that adolescents with more serious forms of comorbid developmental psychopathology that are chronic in nature (e.g., ADHD, CD) may need more intensive treatment than traditional 10-week programs to produce positive responses (Barkley et al., 1992). Furthermore, both the father and the adolescent in Dyad 1 reported a number of conflictual issues involving the role of Jan's step- 
mother. Jan expressed a disregard for her step-mother's rules, stating her step-mother did not have the authority to tell her what to do. Parent 1 frequently disregarded Jan's beliefs concerning her step-mother. These comorbid "blended" family issues were not addressed in treatment. Hence, these issues potentially impacted family dysfunction and increased conflict with her father, but were not addressed directly by the treatment.

Another limitation of this study was the lack of consideration of the broader contextual factors that may have contributed to some of the negative treatment outcomes. For example, the parent in Dyad 3 was blind. As a result, there may have been discrepancies between the level of her involvement with and supervision of her adolescent and other parent participants and their adolescents. Although treatment materials were modified to accommodate her condition, the content was similar across all participants. Future studies should examine the influences of comorbid disorders and various contextual factors on parent-adolescent conflict, and how these relations affect treatment programs that target parent-adolescent conflict, such as BE+PSCT.

Generalization and Maintenance via Homework. The addition of the BE component to the PSCT program was postulated to help decrease treatment resistance. It was hypothesized that early success in treatment during the BE phase would heighten the family's compliance with the multiple homework tasks assigned later in PSCT treatment. As a result, the family would benefit more from treatment by maintaining and generalizing treatment gains to novel conflict situations. However, the results of this study failed to support this assumption. Each of the four dyads completed only $44 \%$ of the homework assignments (i.e., no variability between participants). Thus, a limitation of this study is that not all of the homework assignments were completed, potentially limiting the effectiveness of the treatment. In addition, the dyads completed the majority of the homework assigned in the BE phase of treatment, while failing to complete the 
majority of assignments in the PSCT phase of treatment. In fact, the homework assigned in Session 5, in which the participants practice using problem-solving skills, was not completed at home by any of the dyads. Although not directly assessed, results suggest that the addition of the BE component did not facilitate subsequent homework completion. Future studies may look to examine the effects of a BE treatment on subsequent PSCT treatment homework completion by utilizing a control comparison group.

The results of the present study are similar to those obtained in the one other study (i.e., Barkley et al., 1992) that looked at therapists' ratings of family cooperation and motivation to participate in treatment. When Barkley and colleagues compared a PSCT treatment with two other forms of family therapy for parent and adolescent conflict, they found that the PSCT treatment had relatively more homework assignments. This led Barkley et al. to hypothesize that PSCT was a more demanding treatment for families when compared with other family therapy programs. Anecdotal report from the participants in this study suggested that this, in fact, may be the case. The most common reason the participants gave as to why they did not complete the homework was that they did not have time to complete the work. As a result, many of the homework assignments that were designed to promote generalization and maintenance through practice were not completed. Given that adolescents and parents are likely to experience conflict associated with a number of novel issues as the adolescent becomes older, a major limitation of this study was the failure to program adequate consequences for homework completion. Future studies are needed to examine what aspects of the assigned homework are difficult for families to complete and how these assignments may be modified in order to achieve the goal of having families practice the new skills taught in treatment. 


\section{Conclusion}

This study provided an initial evaluation of the combined effects of a BE+PSCT treatment package for parent and adolescent conflict. Despite a number of limitations, this study suggests that $\mathrm{BE}+\mathrm{PSCT}$ appears to be a promising treatment for reducing parent-adolescent conflict. Results of this study indicate that the BE+PSCT treatment led to observable and notable increases in all four dyads' use of problem-solving skills. Additionally, for all four dyads, $\mathrm{BE}+\mathrm{PSCT}$ treatment resulted in increases in the use of communication skills, as observed in the weekly assessment sessions. Furthermore, families were able to exhibit the problem-solving and communication skills 2 weeks after terminating treatment. In addition, a majority of the participants found $\mathrm{BE}+\mathrm{PSCT}$ to be an acceptable form of treatment for parents and adolescents experiencing conflict. Unfortunately, the results are less conclusive when examining the discrepancies among participants' self-reports concerning general ratings of conflict and distress, use of problem-solving and communication skills at home, and adherence to irrational or distorted beliefs. These differential treatment outcomes for very different participants indicate that further research is needed to identify the specific factors and predictors that lead to treatment successes. Results of this study provide preliminary evidence supporting the use of BE+PSCT for reducing parent-adolescent conflict and warrant continued evaluation of the treatment for restoring family relations. 


\section{References}

Achenbach, T.M. (1978). The Child Behaviour Profile: I. Boys aged 6-11. Journal of Consulting and Clinical Psychology, 46, 478-488.

Achenbach, T.M., \& Edelbrock, C. (1991a). Manual for the Child Behavior Checklist and Revised Child Behavior Profile. Burlington, VT: University of Vermont, Department of Psychiatry.

Achenbach, T. M., \& Edelbrock, C. (1991b). Manual for the Youth Self Report and 1991 Profile. Burlington: University of Vermont, Department of Psychiatry.

Alexander, J.F., Waldron, H.B., Barton, C., \& Mas, C.H. (1989). The minimizing of blaming attributions and behaviors in delinquent families. Journal of Consulting and Clinical Psychology, 57, 19-24.

Bachman, J.G., Green, S., \& Wirtanen, I.D. (1971). Youth in transition: Dropping outproblem or symptom? Ann Arbor: Survey Research Center, Institute for Social Research, 1971.

Barkley, R.A., Fischer, M., Edelbrock, C.S., \& Smallish, L. (1991). The adolescent outcome of hyperactive children diagnosed by research criteria: III. Mother-child interactions, family conflicts, and maternal psychopathology. Journal of Child Psychology and Psychiatry, 32, $233-256$.

Barkley, R.A., Guevremont, D.C., Anastopoulos, A.D., \& Fletcher, K.E. (1992). A comparison of three family therapy programs for treating family conflicts in adolescents with attention-deficit hyperactivity disorder. Journal of Consulting and Clinical Psychology, 60, 450462.

Barkley, R.A., Edwards, G.H., \& Robin, A.L. (1999). Defiant teens: A clinician's manual for assessment and family intervention. New York: Guilford Press. 
Baucom, D.H., \& Hoffman, J.A. (1986). The effectiveness of marital therapy: Current status and application to the clinical setting. In N.S. Jacobson \& A.S. Gurman (Eds.), Clinical handbook of marital therapy (pp. 597-620). New York: Guilford Press.

Besalel, V.A., \& Azrin, N.H. (1981). The reduction of parent-youth problems by reciprocity counseling. Behavior Research and Therapy, 19, 297-301.

Brigham, T.A. (1989). Self-Management for Adolescents: A Skills Training Program. New York: Guilford Press.

Christensen, A., Jacobson, N.S., \& Babcock, J.C. (1995). Integrative behavioral couple therapy. In N.S. Jacobson \& A.S. Gurman (Eds.), Clinical Handbook of Couples Therapy (pp. 31-64). New York: Sage.

Conger, J.J. (1977). Adolescence and youth: Psychological development in a changing world. New York: Harper.

Crits-Christoph, P., Frank, E., Chambless, D.L., Brody, C., \& Karp, J.F. (1995). Training in empirically validated treatments: What are clinical psychology students learning? Professional Psychology: Research and Practice, 26, 514-522.

D’Zurilla, T.J. (1988). Problem-solving therapies. In K.S. Dobson (Ed.), Handbook of cognitive-behavioral therapies. (pp.85-135). New York: Guilford Press.

Eisenstadt, T.E., Eyberg, S., McNeil, C.B., Newcomb, K., \& Funderburk, B. (1993). Parent-child interaction therapy with behavior problem children: Relative effectiveness of two stages and overall treatment outcome. Journal of Child Clinical Psychology, 23, 42-51.

Foster, S.L. (1987). Issues in behavioral assessment of parent-adolescent conflict. Behavioral Assessment, 9, 253-269. 
Foster, S.L., Prinz, R.J., \& O’Leary, K.D. (1983). Impact of problem-solving communication training and generalization procedures on family conflict. Child and Family Behavior Therapy, 5, 1-23.

Foster, S.L., \& Robin, A.L. (1998). Parent-adolescent conflict and relationship discord. In E.J. Mash \& R.A. Barkley (Eds.), Treatment of childhood disorders (2nd ed., pp. 601-646). New York: Guilford Press.

Gottlieb, D., \& Chafetz, J.S. (1977). Dynamics of familial, generational conflict and reconciliation. Youth and Society, 9, 213-224.

Hahlweg, K., \& Markman, H.J. (1988). Effectiveness of behavioral marital therapy: Empircial status of behavioral techniques in preventing and alleviating marital distress. Journal of Consulting and Clinical Psychology, 56, 440-447.

Hawkins, R.P. (1991). Is social validity what we are interested in? Argument for a functional approach. Journal of Applied Behavior Analysis, 24, 205-213.

Hembree-Kigin, T.L., \& McNeil, C.B. (1995). Parent-Child Interaction Therapy. New York: Plenum Press.

Henggeler, S.W., Schoenwald, S.K., Borduin, C.M., Rowland, M.D., \& Cunningham, P.B. (1998). Multisystemic Treatment of Antisocial Behavior in Children and Adolescents. New York: Guilford Press.

Hereford, C.F. (1963). Changing Parental Attitudes through Group Discussion. University of Texas, Austin, Texas.

Hinshaw, S.P. (1994). Attention deficits and hyperactivity in children. Thousand Oaks, CA: Sage. 
Jacobson, N.S. (1984). A component analysis of behavioral marital therapy: The relative effectiveness of behavior exchange and communication/problem-solving training. Journal of Consulting and Clinical Psychology, 52, 295-305.

Jacobson, N.S., Follette, V.M., Follette, W.C., Holtzworth-Munroe, A., Hatt, J.L., \& Schmaling, K.B. (1985). A component analysis of behavioral marital therapy: One-year followup. Behavior Research and Therapy, 23, 549-555.

Jacobson, N.S., \& Margolin, G. (1979). Marital therapy: Strategies based on social learning and behavior exchange principles. New York: Brunner/Mazel.

Jacobson, N.S., Schmaling, K.B., \& Hotzworth-Munroe, A. (1987). Component analysis of behavioral marital therapy: Two-year follow-up and prediction of relapse. Journal of Marital and Family Therapy, 13, 187-195.

Lawrence, E., Eldridge, K., Christensen, A., \& Jacobson, N.S. (1999). Integrative couple therapy: The dyadic relationship of acceptance and change. In J.M. Donovan (Ed.), Short-Term Couple Therapy. New York: Guilford Press.

Long, E.S., Adams, C. D., Ruggiero, K.D. (2000). An Investigation of the Psychometric Properties of the Conflict Behavior Questionnaire-20. Manuscript submitted for publication.

Moos, R.H., Insel, P.M., \& Humphrey, B. (1974). Combined Preliminary Manual for the Family, Work, and Group Environment Scales. Palo Alto: Consulting Psychologists Press.

Mittl, V.F. \& Robin, A.L. (1987). Acceptability of alternative interventions for parentadolescent conflict. Behavioral Assessment, 9, 417-428.

Montemayor, R. (1983). Parents and adolescents in conflict: All families some of the time and some families most of the time. Journal of Early Adolescents, 3, 83-103. 
Nayar, M. (1985). Cognitive factors in the treatment of parent-adolescent conflict. Unpublished doctoral dissertation. Wayne State University, Detroit, MI.

Patterson, G.R. (1982). Coercive Family Process. Eugene, OR: Castalia.

Prinz, R.J., Foster, S., Kent, R.N., \& O’Leary, K.D. (1979). Multivariate assessment of conflict in distressed and non-distressed mother-adolescent dyads. Journal of Applied Behavior Analysis, 12, 691-700.

Prinz, R.J., \& Kent, R.N. (1978). Recording parent-adolescent interactions without the use of frequency or interval-by-interval coding. Behavior Therapy, 9, 602-604.

Raue, J., \& Spence, S.H. (1985). Group versus individual applications of reciprocity training for parent-youth conflict. Behavior Research and Therapy, 23, 177-186.

Repp, A.C., \& Horner, R.H. (1999). Functional analysis of problem behavior. Belmont, CA: Wadsworth Publishing Company.

Robin, A.L. (1981). A controlled evaluation of problem-solving communication training with parent-adolescent conflict. Behavior Therapy, 12, 593-609.

Robin, A.L. (1998). ADHD in adolescents: Diagnosis and treatment. New York: Guilford Press.

Robin, A.L., \& Foster, S.L. (1989). Negotiating parent-adolescent conflict. New York: Guilford Press.

Robin, A.L., \& Foster, S.L. (1984). Problem-solving communication training: A behavioral-family systems approach to parent-adolescent conflict. In P. Karoly \& J.J. Steffen (Eds.), Adolescent behavior disorders: Foundations and contemporary concerns. (pp. 195-240). Lexington, MA: D.C. Heath. 
Robin, A.L., Kent, R.N., O’Leary, K.D., Foster, S.L., \& Prinz, R.J. (1977). An approach to teaching parents and adolescents problem-solving communication skills: A preliminary report. Behavior Therapy, 8, 639-643.

Robin, A.L., Koepke, T., \& Moye, A. (1990). Multidimensional assessment of parentadolescent relations. Psychological Assessment: A journal of consulting and clinical psychology, 2, 451-459.

Robin, A.L., Koepke, T., \& Nayar, M. (1986). Conceptualizing, addressing, and treating parent-adolescent conflict. In B.B. Lahey \& A.E. Kazdin (Eds.), Advances in clinical child psychology. (vol.9, pp.87-124). New York: Plenum.

Robin, A.L., Siegel, P.T., \& Moye, A. (1995). Family versus individual therapy for anorexia: Impact on family conflict. International Journal of Eating Disorder, 17, 313-322.

Robin, A.L., \& Weiss, J.G. (1980). Criterion-related validity of behavioral and self-report measures of problem-solving communication skills in distressed and non-distressed parentadolescent dyads. Behavioral Assessment, 2, 339-352.

Spanier, G.B. (1976). Measuring dyadic adjustment: New scales for assessing the quality of marriage and similar dyads. Journal of Marriage and the Family, 37, 15-28.

Vincent-Roehling, P., \& Robin, A.L. (1986). Development and validation of the Family Beliefs Inventory: A measure of unrealistic beliefs among parents and adolescents. Journal of Consulting and Clinical Psychology, 54, 693-697.

Weiss, R.L., \& Perry, B.A. (1979). Assessment and treatment of marital dysfunction. Eugene, Oregon: Oregon Marital Studies Program. New York: Guilford Press. 
Table 1

$\underline{\text { Treatment Integrity Percentages for Each Therapist }}$

\begin{tabular}{|c|c|c|}
\hline & $\begin{array}{l}\text { Session Number } \\
\text { Observed }\end{array}$ & $\begin{array}{c}\text { Percent of Session Steps } \\
\text { Appropriately Implemented }\end{array}$ \\
\hline \multicolumn{3}{|l|}{ Therapist A } \\
\hline Dyad 1 & $\begin{array}{l}2 \\
5 \\
6\end{array}$ & $\begin{array}{l}100 \% \\
100 \% \\
100 \%\end{array}$ \\
\hline Dyad 3 & $\begin{array}{l}4 \\
8 \\
10\end{array}$ & $\begin{array}{l}100 \% \\
100 \% \\
100 \%\end{array}$ \\
\hline \multicolumn{3}{|l|}{ Therapist B } \\
\hline Dyad 2 & $\begin{array}{l}1 \\
5 \\
7\end{array}$ & $\begin{array}{l}100 \% \\
92 \% \\
100 \%\end{array}$ \\
\hline \multicolumn{3}{|l|}{ Therapist $\mathrm{C}$} \\
\hline Dyad 4 & $\begin{array}{l}1 \\
3 \\
6\end{array}$ & $\begin{array}{l}100 \% \\
100 \% \\
100 \%\end{array}$ \\
\hline
\end{tabular}


Table 2

Percent Interobserver Agreement for Each Observers' Total PSBC Score and IBC Total Positive and Negative Scores on Test Videotapes.

\begin{tabular}{|c|c|c|c|c|c|c|}
\hline Observer & Videotape \# & $\begin{array}{c}\text { Total } \\
\text { PSBC }\end{array}$ & $\begin{array}{c}\text { Negative } \\
\text { IBC Parent }\end{array}$ & $\begin{array}{c}\text { Negative IBC } \\
\text { Adolescent }\end{array}$ & $\begin{array}{c}\text { Positive } \\
\text { IBC Parent }\end{array}$ & $\begin{array}{c}\text { Positive IBC } \\
\text { Adolescent }\end{array}$ \\
\hline \multirow[t]{3}{*}{ A } & 1 & $93.8 \%$ & $87.1 \%$ & $83.9 \%$ & $100 \%$ & $100 \%$ \\
\hline & 2 & $100 \%$ & $90.3 \%$ & $87.1 \%$ & $85.7 \%$ & $100 \%$ \\
\hline & 3 & $93.8 \%$ & $93.5 \%$ & $93.5 \%$ & $100 \%$ & $85.7 \%$ \\
\hline \multirow[t]{3}{*}{ B } & 1 & $87.5 \%$ & $87.1 \%$ & $100 \%$ & $100 \%$ & $100 \%$ \\
\hline & 2 & $93.8 \%$ & $93.5 \%$ & $90.3 \%$ & $100 \%$ & $100 \%$ \\
\hline & 3 & $93.8 \%$ & $83.9 \%$ & $83.9 \%$ & $100 \%$ & $85.7 \%$ \\
\hline \multirow[t]{3}{*}{$\mathrm{C}$} & 1 & $81.3 \%$ & $83.9 \%$ & $87.1 \%$ & $100 \%$ & $100 \%$ \\
\hline & 2 & $100 \%$ & $90.3 \%$ & $93.5 \%$ & $100 \%$ & $85.7 \%$ \\
\hline & 3 & $81.3 \%$ & $83.9 \%$ & $90.3 \%$ & $85.7 \%$ & $85.7 \%$ \\
\hline \multirow[t]{3}{*}{$\mathrm{D}$} & 1 & $81.3 \%$ & $83.9 \%$ & $83.9 \%$ & $85.7 \%$ & $85.7 \%$ \\
\hline & 2 & $93.8 \%$ & $85.7 \%$ & $85.7 \%$ & $100 \%$ & $100 \%$ \\
\hline & 3 & $87.5 \%$ & $83.9 \%$ & $80.6 \%$ & $85.7 \%$ & $85.7 \%$ \\
\hline
\end{tabular}


Table 3

Mean Percent Interobserver Agreement for Each Dyad's Total PSBC Score and IBC Positive and

Negative Scores.

\begin{tabular}{cccccc}
\hline Dyad & Total PSBC & $\begin{array}{c}\text { Negative IBC } \\
\text { Parent }\end{array}$ & $\begin{array}{c}\text { Negative IBC } \\
\text { Adolescent }\end{array}$ & $\begin{array}{c}\text { Positive IBC } \\
\text { Parent }\end{array}$ & $\begin{array}{c}\text { Positive IBC } \\
\text { Adolescent }\end{array}$ \\
\hline \multirow{2}{*}{1} & 92.3 & 87.7 & 92.3 & 82.8 & 91.4 \\
& $(75-100)$ & $(80.6-96.8)$ & $(87.1-96.8)$ & $(71.4-85.7)$ & $(85.7-100)$ \\
2 & 93.0 & 92.9 & 92.9 & 94.3 & 94.3 \\
& $(62.5-100)$ & $(80.6-96.8)$ & $(90.3-96.8)$ & $(71.4-100)$ & $(85.7-100)$ \\
3 & & & & \\
& $(81.3-100)$ & $(77.4-96.8)$ & $(83.9-96.8)$ & $(85.7-71.4)$ & $(85.7-100)$ \\
& & & & \\
4 & 92.3 & 94.9 & 96.8 & 87.7 & 87.7 \\
& $(81.2-100)$ & $(87.1-100)$ & $(93.5-100)$ & $(57.1-100)$ & $(57.1-100)$ \\
\hline
\end{tabular}


Table 4

Pre, Post, and 2-Week Follow-up Data for Dyad 1 Parent (i.e., Rob).

\begin{tabular}{|c|c|c|c|c|}
\hline Parent Measure & Pre & Post & Difference & $\begin{array}{c}2 \text {-Week } \\
\text { Follow-up }\end{array}$ \\
\hline Conflict Behavior Questionnaire-20 & 20 & 15 & $5^{*}$ & 9 \\
\hline Family Beliefs Inventory & & & & N/A \\
\hline Ruination & 28 & 33 & +5 & \\
\hline Perfection & 34 & 42 & +8 & \\
\hline Approval & 12 & 21 & +9 & \\
\hline Obedience & 40 & 40 & 0 & \\
\hline Self-Blame & 21 & 25 & +4 & \\
\hline Malicious Intent & 15 & 18 & +3 & \\
\hline \multicolumn{5}{|l|}{ Issues Checklist } \\
\hline Number of Issues & 20 & 8 & $-12 *$ & 7 \\
\hline Average Intensity/Issue & 1.7 & 1.9 & +0.2 & 1.9 \\
\hline Weighted Average Frequency X & & & & \\
\hline Intensity & 1.6 & 1.8 & +0.2 & 1.5 \\
\hline \multicolumn{5}{|l|}{ Parent Adolescent } \\
\hline Relationship Questionnaire & & & & N/A \\
\hline Global Distress & 12 & 6 & $-6^{*}$ & \\
\hline Communication & 12 & 6 & $-6^{*}$ & \\
\hline Problem-Solving & 14 & 10 & $-4 *$ & \\
\hline Beliefs & & & & \\
\hline Ruination & 6 & 2 & $-4 *$ & \\
\hline Perfectionism & 2 & 5 & +3 & \\
\hline Self-Blame & 3 & 1 & $-2 *$ & \\
\hline Malicious Intent & 0 & 0 & 0 & \\
\hline Obedience & 7 & 6 & -1 & \\
\hline Cohesion & 5 & 9 & +4 & \\
\hline Conventionalization & 0 & 1 & +1 & \\
\hline Hierarchy Reversal & 7 & 4 & $-3 *$ & \\
\hline \multicolumn{4}{|l|}{ Child Behavior Checklist (T-Scores) } & N/A \\
\hline Total & 55 & 56 & +1 & \\
\hline Internal & 50 & 56 & +6 & \\
\hline External & 57 & 53 & $-4 *$ & \\
\hline Withdrawn & 50 & 57 & +7 & \\
\hline Somatic Complaints & 56 & 56 & 0 & \\
\hline Anxious/Depressed & 54 & 56 & +2 & \\
\hline Social Problems & 50 & 50 & 0 & \\
\hline Thought Problems & 57 & 50 & $-7 *$ & \\
\hline Attention Problems & 67 & 66 & $-1 *$ & \\
\hline Delinquent Behavior & 51 & 51 & 0 & \\
\hline Aggressive Behavior & 58 & 53 & $-5^{*}$ & \\
\hline
\end{tabular}

Note: $*$ change in the direction of improvement 


\section{Table 5}

Pre, Post, and 2-Week Follow-up Data for Dyad 1 Adolescent (i.e., Jan).

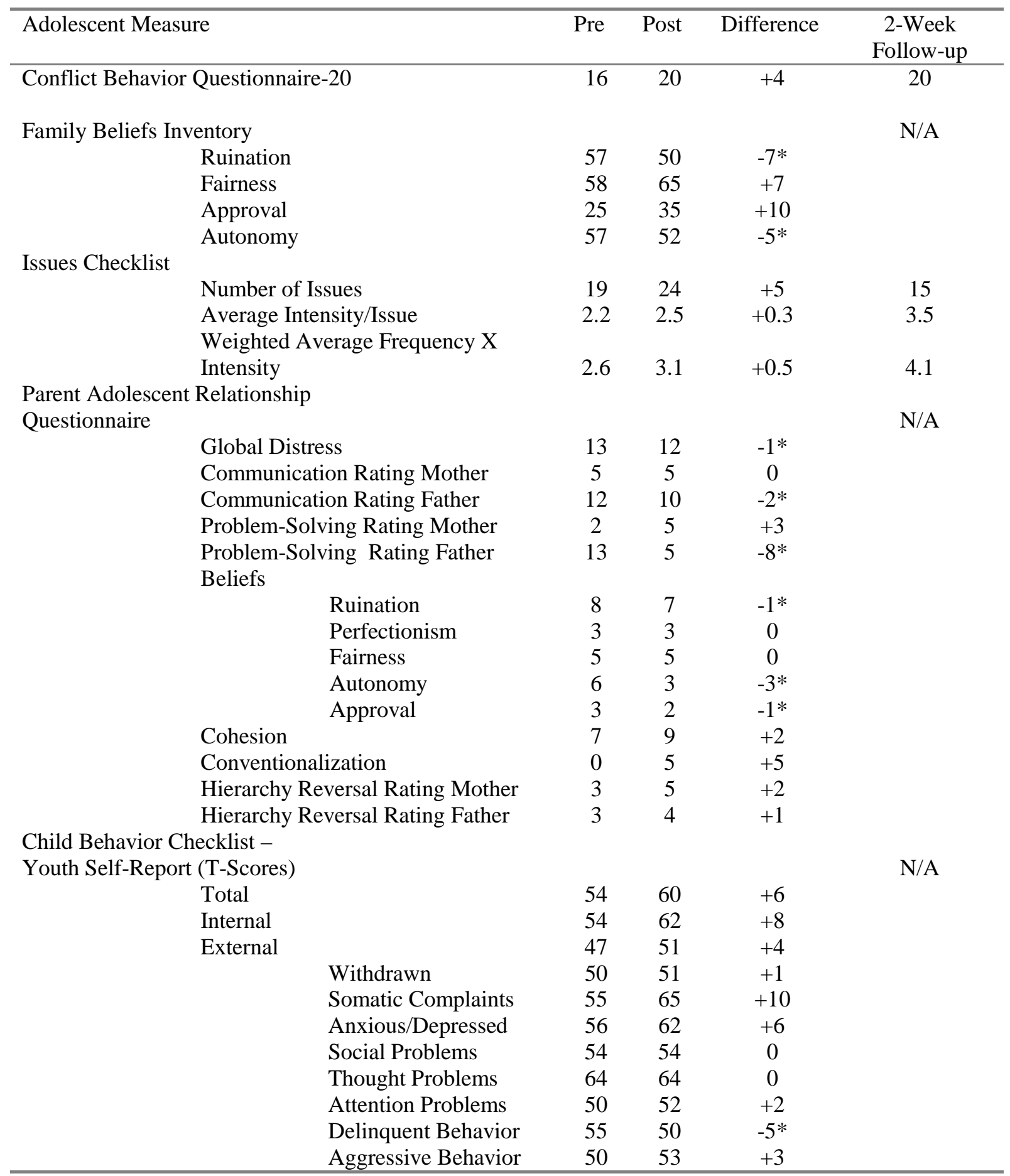

Note: $*$ change in the direction of improvement 
Table 6

Therapist Rating of Family Cooperation (TRFC) Scores for Dyad 1.

\begin{tabular}{lcc}
\hline & $\begin{array}{c}\text { Total } \\
\text { Score }\end{array}$ & $\begin{array}{c}\text { Mean Therapist Ratings } \\
\text { of Family Cooperation } \\
\text { (1=low; 4=average; 7=high) }\end{array}$ \\
\hline Acceptance of therapist & 48 & 4.8 \\
Quality of communication & 32 & 3.2 \\
Quality of effort in problem solving & 35 & 3.5 \\
Completion of homework & 26 & 2.9 \\
Achievement of goals & 46 & 4.6 \\
Total TRFC Score & 187 & \\
\hline
\end{tabular}


Table 7

Pre, Post, and 2-Week Follow-up Data for Dyad 2 Parent (i.e., Nina).

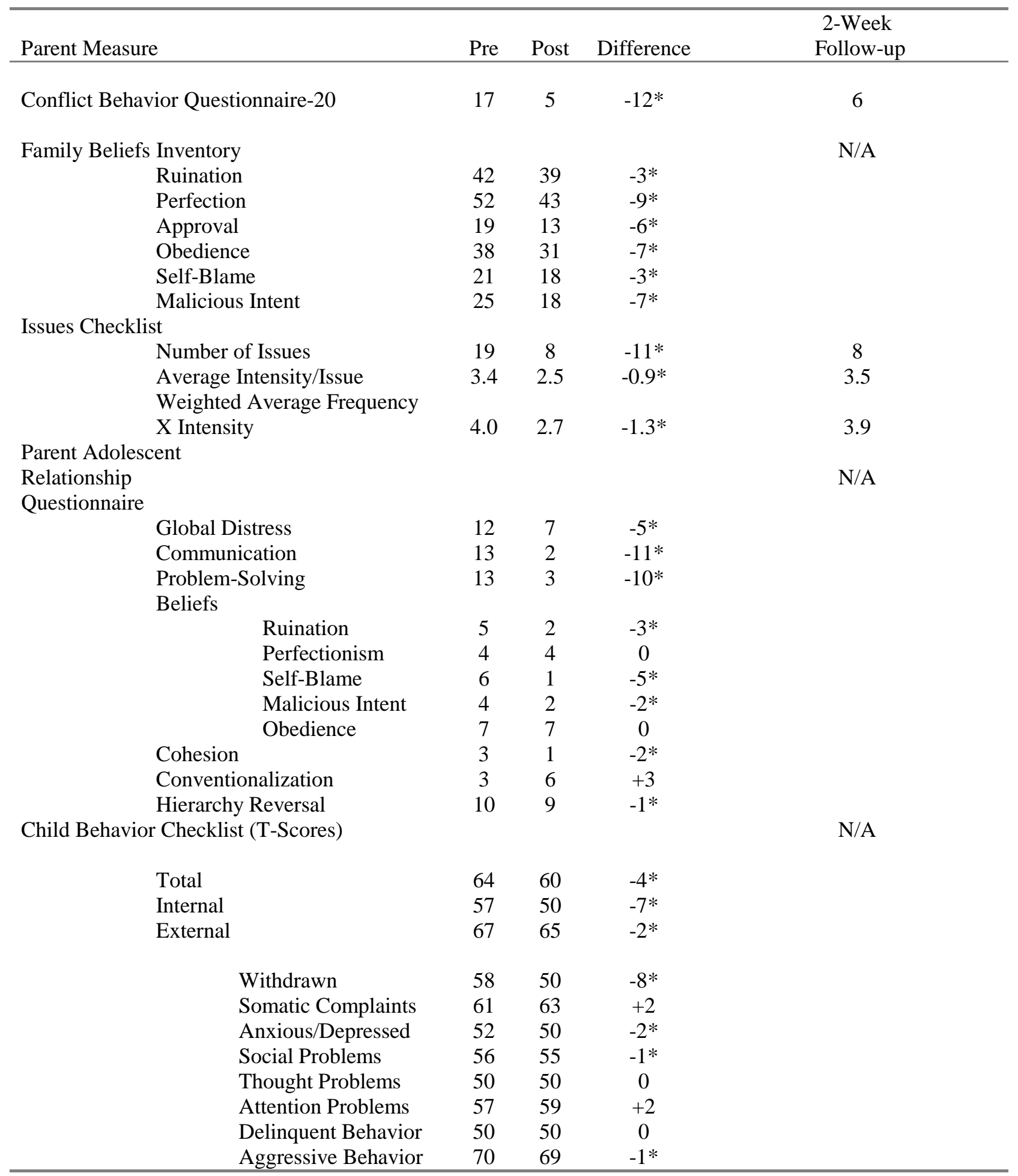

Note: $*$ change in the direction of improvement 
Table 8

Pre, Post, and 2-Week Follow-up Data for Dyad 2 Adolescent (i.e., Tom).

\begin{tabular}{|c|c|c|c|c|c|}
\hline \multicolumn{2}{|c|}{ Adolescent Measure } & Pre & Post & Difference & $\begin{array}{l}\text { 2-Week } \\
\text { Follow-up }\end{array}$ \\
\hline \multicolumn{2}{|c|}{ Conflict Behavior Questionnaire-20 } & 6 & 2 & $-4 *$ & 1 \\
\hline \multicolumn{5}{|c|}{ Family Beliefs Inventory } & N/A \\
\hline & Ruination & 19 & 40 & +21 & \\
\hline & Fairness & 26 & 50 & +24 & \\
\hline & Approval & 38 & 32 & $-6^{*}$ & \\
\hline & Autonomy & 28 & 45 & +17 & \\
\hline \multicolumn{5}{|l|}{ Issues Checklist } & 8 \\
\hline \multicolumn{2}{|r|}{ Average Intensity/Issue } & 2.2 & 2.2 & 0 & 2.5 \\
\hline \multicolumn{2}{|r|}{$\begin{array}{l}\text { Weighted Average Frequency X } \\
\text { Intensity }\end{array}$} & 2.8 & 2.3 & $-0.5^{*}$ & 3.1 \\
\hline \multicolumn{6}{|c|}{ Parent Adolescent Relationship } \\
\hline \multirow{2}{*}{\multicolumn{2}{|c|}{ Questionnaire }} & & & & N/A \\
\hline & & 2 & 2 & 0 & \\
\hline & Communication Rating Mother & 3 & 1 & $-2 *$ & \\
\hline \multicolumn{2}{|r|}{ Communication Rating Father } & 0 & 0 & 0 & \\
\hline \multicolumn{2}{|r|}{ Problem-Solving Rating Mother } & 0 & 1 & +1 & \\
\hline \multicolumn{2}{|r|}{$\begin{array}{l}\text { Problem-Solving Rating Father } \\
\text { Beliefs }\end{array}$} & 0 & 1 & +1 & \\
\hline & Ruination & 0 & 0 & 0 & \\
\hline & Perfectionism & 3 & 4 & +1 & \\
\hline & Fairness & 1 & 2 & +1 & \\
\hline & Autonomy & 1 & 1 & 0 & \\
\hline & Approval & 3 & 6 & +3 & \\
\hline & Cohesion & 10 & 13 & +3 & \\
\hline & Conventionalization & 5 & 8 & +3 & \\
\hline & Hierarchy Reversal Rating Mother & 5 & 3 & $-2 *$ & \\
\hline & Hierarchy Reversal Rating Father & 2 & 0 & $-2 *$ & \\
\hline \multicolumn{5}{|c|}{ Child Behavior Checklist - } & N/A \\
\hline \multicolumn{2}{|r|}{ Total } & 40 & 45 & +5 & \\
\hline \multicolumn{2}{|r|}{ Internal } & 45 & 41 & $-4 *$ & \\
\hline \multicolumn{2}{|r|}{ External } & 45 & 56 & +11 & \\
\hline & Withdrawn & 50 & 50 & 0 & \\
\hline & Somatic Complaints & 56 & 59 & +3 & \\
\hline & Anxious/Depressed & 50 & 50 & 0 & \\
\hline & Social Problems & 50 & 50 & 0 & \\
\hline & Thought Problems & 50 & 50 & 0 & \\
\hline & Attention Problems & 50 & 51 & +1 & \\
\hline & Delinquent Behavior & 50 & 51 & +1 & \\
\hline & Aggressive Behavior & 50 & 57 & +7 & \\
\hline
\end{tabular}

Note: $*$ change in the direction of improvement 
Table 9

Therapist Rating of Family Cooperation (TRFC) Scores for Dyad 2.

\begin{tabular}{lcc}
\hline TRFC Item & $\begin{array}{c}\text { Total } \\
\text { Score }\end{array}$ & $\begin{array}{c}\text { Mean Therapist Ratings } \\
\text { of Family Cooperation } \\
\text { (1=low; 4=average; 7=high) }\end{array}$ \\
\hline Acceptance of therapist & 60 & 6.0 \\
Quality of communication & 46 & 4.6 \\
Quality of effort in problem solving & 47 & 4.7 \\
Completion of homework & 23 & 2.6 \\
Achievement of goals & 44 & 4.4 \\
Total TRFC Score & 220 & \\
\hline
\end{tabular}


Table 10

Pre, Post, and 2-Week Follow-up Data for Dyad 3 Parent (i.e., Donna).

\begin{tabular}{|c|c|c|c|c|}
\hline Parent Measure & Pre & Post & Difference & $\begin{array}{l}\text { 2-Week } \\
\text { Follow-up }\end{array}$ \\
\hline \multicolumn{5}{|l|}{ Conflict Behavior } \\
\hline Questionnaire-20 & 8 & 7 & $-1 *$ & 5 \\
\hline Family Beliefs Inventory & & & & N/A \\
\hline Ruination & 34 & 35 & +1 & \\
\hline Perfection & 44 & 53 & +9 & \\
\hline Approval & 33 & 26 & $-7 *$ & \\
\hline Obedience & 38 & 45 & +7 & \\
\hline Self-Blame & 29 & 21 & $-8 *$ & \\
\hline Malicious Intent & 17 & 14 & $-3 *$ & \\
\hline \multicolumn{5}{|l|}{ Issues Checklist } \\
\hline Number of Issues & 26 & 28 & +2 & 28 \\
\hline $\begin{array}{l}\text { Average Anger- } \\
\text { Intensity/Issue }\end{array}$ & 2.6 & 2.1 & $-0.5 *$ & 2.5 \\
\hline $\begin{array}{l}\text { Weighted Average } \\
\text { Frequency X Intensity }\end{array}$ & 4.3 & 3.0 & $-1.3 *$ & 3.2 \\
\hline \multicolumn{5}{|l|}{ Parent Adolescent } \\
\hline $\begin{array}{l}\text { Relationship } \\
\text { Questionnaire }\end{array}$ & & & & N/A \\
\hline Global Distress & 13 & 13 & 0 & \\
\hline Communication & 12 & 12 & 0 & \\
\hline $\begin{array}{l}\text { Problem-Solving } \\
\text { Beliefs }\end{array}$ & 8 & 9 & +1 & \\
\hline Ruination & 5 & 2 & $-3 *$ & \\
\hline Perfectionism & 7 & 4 & $-3 *$ & \\
\hline Self-Blame & 4 & 2 & $-2 *$ & \\
\hline Malicious Intent & 4 & 2 & $-2 *$ & \\
\hline Obedience & 7 & 7 & 0 & \\
\hline Cohesion & 9 & 9 & 0 & \\
\hline Conventionalization & 0 & 1 & +1 & \\
\hline Hierarchy Reversal & 9 & 8 & $-1 *$ & \\
\hline $\begin{array}{l}\text { Child Behavior Checklist } \\
\text { (T-Scores) }\end{array}$ & & & & N/A \\
\hline Total & 70 & 71 & +1 & \\
\hline Internal & 61 & 61 & 0 & \\
\hline External & 76 & 75 & $-1 *$ & \\
\hline Withdrawn & 58 & 62 & +4 & \\
\hline Somatic Complaints & 63 & 63 & 0 & \\
\hline Anxious/Depressed & 60 & 58 & $-2 *$ & \\
\hline Social Problems & 59 & 66 & +7 & \\
\hline Thought Problems & 50 & 57 & +7 & \\
\hline Attention Problems & 67 & 65 & $-2 *$ & \\
\hline Delinquent Behavior & 69 & 72 & +3 & \\
\hline Aggressive Behavior & 81 & 75 & $-6^{*}$ & \\
\hline
\end{tabular}

Note: $*=$ change in the direction of improvement 
Table 11

Pre, Post, and 2-Week Follow-up Data for Dyad 3 Adolescent (i.e., Jon).

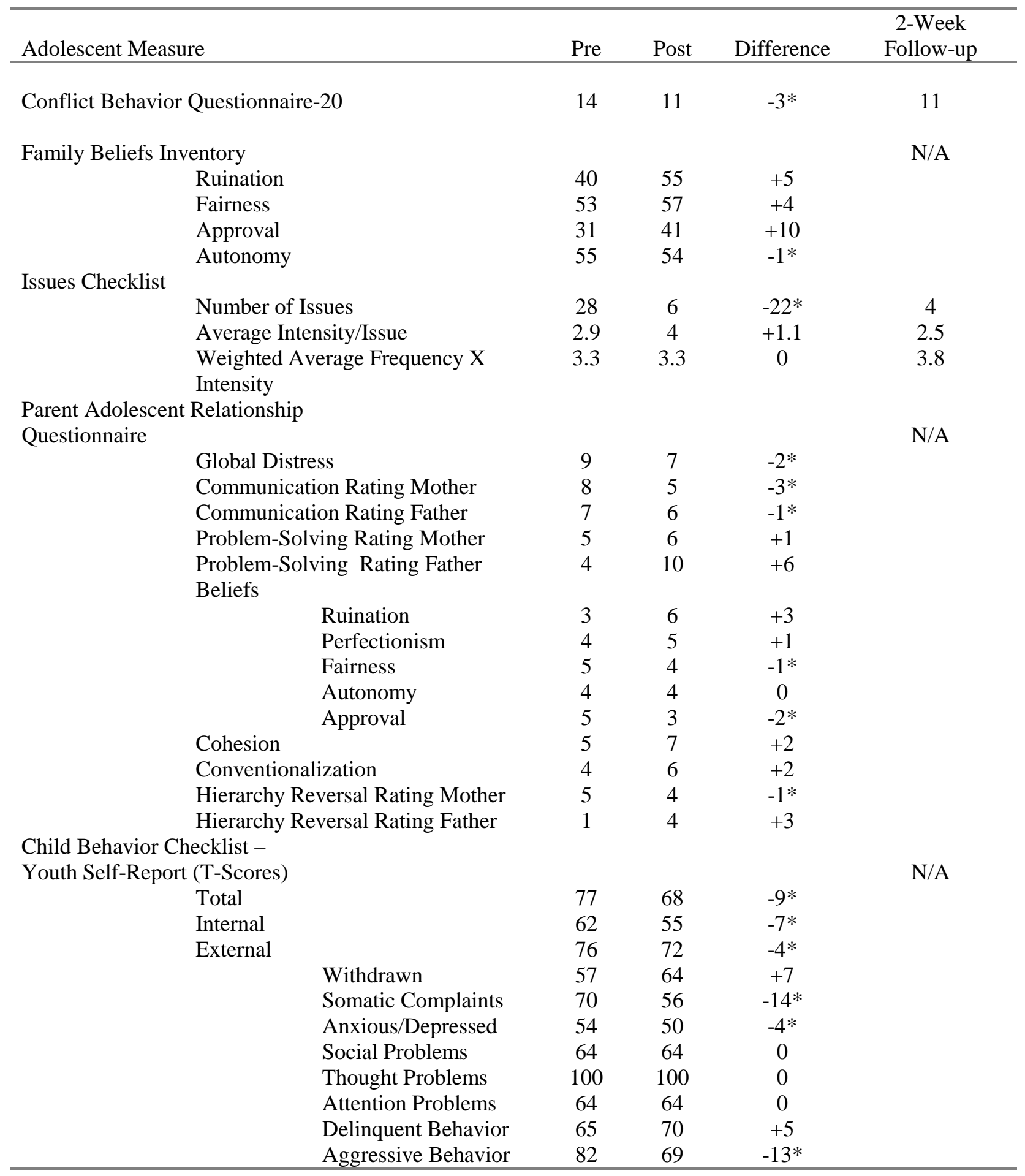

Note: $*$ change in the direction of improvement 
Table 12

Therapist Rating of Family Cooperation (TRFC) Scores for Dyad 3.

\begin{tabular}{lcc}
\hline & $\begin{array}{c}\text { Total } \\
\text { Score }\end{array}$ & $\begin{array}{c}\text { Mean Therapist Ratings } \\
\text { of Family Cooperation } \\
\text { (1=low; 4=average; 7=high) }\end{array}$ \\
\hline Acceptance of therapist & 51 & 5.7 \\
Quality of communication & 47 & 4.7 \\
Quality of effort in problem solving & 45 & 4.5 \\
Completion of homework & 29 & 3.2 \\
Achievement of goals & 49 & 4.9 \\
Total TRFC Score & 221 & \\
\hline
\end{tabular}


Table 13

Pre, Post, and 2-Week Follow-up Data for Dyad 4 Parent (i.e., Sally).

\begin{tabular}{|c|c|c|c|c|}
\hline Parent Measure & Pre & Post & Difference & $\begin{array}{l}\text { 2-Week } \\
\text { Follow-up }\end{array}$ \\
\hline $\begin{array}{l}\text { Conflict Behavior } \\
\text { Questionnaire-20 }\end{array}$ & 3 & 3 & 0 & 3 \\
\hline $\begin{array}{l}\text { Family Beliefs Inventory } \\
\qquad \begin{array}{l}\text { Ruination } \\
\text { Perfection } \\
\text { Approval } \\
\text { Obedience } \\
\text { Self-Blame } \\
\text { Malicious Intent }\end{array}\end{array}$ & $\begin{array}{l}27 \\
41 \\
16 \\
29 \\
26 \\
15\end{array}$ & $\begin{array}{l}30 \\
50 \\
17 \\
32 \\
22 \\
16\end{array}$ & $\begin{array}{l}+3 \\
+9 \\
+1 \\
+3 \\
-4 * \\
+1\end{array}$ & N/A \\
\hline $\begin{array}{l}\text { Issues Checklist } \\
\qquad \begin{array}{l}\text { Number of Issues } \\
\text { Average Intensity/Issue } \\
\text { Weighted Average } \\
\text { Frequency X Intensity }\end{array}\end{array}$ & $\begin{array}{l}11 \\
2.6 \\
3.2\end{array}$ & $\begin{array}{c}8 \\
2.3 \\
2.7\end{array}$ & $\begin{array}{c}-3^{*} \\
-0.3^{*} \\
-0.5^{*}\end{array}$ & $\begin{array}{c}7 \\
3.6 \\
3.9\end{array}$ \\
\hline $\begin{array}{l}\text { Parent Adolescent Relationship } \\
\text { Questionnaire } \\
\qquad \begin{array}{l}\text { Global Distress } \\
\text { Communication } \\
\text { Problem-Solving } \\
\text { Beliefs }\end{array}\end{array}$ & $\begin{array}{c}11 \\
5 \\
2\end{array}$ & $\begin{array}{l}3 \\
1 \\
0\end{array}$ & $\begin{array}{l}-8^{*} \\
-4^{*} \\
-2^{*}\end{array}$ & N/A \\
\hline $\begin{array}{ll} & \begin{array}{l}\text { Ruination } \\
\text { Perfectionism } \\
\text { Self-Blame } \\
\text { Malicious Intent } \\
\text { Obedience }\end{array} \\
\text { Cohesion } & \\
\text { Conventionalization } \\
\text { Hierarchy Reversal }\end{array}$ & $\begin{array}{l}1 \\
5 \\
2 \\
1 \\
5 \\
2 \\
3 \\
6\end{array}$ & $\begin{array}{l}0 \\
4 \\
0 \\
0 \\
2 \\
0 \\
5 \\
6\end{array}$ & $\begin{array}{l}-1^{*} \\
-1^{*} \\
-2^{*} \\
-1^{*} \\
-3^{*} \\
-2^{*} \\
+2 \\
0\end{array}$ & \\
\hline $\begin{array}{l}\text { Child Behavior Checklist } \\
\text { (T-Scores) } \\
\qquad \begin{array}{l}\text { Total } \\
\text { Internal } \\
\text { External }\end{array}\end{array}$ & $\begin{array}{l}39 \\
43 \\
45\end{array}$ & $\begin{array}{l}33 \\
32 \\
43\end{array}$ & $\begin{array}{c}-6^{*} \\
-11^{*} \\
-2^{*}\end{array}$ & N/A \\
\hline $\begin{array}{l}\text { Withdrawn } \\
\text { Somatic Complaints } \\
\text { Anxious/Depressed } \\
\text { Social Problems } \\
\text { Thought Problems } \\
\text { Attention Problems } \\
\text { Delinquent Behavior } \\
\text { Aggressive Behavior }\end{array}$ & $\begin{array}{l}50 \\
53 \\
50 \\
50 \\
50 \\
50 \\
50 \\
50\end{array}$ & $\begin{array}{l}50 \\
50 \\
50 \\
50 \\
50 \\
50 \\
50 \\
50\end{array}$ & $\begin{array}{c}0 \\
-3^{*} \\
0 \\
0 \\
0 \\
0 \\
0 \\
0\end{array}$ & \\
\hline
\end{tabular}

Note: $*=$ change in the direction of improvement 
Table 14

Pre, Post, and 2-Week Follow-up Data for Dyad 4 Adolescent (i.e., Don).

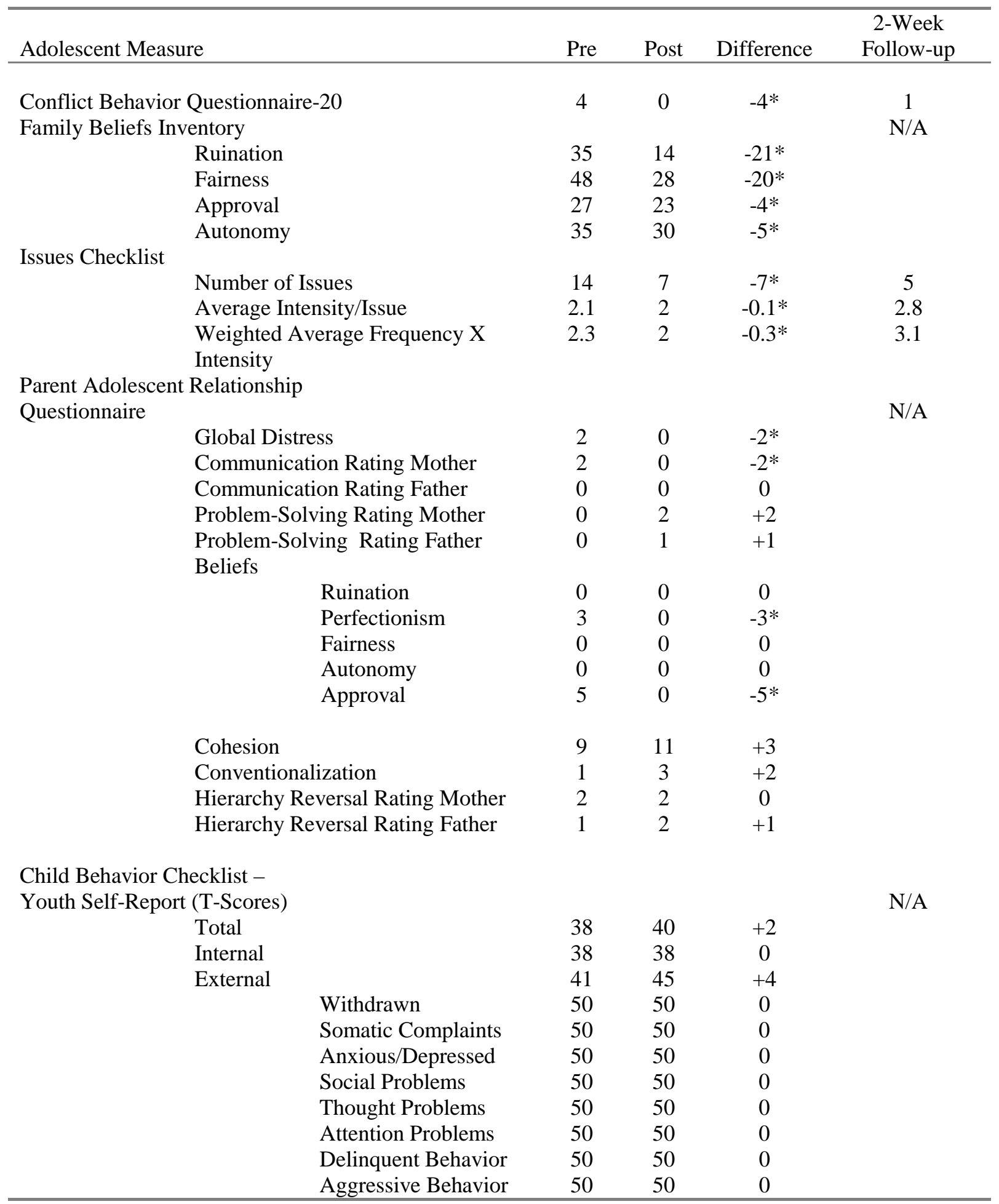

Note: $*$ change in the direction of improvement 
Table 15

Therapist Rating of Family Cooperation (TRFC) Scores for Dyad 4.

\begin{tabular}{lcc}
\hline TRFC Item & $\begin{array}{c}\text { Total } \\
\text { Score }\end{array}$ & $\begin{array}{c}\text { Mean Therapist Ratings } \\
\text { of Family Cooperation } \\
\text { (1=low; 4=average; 7=high) }\end{array}$ \\
\hline Acceptance of therapist & 61 & 6.1 \\
Quality of communication & 50 & 5.0 \\
Quality of effort in problem solving & 58 & 5.8 \\
Completion of homework & 27 & 3.0 \\
Achievement of goals & 54 & 5.4 \\
Total TRFC Score & 250 & \\
\hline
\end{tabular}


Table 16

Consumer Satisfaction Survey Average Item Scores obtained for Dyads 1-4 for Treatment

$\underline{\text { Sessions 1-10. }}$

\begin{tabular}{|c|c|c|c|c|c|c|c|c|}
\hline \multirow{2}{*}{$\begin{array}{c}\text { Treatment } \\
\text { Session Number }\end{array}$} & \multicolumn{2}{|c|}{ Dyad 1} & \multicolumn{2}{|c|}{ Dyad 2} & \multicolumn{2}{|c|}{ Dyad 3} & \multicolumn{2}{|c|}{ Dyad 4} \\
\hline & $\mathrm{P}$ & A & $\mathrm{P}$ & A & $\mathrm{P}$ & A & $\mathrm{P}$ & A \\
\hline 1 & 3.8 & 4.0 & 4.0 & 4.0 & 4.4 & 4.4 & 4.4 & 4.0 \\
\hline 2 & 3.6 & 4.5 & 4.0 & 4.0 & 4.7 & 5.0 & 4.9 & 4.0 \\
\hline 3 & 3.4 & 4.2 & 4.0 & 4.0 & 4.8 & 4.8 & 4.8 & 5.0 \\
\hline 4 & 3.0 & 4.1 & 4.0 & 4.0 & 4.1 & 5.0 & 5.0 & 5.0 \\
\hline 5 & 3.2 & 3.4 & 4.0 & 4.0 & 4.6 & 5.0 & 4.8 & 5.0 \\
\hline 6 & 3.0 & 3.6 & 4.0 & 4.0 & 5.0 & 4.4 & 4.7 & 5.0 \\
\hline 7 & 3.1 & 4.3 & 4.0 & 4.0 & 4.5 & 4.9 & 5.0 & 5.0 \\
\hline 8 & 3.1 & 3.9 & 4.0 & 4.0 & 4.7 & 5.0 & 4.7 & 4.9 \\
\hline 9 & 3.2 & 3.8 & 4.0 & 4.0 & 4.5 & 5.0 & 5.0 & 5.0 \\
\hline 10 & 3.0 & 3.8 & 4.0 & 4.0 & 5.0 & 5.0 & 5.0 & 5.0 \\
\hline Therapist & & & & & & & & \\
\hline
\end{tabular}

Note. $1=$ strongly dissatisfied, $2=$ dissatisfied, $3=$ neutral, 4=satisfied, $5=$ =strongly satisfied;

$\mathrm{P}=$ Parent, $\mathrm{A}=$ Adolescent 


\section{Appendix A \\ Therapist Rating of Family Cooperation}

The lead therapist should complete this measure after each therapy session.

Session \#: $\quad$ Family \#: Date:

1. How would you rate this family's acceptance of you as a therapist?
1
3
4
5
6
7
Low
Average
High

2. How would you rate the quality of communication between family members in this session?
1
2
3
4
5
6
7
Low
Average
High

3. How would you rate the quality of effort in problem solving displayed by this family?

$\begin{array}{ccccccc}1 & 2 & 3 & 4 & 5 & 6 & 7 \\ \text { Low } & & & \text { Average } & & & \text { High }\end{array}$

4. How would you rate this family's completion of the assigned homework?

$\begin{array}{ccccccc}1 & 2 & 3 & 4 & 5 & 6 & 7 \\ \text { Low } & & & \text { Average } & & & \text { High }\end{array}$

5. How would you rate this family's ability to achieve this session's goals?

$\begin{array}{ccccccc}1 & 2 & 3 & 4 & 5 & 6 & 7 \\ \text { Low } & & & \text { Average } & & & \text { High }\end{array}$




\section{Appendix B}

\section{Consumer Satisfaction Survey}

Please complete the items listed below by placing a checkmark on the line next to each question that best indicates how you feel about the treatment. Please read the items carefully.

1. I found this treatment to be a good way of dealing with my family's conflict.

\begin{tabular}{|c|c|c|c|}
\hline $\begin{array}{l}\text { strongly } \\
\text { disagree }\end{array}$ & $\overline{\text { disagree }}$ & $\overline{\text { neutral }}$ & $\overline{\text { agree }}$ \\
\hline
\end{tabular}

2. I like the procedures used in this treatment.

\begin{tabular}{|c|c|c|c|}
\hline $\begin{array}{l}\overline{\text { strongly }} \\
\text { disagree }\end{array}$ & $\overline{\text { disagree }}$ & neutral & agree \\
\hline
\end{tabular}

3. I believe this treatment is likely to be effective.

\begin{tabular}{|c|c|c|c|}
\hline $\begin{array}{l}\overline{\text { strongly }} \\
\text { disagree }\end{array}$ & $\overline{\text { disagree }}$ & neutral & agree \\
\hline
\end{tabular}

4. I believe this treatment is good to use with adolescents and parents.

\begin{tabular}{|c|c|c|c|}
\hline $\begin{array}{l}\overline{\text { strongly }} \\
\text { disagree }\end{array}$ & $\overline{\text { disagree }}$ & $\overline{\text { neutral }}$ & $\overline{\text { agree }}$ \\
\hline
\end{tabular}

5. I liked the format (e.g., \# of sessions, duration of session time, topics) of this treatment program.

\begin{tabular}{|c|c|c|c|}
\hline $\begin{array}{l}\overline{\text { strongly }} \\
\text { disagree }\end{array}$ & $\overline{\text { disagree }}$ & neutral & agree \\
\hline
\end{tabular}


6. Overall, I have a positive reaction to this treatment.

\begin{tabular}{|c|c|c|c|}
\hline $\begin{array}{l}\overline{\text { strongly }} \\
\text { disagree }\end{array}$ & disagree & neutral & agree \\
\hline
\end{tabular}

7. I thought my therapist was effective in dealing with my family's conflict.

\begin{tabular}{|c|c|c|c|}
\hline $\begin{array}{l}\text { strongly } \\
\text { disagree }\end{array}$ & disagree & neutral & agree \\
\hline
\end{tabular}

8. My therapist was caring.

\begin{tabular}{|c|c|c|c|}
\hline $\begin{array}{l}\text { strongly } \\
\text { disagree }\end{array}$ & disagree & neutral & agree \\
\hline
\end{tabular}

9. I liked my therapist.

$\begin{array}{llll}\overline{\text { strongly }} & \overline{\text { neutral }} & \overline{\text { agree }} & \begin{array}{c}\overline{\text { strongly }} \\ \text { agree }\end{array}\end{array}$

10. I would recommend this therapist to other parents and adolescents who are having family conflict.

strongly

$\overline{\text { disagree }}$

$\overline{\text { neutral }}$

agree

strongly

disagree

agree 


\section{Appendix C}

\section{Interaction Behavior Code}

\section{Positive}

Mom Dad Adol

\begin{tabular}{|c|c|c|c|}
\hline $\begin{array}{l}\text { 1. Stating the other's opinion - an effort to express the other person's views in a noncondemnatory fashion, } \\
\text { e.g., by paraphrasing without losing the original intent. }\end{array}$ & $\mathrm{Y} / \mathrm{N}$ & $\mathrm{Y} / \mathrm{N}$ & $\mathrm{Y} / \mathrm{N}$ \\
\hline $\begin{array}{l}\text { 2. Making suggestions - offering solutions and possible ideas (without demanding) of things that can be } \\
\text { done differently in the future. }\end{array}$ & $\mathrm{Y} / \mathrm{N}$ & $\mathrm{Y} / \mathrm{N}$ & $\mathrm{Y} / \mathrm{N}$ \\
\hline $\begin{array}{l}\text { 3. Asking what the other would like, want - attempting to find out what the other person wants, expects, } \\
\text { or prefers. }\end{array}$ & $\mathrm{Y} / \mathrm{N}$ & $\mathrm{Y} / \mathrm{N}$ & $\mathrm{Y} / \mathrm{N}$ \\
\hline $\begin{array}{l}\text { 4. Praising, complimenting - expressing approval of the other person; to commend, say something positive } \\
\text { about the other. }\end{array}$ & $\mathrm{Y} / \mathrm{N}$ & $\mathrm{Y} / \mathrm{N}$ & $\mathrm{Y} / \mathrm{N}$ \\
\hline $\begin{array}{l}\text { 5. Joking (good natured) - adding some levity to the conversation, possibly resulting in laughter, without } \\
\text { making fun or ridiculing. }\end{array}$ & $\mathrm{Y} / \mathrm{N}$ & $\mathrm{Y} / \mathrm{N}$ & $\mathrm{Y} / \mathrm{N}$ \\
\hline 6. Listening & $\mathrm{Y} / \mathrm{N}$ & $\mathrm{Y} / \mathrm{N}$ & $\mathrm{Y} / \mathrm{N}$ \\
\hline 7. Compromising - modifying original intentions or preferences, willingness to do so. & $\mathrm{Y} / \mathrm{N}$ & $\mathrm{Y} / \mathrm{N}$ & $\mathrm{Y} / \mathrm{N}$ \\
\hline
\end{tabular}

$$
\text { Yes }=1 \quad \text { No }=0
$$

TOTAL: 


\section{Negative}

Mom Dad Adol

\begin{tabular}{|c|c|c|c|}
\hline 1. Repeating one's opinion with insistence - excessively and repeatedly stating the same opinion. & $\mathrm{Y} / \mathrm{N}$ & $\mathrm{Y} / \mathrm{N}$ & $\mathrm{Y} / \mathrm{N}$ \\
\hline 2. Denying responsibility & $\mathrm{Y} / \mathrm{N}$ & $\mathrm{Y} / \mathrm{N}$ & $\mathrm{Y} / \mathrm{N}$ \\
\hline $\begin{array}{l}\text { 3. Disregarding the other person's points - lack of acknowledgment of other's statements; speaking as } \\
\text { though the other person did not say anything. }\end{array}$ & $\mathrm{Y} / \mathrm{N}$ & $\mathrm{Y} / \mathrm{N}$ & $\mathrm{Y} / \mathrm{N}$ \\
\hline $\begin{array}{l}\text { 4. Interrupting with criticism - to break in with questions or remarks of a critical nature while the other is } \\
\text { speaking. }\end{array}$ & $\mathrm{Y} / \mathrm{N}$ & $\mathrm{Y} / \mathrm{N}$ & $\mathrm{Y} / \mathrm{N}$ \\
\hline $\begin{array}{l}\text { 5. Making quick, negative judgments of other's suggestions - to negate, reject, or criticize the } \\
\text { other person's suggestions without verbal or temporal signs of taking the suggestion under consideration. }\end{array}$ & $\mathrm{Y} / \mathrm{N}$ & $\mathrm{Y} / \mathrm{N}$ & $\mathrm{Y} / \mathrm{N}$ \\
\hline 6. Humoring, discounting & $\mathrm{Y} / \mathrm{N}$ & $\mathrm{Y} / \mathrm{N}$ & $\mathrm{Y} / \mathrm{N}$ \\
\hline 7. Asking accusing questions - asking a question which implies some wrongdoing. & $\mathrm{Y} / \mathrm{N}$ & $\mathrm{Y} / \mathrm{N}$ & $\mathrm{Y} / \mathrm{N}$ \\
\hline $\begin{array}{l}\text { 8. Ridiculing, making fun of - to tease, mock, or belittle the other aimed at hurting the other person. Intent } \\
=\text { put down. Said in acid or sarcastic tone. }\end{array}$ & $\mathrm{Y} / \mathrm{N}$ & $\mathrm{Y} / \mathrm{N}$ & $\mathrm{Y} / \mathrm{N}$ \\
\hline $\begin{array}{l}\text { 9. Threatening - an expression of intention to do harm or to levy negative consequences. Exclude statements in } \\
\text { which a negative consequence is stated as a possible response to a behavior and is considered by both parties as a } \\
\text { possible solution to a problem. }\end{array}$ & $\mathrm{Y} / \mathrm{N}$ & $\mathrm{Y} / \mathrm{N}$ & $\mathrm{Y} / \mathrm{N}$ \\
\hline $\begin{array}{l}\text { 10. Name calling (negative) - applying a name to the other person which connotes something negative. } \\
\text { Must be a noun. }\end{array}$ & $\mathrm{Y} / \mathrm{N}$ & $\mathrm{Y} / \mathrm{N}$ & $\mathrm{Y} / \mathrm{N}$ \\
\hline 11. Yelling - raising the volume of one's voice in an angry manner. & $\mathrm{Y} / \mathrm{N}$ & $\mathrm{Y} / \mathrm{N}$ & $\mathrm{Y} / \mathrm{N}$ \\
\hline 12. Making demands - clear-cut commands; requests which require action. & $\mathrm{Y} / \mathrm{N}$ & $\mathrm{Y} / \mathrm{N}$ & $\mathrm{Y} / \mathrm{N}$ \\
\hline $\begin{array}{l}\text { 13. Negatively exaggerating - putting excessive emphasis on the other person' negative qualities; } \\
\text { overgeneralizing (look for key words "always" and "never"). Do not rate overgeneralizations said in a joking } \\
\text { fashion. }\end{array}$ & $\mathrm{Y} / \mathrm{N}$ & $\mathrm{Y} / \mathrm{N}$ & $\mathrm{Y} / \mathrm{N}$ \\
\hline $\begin{array}{l}\text { 14. Giving short, unhelpful responses - answering questions or statements with utterances that have no } \\
\text { benefits to the discussion, e.g., "Uh huh," "I don't know." }\end{array}$ & $\mathrm{Y} / \mathrm{N}$ & $\mathrm{Y} / \mathrm{N}$ & $\mathrm{Y} / \mathrm{N}$ \\
\hline 15. Using big words & $\mathrm{Y} / \mathrm{N}$ & $\mathrm{Y} / \mathrm{N}$ & $\mathrm{Y} / \mathrm{N}$ \\
\hline 16. Arguing over small points & $\mathrm{Y} / \mathrm{N}$ & $\mathrm{Y} / \mathrm{N}$ & $\mathrm{Y} / \mathrm{N}$ \\
\hline 17. Talking very little (throughout) - minimal participation throughout the discussion. & $\mathrm{Y} / \mathrm{N}$ & $\mathrm{Y} / \mathrm{N}$ & $\mathrm{Y} / \mathrm{N}$ \\
\hline 18. Talking a great deal (throughout) - monopolizing the discussion. & $\mathrm{Y} / \mathrm{N}$ & $\mathrm{Y} / \mathrm{N}$ & $\mathrm{Y} / \mathrm{N}$ \\
\hline 19. Mind reading - stating or attributing beliefs to the other person. & $\mathrm{Y} / \mathrm{N}$ & $\mathrm{Y} / \mathrm{N}$ & $\mathrm{Y} / \mathrm{N}$ \\
\hline 20. Dwelling on the past & $\mathrm{Y} / \mathrm{N}$ & $\mathrm{Y} / \mathrm{N}$ & $\mathrm{Y} / \mathrm{N}$ \\
\hline $\begin{array}{l}\text { 21. Abruptly changing the subject - a sudden change of topic which leaves the original topic unresolved } \\
\text { and does not follow from what the other person said. }\end{array}$ & $\mathrm{Y} / \mathrm{N}$ & $\mathrm{Y} / \mathrm{N}$ & $\mathrm{Y} / \mathrm{N}$ \\
\hline 22. Failing to make eye contact & $\mathrm{Y} / \mathrm{N}$ & $\mathrm{Y} / \mathrm{N}$ & $\mathrm{Y} / \mathrm{N}$ \\
\hline
\end{tabular}

$$
\text { Yes }=1 \quad \text { No }=0
$$

TOTAL: 


\begin{tabular}{|c|c|c|c|}
\hline $\begin{array}{llll}\text { Negative } & \mathbf{1}=\text { Absent } & \mathbf{2}=\mathbf{A} \text { Little } & \mathbf{3}=\mathbf{A} \text { Lot } \\
& (1=0 \text {-point }) & (2=.5 \text {-point }) & (3=1 \text {-point })\end{array}$ & Mom & Dad & Adol \\
\hline 1. Anger-to be annoyed, disgusted, or enraged with the other person. & 123 & 123 & 123 \\
\hline $\begin{array}{l}\text { 2. Personal attack - to speak of the other person accusingly; to make a verbal judgment about the other } \\
\text { person which includes a negative trait, e.g., "You are lazy." }\end{array}$ & 123 & 123 & 123 \\
\hline 3. Criticism - finding fault with the other person's actions, statements or beliefs. & 123 & 123 & 123 \\
\hline $\begin{array}{l}\text { 4. Sarcasm - making sarcastic or derisive remarks about the other; implying criticism or dislike in an acid } \\
\text { tone. }\end{array}$ & 123 & 123 & 123 \\
\hline $\begin{array}{l}\text { 5. Demanding (coercive) - making repeated demands and using tone of voice which suggests that the } \\
\text { speaker expects compliance. }\end{array}$ & 123 & 123 & 123 \\
\hline 6. Aquiescence (over agree) - overly accepting or agreeing. & 123 & 123 & 123 \\
\hline $\begin{array}{l}\text { 7. Silence; ignoring others -refusing to participate, avoiding questions, not talking (for longer than a } \\
\text { couple of seconds). }\end{array}$ & 123 & 123 & 123 \\
\hline 8. Lecturing; preaching & 123 & 123 & 123 \\
\hline 9. Fidgeting; slouching & 123 & 123 & 123 \\
\hline
\end{tabular}
$(1=0 p t)$
$(2=.5 p t)$
$(3=1 p t)$
TOTAL:

\section{SUMMARY SCORES}

MOTHER:

Negative Behavior: Pg.2 (__ $)+\operatorname{Pg} .3\left({ }_{\ldots}\right)=$

Positive Behavior: Pg.1

FATHER:

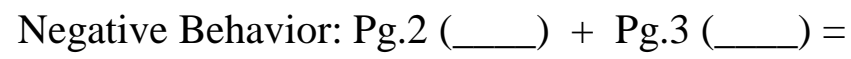

Positive Behavior: Pg.1

ADOLESCENT: Negative Behavior: Pg.2 (

$+\operatorname{Pg} .3($

Positive Behavior: Pg.1 


\section{Appendix D}

\section{Problem-Solving Behavior Code}

\begin{tabular}{|c|c|c|c|}
\hline $\begin{array}{l}\text { \#1. Defines the } \\
\text { problem }\end{array}$ & 1. At least one family member verbally defines the problem. & $\mathrm{Y}$ & $\mathrm{N}$ \\
\hline & 2. Definition of problem does not blame anyone, only behavior. & Y & $\mathrm{N}$ \\
\hline & 3. All family members verbally state they agree with the problem definition. & Y & $\mathrm{N}$ \\
\hline \multicolumn{4}{|c|}{ TOTAL FOR SKILL \#1: } \\
\hline $\begin{array}{l}\text { \#2. Generating } \\
\text { Solutions }\end{array}$ & 4. Each family member generates a solution. & $\mathrm{Y}$ & $\mathrm{N}$ \\
\hline & 5. Each family member generates at least 2 solutions. & $\mathrm{Y}$ & $\mathrm{N}$ \\
\hline & $\begin{array}{l}\text { 6. Each family member does not "judge" (e.g., show disapproval by rolling } \\
\text { eyes or verbally stating disapproval) other family member's proposed solution } \\
\text { until everyone has had a chance to generate } 1 \text { solution. }\end{array}$ & $\mathrm{Y}$ & $\mathrm{N}$ \\
\hline \multicolumn{4}{|c|}{ TOTAL FOR SKILL \#2: } \\
\hline \#3. Evaluate Solution & $\begin{array}{l}\text { 7. Each solution is evaluated by parent(s). (This consists of some form of } \\
\text { verbal discussion of each idea. Discussion can be minimal, but needs to occur.) }\end{array}$ & $\mathrm{Y}$ & $\mathrm{N}$ \\
\hline
\end{tabular}

verbal discussion of each idea. Discussion can be minimal, but needs to occur.)

\begin{tabular}{llll}
\hline & & TOTAL FOR SKILL \#3: & \\
\hline \#4. Select a Solution & 9. Family reaches an agreement on a solution. & & $\mathrm{N}$ \\
& & & \\
\hline
\end{tabular}

10. Each family member shows (e.g., nod head in the affirmative) or verbally states approval of solution. (Family members are allowed to negotiate a solution that was not previously stated, provided they all voice or show $\quad \mathrm{Y} \quad \mathrm{N}$ agreement to the solution.)

\begin{tabular}{llcc}
\hline & TOTAL FOR SKILL \#4: & \\
\hline $\begin{array}{l}\text { \#5. Plan to } \\
\text { Implement Solution }\end{array}$ & 11. At least one family member states what parent(s) will do re: solution. & Y & $\mathrm{N}$ \\
\hline & 12. At least one family member states what adolescent will do re: solution & $\mathrm{Y}$ & $\mathrm{N}$ \\
& & $\mathrm{Y}$ & $\mathrm{N}$ \\
\hline 13. At least one family member states when the solution will be implemented. & $\mathrm{N}$ \\
\hline 14. At least one family member states where the solution will be implemented. & $\mathrm{Y}$ & $\mathrm{N}$ \\
\hline 15. At least one family member states who will monitor compliance to solution. & $\mathrm{Y}$ & $\mathrm{N}$ \\
\hline 16. At least one family member states how monitoring of solution will be & $\mathrm{Y}$ & $\mathrm{N}$
\end{tabular}
carried out. CODER: 
Appendix E

Problem-Solving Discussion Instructions and Topics

\section{$\underline{\text { Problem-Solving Discussion Instructions }}$}

Problems will be randomly selected and presented to the parent(s) and adolescent. After participants are seated in an assessment room, the following rationale will be presented:

"We want to learn more about how you communicate and solve problems, and we have found that one way to do this is to ask you to discuss an issue. I've selected a discussion topic that is common to parents and adolescents.

I would like you to discuss this problem for ten minutes and try to resolve it as best as you can. When I leave the room, I would like for you to start. No interruptions - like talking about other topics, leaving the room, or talking to me - will be permitted during these discussions. Are there any questions? (pause)

The first problem will be (Researcher reads the example problem to both the parent(s) and adolescent). I would like you to pretend that this is a problem for your family. Do you have any questions? (pause)

Please discuss the problem of (brief label) as best as you can, trying to resolve it. Remember, there are to be no interruptions. If you finish early, please do not get up from your seats. Relax and I will return to tell you that the ten minutes are up."

After providing the rationale, the researcher will start the video camera, instruct the participants to "Begin their discussion," start the stop watch, and leave the room. After ten minutes, the researcher will return to the room, turn off the video camera, and ask the participants to stop. 


\section{Example Problems for Discussion}

\section{Telephone Calls}

Adolescent: You would like to talk to your friends every time they call and at whatever time they call you.

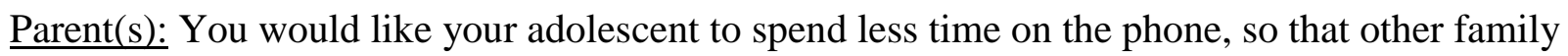
members may use it too.

\section{Time for going to bed}

Adolescent: You currently are told when to go to bed. You would like to stay up later to watch your favorite TV show and to talk on the phone.

Parent: You would like your child to go to bed and turn off the light at the set bedtime.

\section{Cleaning up the bedroom}

Adolescent: You feel your room is clean enough for you.

Parent: You would like your child to keep his/her room cleaner.

\section{Doing homework}

Adolescent: You want to do your homework when you want and where you want.

Parent: You would like your adolescent to have a set time and place to do his/her homework.

\section{Which clothes to wear}

Adolescent: You want to wear clothes that are like those that your friends wear.

Parent: You think your adolescent should dress more appropriately for school. 


\section{Using the television}

Adolescent: You feel that you should be able to watch whatever show you like on television whenever you want to do so.

Parent: You would like your child to watch less violent television shows and not to television so often.

\section{Making too much noise at home}

Adolescent: You feel that this is your home and you aren't really that loud. Besides, other kids play their radios and things as loud as you do.

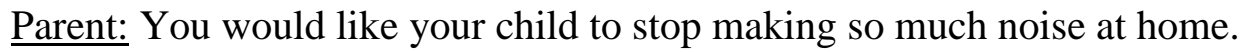

\section{Fighting with brothers and sisters}

Adolescent: You feel your brother and sister are always bothering you.

Parent: You would like your child to stop arguing and fighting with his/her siblings.

\section{Cursing}

Adolescent: You feel like you are old enough to say what you want. Besides, other kids swear too.

Parent: You would like your child to stop swearing.

\section{Taking care of CDs, games, bikes, pets, and other things.}

Adolescent: You feel like you take care of your things as much as you need.

Parent: You would like your child to take better care of his/her things.

\section{Who should be friends}

Adolescent: You feel like you are old enough to choose your own friends.

Parent: You would like your child to not hang around with certain friends. 


\section{Coming home on time}

Adolescent: You feel like you should be allowed to come home as late as your friends do.

Parent: You would like your child to come home at the designated curfew time.

\section{Getting low grades in school}

Adolescent: You feel like school is boring and your grades are fine.

$\underline{\text { Parent: }}$ You would like your child to earn better grades.

\section{Getting in trouble in school}

Adolescent: You feel that your teachers are picking on you.

Parent: You would like your child to behave better in school.

\section{Helping out around the house}

Adolescent: You feel like you do enough chores around the house.

Parent: You would like your child to help out more around the house.

\section{Getting up in the morning}

Adolescent: You feel you should be able to wake up when you want.

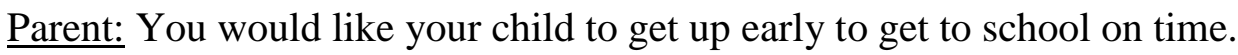

\section{How money is spent}

Adolescent: You feel you should be able to spend your money on the things you like, after all it's your money.

Parent: You would like your child to spend their money in a responsible way.

\section{Lying}

Adolescent: You feel like you usually tell the truth.

Parent: You would like your child to be more honest. 


\section{Allowance}

Adolescent: You feel you should get more allowance.

Parent: You feel your child earns enough allowance.

\section{Talking back to parents}

Adolescent: You feel like it's important to express your opinion or how you feel, even if your parents don't like it.

Parent: You would like your child to not talk back when you ask him/her to do something. 
Appendix F

Treatment Manual

Treatment Session 1: Intro \& BE

(Robin \& Foster; Chapter 2) (Defiant Teens; Chapter 1 \& Pg.75-79)

Goals

1. Provide family with overview of treatment

2. Establish rapport with adolescent

3. Educate parents and adolescent about behavioral-family systems theory of parent adolescent conflict

4. Begin to increase positive behavioral exchanges

$\underline{\text { Materials }}$

- Tape Recorder

- (2) Consumer Satisfaction Survey/Envelope

- Parent Handout "Paying Attention to Your Teen's Good Behavior (Barkley et al., 1999)"

- In-session BE Lists (Parent \& Adolescent)

- BE Monitoring sheet

- Reinforcement Ideas (Bloomquist, 1996)

$\underline{\text { Session Outline }}$

- Provide family with overview of treatment. Questions and answer session.

The therapist will have already gained consent and explained the format to the family during baseline assessment sessions. However, a brief review of the treatment protocol should be provided. Explain that therapy sessions will be conducted for 10 weeks. Sessions will last approximately 60-90 min. and the family should plan for $90 \mathrm{~min}$. sessions. Stress that the family will be expected to complete homework assignments to fully benefit from therapy. Explain procedures for rescheduling and parking. Explain confidentiality guidelines. Review their consent.

- Establish rapport with adolescent

After reviewing procedures and explaining policy to the entire family, the therapist should meet with the adolescent individually for approximately 5-15 $\mathbf{~ m i n}$. The therapist should attempt to draw the adolescent into the session with small talk. Ask about recent activities and the adolescent's likes and dislikes. Briefly explain that we will be teaching the adolescent ways to get along with the family better, and in doing so, it should help him/her to gain more independence. Ask if the adolescent has any comments or concerns. Emphasize that the adolescent can ask questions and/or speak to the therapist privately throughout therapy.

- Educate parent(s) and adolescent about factors that contribute to conflict. 
The therapist should then meet with both the parents and the adolescent and explain that becoming independent from the family is the primary task of adolescence. Adolescents go from being highly dependent on their parents to being relatively independent of their parents in young adulthood. Thus, a certain amount of conflict is developmentally normal as adolescents individuate from their parents. To prepare adolescents for independence, parents should encourage independence gradually, as the adolescent demonstrates responsibility. As a result, parents should view granting independence as a step-by-step procedure.

Next, the therapist should explain that although family members care very much about each other, communication and problem-solving skill deficits have been found to hurt their ability to communicate with each other. These deficits frequently lead to misunderstandings that add to the conflict. As a result, this treatment will focus on teaching the family members skills that can help them to communicate better. We will teach family members a way to systematically problem-solve issues that frequently cause family conflict. In addition, we will be asking family members to change some of the ways in which they communicate.

The therapist should explain each of the following 5 points that this treatment will focus on: 1) gradually granting independence to the adolescent, 2) helping parents and adolescents distinguish between negotiable and nonnegotiable issues, 3 ) involving adolescents in problem solving negotiable issues, 4) maintaining good family communication, and 5) helping parents and adolescents develop reasonable expectations.

- Discuss how their interactions greatly affect each other. Introduce rationale for increasing number of positive behavior exchanges.

The therapist should explain to the family that before we teach these problem-solving skills, we will first focus on restoring and improving their relationship. Explain that often by the time a family comes to treatment, they are angry and upset with each other. These negative interactions make it difficult to communicate and work together. Frequently, when family members are angry, they do not see situations clearly and their ability to generate solutions is diminished. We recommend working on improving their relationships before teaching some of the more difficult, preventative skills. As a result, we will not be focusing on specific problems and issues for the first few sessions. We will first attempt to improve family members' relations, so that they will find it easier to work together later in therapy. Explain that the way we hope to improve relations is by having you identify and do the things that you like to do together. The first thing we will have you do is list those things you like about and do for the each other. 
- Complete BE In-session list with both parent and adolescent. Have parents and adolescents list "Things I like about my adolescent (parent)," "What my adolescent (parent) does for me," and "What I do for my adolescent (parent)." Teach participants to identify and list existing reciprocity of reinforcement.

- Discuss lists and explain how family members will begin to monitor BEs. Explain to family members the need to be aware of when these BEs occur, especially during positive time (see discussion below).

- Establish One-on-One Positive Time (see discussion below). Discuss the importance of how the family needs to increase the amount of weekly and daily positive interactions in order to help work together in the future. Review and problem solve implementation.

The therapist should explain to the family that in order to improve their relationships, they should set aside 15-min a day for at least 3 days to focus on the positive things they listed. During this 15-min period the family should not discuss any problem situations. There should be no arguing or discussing anything negative. Parents and adolescents should be encouraged to come up with a list of various activities that they can do together for 15-min that will not result in an argument (e.g., play video game, watch T.V. show, eating dinner, shooting baskets). Use the Reinforcement Ideas Handout, if necessary.

In addition, the family should be instructed to spend one-hour of positive time together sometime during the week. Parents should be instructed to make available 1-hr that they can devote their individual attention to the adolescent. They should be instructed to get a baby sitter to watch siblings, if necessary. Activities should be something that the adolescent enjoys and the parent can participate in (e.g., go out to eat, go to the mall, rent a movie, basketball, games). The adolescent should be instructed to talk with his/her parents and focus on the positive things that they listed regarding their parents. The therapist should problem-solve implementation with the family. Who, what, when, where, and how should be covered and written down on the BE Monitoring sheet before the family leaves the first session. Pass out and discuss each suggestion listed in the parent handout Paying Attention to Your Teen's Good Behavior. Ask the parent for feedback regarding suggestions. Have family complete CSS survey and place in envelope - signing on back seal. Stress that therapist won't see - only Ethan.

Homework

- Parents and adolescent participate in $15 \mathrm{~min}$ 1-to-1 positive times at least 3 times a week. Have them write down what they did and how it went on the BE Monitoring sheet. In addition, tape record one session to review.

- Parents should record what they did and how the 1-hr activity went on the BE Monitoring sheet.

- Parents and adolescents monitor throughout the week the frequency of positive exchanges relevant to the In-session BE list. Participants should record on BE Monitoring list at the end of each day.

- Assign family tape recorder and cassette tape.

Therapist Complete Rating of Family Cooperation (Appendix G) and place envelope and Rating in Folder 
(Defiant Teens; Chapter 1 \& Pg.75-79), Besalel \& Azrin (1981), Raue \& Spence (1985), and (Behavioral Marital Therapy, Chapter 6, Jacobson \& Margolin;1979).

$\underline{\text { Goals }}$

1. Teach parents and adolescents how to increase BEs by establishing behavioral goals.

2. Educate parents and adolescents on how to use a behavioral contract.

3. Introduce communication skills. Train family members to provide non-contingent verbal reinforcers (e.g., compliments) and contingent verbal reinforcers (e.g., statements of appreciation).

$\underline{\text { Materials }}$

- Sample Behavior Contracts (1 \& 2)

- Blank Behavioral Contract

- Family Communication Skills handout (Bloomquist, 1996)

- How to Give Commands Parent Handout (Barkley et al., 1999)

- BE Monitoring sheet

- New Cassette Tape

- Parent and Adol Like and Dislike Lists from last session

- CSS Survey and Envelope (in client folder)

$\underline{\text { Session Outline }}$

- Review homework. Discuss positive 1-to-1 time procedure if used. COLLECT THE TAPE of the 1-to-1 time discussion assigned last week. Review BE monitoring sheets. Problem solve and re-assign similar assignment for the next week. Provide family with new BE monitoring sheets.

- $\quad$ Review the Parent \& Adol Like and Dislike lists developed last session. See if new information can be added or deleted from the sheets.

- Establish BE behavioral goals based on homework. Stress that BEs need to increase independent of other types of negative interactions (see below)

Upon examining the homework, the therapist should attempt to set behavioral goals with the family members to either increase the quantity of BEs in a week or the quality of the BE time. This could relate to the 1-hr time or the number of 10-min 1-to-1 sessions. For example, if the family only conducted three 10-min BE sessions in the previous week, the goal for the next week would be to conduct four 10-min sessions. In addition, if the family spent 1 hour watching TV together but not interacting with each other, the goal should be to spend 1 hour together engaged in an activity that requires interaction (e.g., games, making a favorite meal). Goals should designate the desired positive behavior changes. 
Furthermore, the therapist should explain that despite any conflict among family members, they should continue to try and increase the number of positive behavioral exchanges. The family should be reminded that their specific concerns will be addressed in future sessions, but for now we will continue to work on improving their relationships. Remind them that it will be easier to work together later if they work to improve their relationship now.

- Introduce behavioral contracts. Train participants in how to contract. Extend discussion to incorporate BE behavioral goals. Pass out sample behavior contracts.

The therapist should introduce behavioral contracts by passing out the sample contracts. Explain that we have found that contracts help to ensure that all family members meet their behavioral goals. Review the sample contracts, highlighting the various sections (e.g., Adol changes, Parent changes, and CONSEQUENCES).

- Have participants write and sign agreements regarding the positive changes they intend to make in their behavior.

Show the family how to complete a behavioral contract by designating changes they will make in their behavior. Regarding their behavior changes, have the family account for time, duration, place, and the nature and degree of their actions. Have the parent and the adolescent take turns completing their sections.

- Discuss Family Communication Skills handout. Train family members to provide noncontingent verbal reinforcers (e.g., compliments) and contingent verbal reinforcers (e.g., statements of appreciation). Emphasize how the way we interact can influence each other's behavior.

Each family member should receive a copy of the Family Communication Skills handout. The therapist should allow time for everyone to look over the handout. BEFORE examining specific communication skills, the therapist should discuss how people generally enjoy meaningful compliments and statements of appreciation. People work harder and feel better when they receive genuine compliments. Discuss how compliments need to be genuine. The therapist should discuss differences in labeled compliments (e.g., "I really appreciate how helpful you are when you watch your little brother," "I really like that shirt you are wearing") and unlabeled compliments (e.g., "You are a good kid," "I really think you have a good sense of humor") and have family members discuss things THEY LIKE to hear and WHEN they like to hear them. Have the family members concentrate on TIMES WHEN THEY can provide each other with the praise statements.

The therapist should also discuss how to make a request (e.g., "Compliments are what you say when someone does something well or does something you like. Requests are how you ask someone to do something well or something you would like.").

When the adolescent makes a request stress eye contact, saying please, and not whining. 
When the parents make a request; stress telling their child what to do, making sure they mean what they request, and avoiding distractions when delivering the request.

$\underline{\text { GIVE }}$ the parents the "How To Give Effective Commands Handout" to read at home.

Then, the therapist should discuss the "DON'Ts" on the handout. Discuss how people like to hear compliments, but do not often like to here the "DON'Ts." Provide examples from handout if the family has questions. Each member should be asked to self-evaluate to determine which "DON'Ts" apply to themselves.

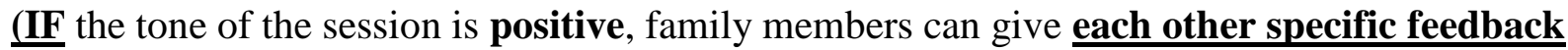
about specific "DON'Ts" they exhibit.)

Then, the therapist should cover the "DOs." Again, provide examples from the handout as necessary. The therapist should have the family practice giving compliments and identify at least 2 "DOs" that they will work on during the next week. (The therapist should try to have family members choose "DOs" that correspond with the opposing, self-identified “DON'Ts.")

Have family complete CSS survey and place in envelope - signing on back seal. Stress that therapist will not see - only Ethan.

$\underline{\text { Homework }}$

- GIVE NEW BE MONITOR SHEET. Continue to monitor the BEs and initiate the use of the behavioral contract to correspond to the behavioral goals set during the session.

This includes continuing positive 1-hr time and 10 min 1-to-1 time procedure. If the family was unable to meet $3 \mathrm{x}$ last week, set that as a goal. If the family was able to meet $3 \mathrm{x}$ last week, increase to 4/week. Or, if interaction during 1-hr time was limited, try to improve on that with a different activity as a goal.

- GIVE NEW TAPE. Record on tape one 10-min session.

- Have parents review How to Give Effective Commands Handout.

- Practice using 2 DOs and providing compliments.

*****Therapist Complete Rating of Family Cooperation and place envelope and CSS Rating in Folder 
Treatment Session 3: Conclude BE

$\underline{\text { Goals }}$

1. Review how to use behavioral contracting to increase BEs by incorporating 1-to-1, $10 \mathrm{~min}$ time and 1-hr time.

2. Review family communication skills; including positive compliments and requests.

$\underline{\text { Materials }}$

- Blank Behavioral Contract

- Sample Behavior Contracts (1 \& 2)

- Family Communication Skills handout (Bloomquist, 1996)

- BE Monitoring sheet

- New Cassette Tape

- CSS Survey and Envelope (in client folder)

$\underline{\text { Session Outline }}$

- Begin by reviewing homework. Examine if behavioral objectives were met and if the contract was implemented correctly. Evaluate and problem solve as necessary. Review 1-to1, 1-hr time and $10 \mathrm{~min}$ time. Modify and reassign as necessary.

The therapist should be sure that the 10min 1-to-1 time during the week and the 1-hr special time is still occurring. Provide feedback from the audiotape assigned from the first week. Collect the audio tape from last week and tell the family you will listen to it and provide them with feedback next session.

- Have family set goals and develop a new contract for this week. Provide minimal feedback during the development process.

The therapist should have the family complete a blank Behavioral Contract in session. Encourage the family to incorporate both 10-min time and 1-hr time into the contract. Encourage them to write out specific times, dates, activities, etc. Modifications may be necessary based on how the family is progressing.

- Review the Family Communication Skills handout, paying particular attention to the DOs that they were working on, and list specific compliments and requests that will increase the likelihood of their positive BEs. Review principles of positive communication and why it is important.

The therapist should spend the majority of this session focusing on covering family communication skills. Ask family members if they were providing more compliments to each other. Discuss how requests where made throughout the week and ask for feedback. Ask if parents have questions regarding the Giving Effective Commands Handout assigned last week. Facilitate discussion around what DOs were used by family members. Ask individuals to identify DON'Ts they found themselves still using. Have family members identify specific DOs they plan to work on in the next week. 
Each member should be asked to self-evaluate to determine which "DON'Ts" apply to themselves.

$\underline{\text { (IF the tone of the session is positive, family members can give each other specific feedback }}$ about specific "DON'Ts" they exhibit.)

Then, the therapist should cover the "DOs." Again, provide examples from the handout as necessary. The therapist should have the family practice giving compliments and identify at least 2 "DOs" that they will work on during the next week. (The therapist should try to have family members choose "DOs" that correspond with the opposing, self-identified 'DON'Ts.')

Have family complete CSS survey and place in envelope - signing on back seal. Stress that therapist will not see - only Ethan.

Homework

- Monitor and fulfill contractual obligations.

- GIVE NEW BE MONITOR SHEET. Continue to implement and record $10 \mathrm{~min}$ 1-to-1 time procedure on BE Monitoring Sheet.

- GIVE NEW TAPE. Tape record one $10 \mathrm{~min}$ 1-to-1 session.

- Practice using DOs and giving and receiving positive compliments and requests.

*****Therapist Complete Rating of Family Cooperation and place envelope and CSS Rating in Folder 
Treatment Session 4: Introduce Problem Solving Steps

NOTE: The therapist should review Barkley et al., 1999 Step 10 (p. 125-132) before beginning this session.

Goals

1. Introduce goals of PSCT

2. Familiarize family with the PSCT model and coach family in practicing PS steps with hypothetical issue.

$\underline{\text { Materials }}$

Handouts (Barkley et al., 1999):

- Steps to Better Problem-Solving (2)

- Problem-Solving Worksheet

- Problem-Solving Exercise (2)

- Blank Behavioral Contract

- BE Monitoring Sheet

Session Outline

- Review homework including behavioral contract and 1-to-1 session tape from last session. Discuss positives and negatives. Provide praise and feedback.

- Have family set goals and develop a new contract for this week. Provide minimal feedback during the development process.

The therapist should have the family complete a blank Behavioral Contract in session. Encourage the family to incorporate both 10-min time and 1-hr time into the contract. Encourage them to write out specific times, dates, activities, etc. The therapist should allow the family to do this own their own, as much as possible.

The therapist should then inform the family that the emphasis in treatment will now shift to focus more on problem solving specific issues. Emphasize that it is still important for the family to continue to increase their BEs and improve their relationship. Stress that the family should continue to spend individual time together and work on communication skills.

- Introduce rationale for problem-solving training. Talk about skills that will promote long term benefits for their relationship.

- Discuss the importance of problem-solving steps (use Problem-Solving Worksheet handout). Introduce each of the 5 steps and define. Walk family through hypothetical situation using each step. Get family participating and provide feedback.

The therapist should introduce the problem-solving steps displaying the Steps for Better Problem-Solving handout. Pass out a handout to each family member. Talk about how this model has been used in the business world (bankruptcy \& company mergers) and in international diplomacy (e.g., Israel \& Palestine). Explain the distinction between negotiable and nonnegotiable issues and explain that problem solving is used to resolve the negotiable issues. For example, use of drugs and violence are not negotiable, but cleaning up the bedroom and how money is spent are negotiable. Explain that problem solving is a way for 
adolescents to be involved in decisions regarding issues that affect them, and that everyone gets to give their opinions, resulting in a compromise solution being reached.

\section{*REMIND FOLKS TO USE THE SKILLS THEY WILL BE LEARNING IN THE MADE-UP ASSESSMENT SESSIONS FOR PRACTICE!!!}

The therapist should then introduce each step at a time and walk the family through each step with the Barkley et al., 1999 example. The example is as follows:

"I know a boy named Billy who is about to turn 16. Billy wants to have a birthday party and invite 100 of his closest friends, and he doesn't want his parents home for the party. His parents aren't happy about the idea."

Family members should take turns filling in the Problem-Solving Worksheet as problemsolving steps are completed.

For Step 1: Define the problem. Each person should make short, nonaccusing statement of what the other person is doing, what the situation is, and why it is a problem. Different family members will have different perspectives on the problem and that is o.k. DO NOT HAVE TO AGREE. Stress the need to speak in terms of "I" rather than "you" to avoid blaming others.

Give Billy e.g., "Mom \& Dad, I get embarrassed when you are around..." Notice no name calling, taking responsibility for own feelings.

Give Parent e.g., "I don't want you to have a party with no parents present because your friends may make poor choices and get into trouble or mess up the house"

The therapist should have each family member take a turn in defining the hypothetical problem. After each person defines the problem, ask another family member to repeat the definition back to check for accuracy of understanding. Provide feedback and correction.

For Step 2: Generate solutions._Stress being creative and not to judge the solutions. Anything goes, even if it is silly. Discuss brainstorming and how it can lead to possibilities we may not have thought of. The therapist should have each family member take turn listing ideas until they generate 12 possible solutions. NEED to watch to see that the solutions being generated go beyond the family members' initial positions and are possible bases for compromises. TAKE TURNS, If run out of ideas suggest, "Parents spy on party through mini cameras....

For Step 3: Evaluate the solution. Each family member will evaluate each solution, giving it a "+" or a "_-", based on whether or not they like the solution and they think it is realistic. These ratings should be recorded on the handout. Stress that families need to discuss why they feel it will or will not work, if they do not discuss a solution, PROMPT to discuss (teach consequential thinking). Recording evaluations. 
For Step 4: Select the option most agreeable to all. The therapist should instruct the family that their goal is to reach a decision that everyone can live with and with which everyone will have to give up something to get something. Review the ideas rated "t" by everyone. If one or more ideas were rated positively, congratulate the family and ask them to combine the ideas into an overall solution. IF no ideas were rated positively by all, help the family negotiate a compromise.

If no compromise was reached, look for the idea that came the closest to agreeing. Clearly state the gap. Ask the family to bridge the gap. Evaluate these new ideas, try to reach agreement

For Step 5: Plan to implement the solution. State the importance of planning out the following details: 1) who will do what, when, and where; 2) who will monitor compliance with the agreement, and how monitoring will be carried out (verbally or with charts); 3 ) the consequences for compliance or noncompliance with the agreement; 4) what, if any, performance reminders will be given; 5) exactly what constitutes compliance; and 6) what difficulties are anticipated in carrying out the agreement. Discuss how the family can write a behavioral contract that specifies each of the following details. Have the family plan to implement the solution with the hypothetical problem.

For the final step, evaluate the implementation of the solution and explain to the family that after a week or two of trying the solution, it is important to find out if the solution is working. Discuss the need for a negative/positives consequence if a member is unmotivated to follow through with an agreed upon solution. Have the family try and anticipate some difficulties that might come up in implementing the hypothetical situation. Answer questions and provide feedback. Pass out Problem-Solving Exercise Homework.

*IF YOU DON'T GET THROUGH ALL OF THE STEPS, DON'T WORRY: FINISH NEXT TIME!

\section{*REMIND FOLKS TO USE THESE SKILLS IN ASSESSMENT SESSIONS!!!}

Homework

- Have family implement BE behavioral contract completed in session

- Have each family member independently complete the Problem-Solving Exercise.

- GIVE NEW BE MONITOR SHEET. Continue to implement and record $10 \mathrm{~min}$ 1-to-1 time procedure on BE Monitoring Sheet.

*****Therapist Complete Rating of Family Cooperation and place envelope and CSS Rating in Folder 
Treatment Session 5: Practicing Problem Solving Steps

Review Barkley et al., 1999; Steps 11 \& 12

$\underline{\text { Goals }}$

1. To begin to get the family used to the problem-solving routine.

2. To work through a low-intensity problem.

3. To complete any activities left over from Session 4.

$\underline{\text { Materials }}$

- Last week's problem-solving video assessment tape.

- Steps to Better Problem-Solving (2)

- Blank Problem-Solving Worksheet

- Initial Issues Checklists completed by family members at baseline

- Parent Handout Steps to Better Problem Solving

- BE Monitoring Sheet

- Cassette Tape

$\underline{\text { Session Outline }}$

- Review the Problem-Solving Exercise homework. Provide feedback.

The therapist should review in detail the Problem-Solving Exercise assigned for homework. Have the family take turns reading aloud the different sections and discussing their answers. If a family member does not complete the homework, do not dwell on it, but simply have that person generate answers during the discussion.

- Complete activities left over from Session 4.

- Review assessment video of family discussing problem. Go through problem-solving steps. Have family members take turns generating examples.

- Select a low-intensity problem from the Issues Checklist (IC) to work through in session.

The therapist should review the family member's IC and select a few possible issues that were low-priority or low-intensity. Have the family select an issue that the family still finds meaningful. If there is no agreement between the parents and the adolescent, inform the family that you will choose a issue from the parent's IC this week and the adolescent's IC next week. The therapist should then guide the family through as many steps as possible correcting and providing feedback throughout the process. Stop premature negative evaluations and provide as much guidance as necessary. Keep the families comments to the point.

*REMIND FOLKS TO PRACTICE THESE SKILLS IN ASSESSMENT SESSIONS!!!

Homework 
- Complete the problem-solving discussion, if not completed in session. Implement solutions generated from the session's discussion.

- Have family practice and tape record a $15 \mathrm{~min}$ problem-solving discussion at home with a selected low-level intensity IC issue. They should complete a Problem-Solving Worksheet while discussing the issue. Have them keep a copy of the handout Steps to Better Problem Solving in front of them during the discussion. Tell them to stop the discussion if it becomes too heated and angry.

- GIVE NEW BE MONITOR SHEET. Continue to implement and record $10 \mathrm{~min}$ 1-to-1 time procedure on BE Monitoring Sheet.

*****Therapist Complete Rating of Family Cooperation and place envelope and CSS Rating in Folder 
Treatment Session 6: Introduction to Communication Skills

(Barkley et al., 1999; Steps 12 \& 13)

$\underline{\text { Goals }}$

1. To continue developing the family's expertise in problem solving.

2. To introduce communication skills.

3. To teach general principles of good communication.

4. To identify and begin to correct specific negative communication styles.

$\underline{\text { Materials }}$

- Previous week's problem-solving video assessment tape.

- Blank Problem-Solving Worksheet

- Communication Habits Handout (Barkley et al., 1999)

- BE Monitoring Sheet

- Cassette Tape

Session Outline

- Review the low intensity-level issue Problem-Solving Worksheet homework assignment.

- Provide feedback regarding Problem-Solving Worksheet and the solution generated.

Collect the tape of the home problem-solving discussion from the family. Discuss how successful the family thought they were at generating solutions. If the family did not do the homework, make that the topic of a problem-solving discussion in this session. Review the implementation of the solution generated in the last session. Ask if it is working, are there modifications needed? Provide feedback and corrective instruction so that family will have more success in implementing solution. If the family did not develop solution or it did not work, help family figure out what went wrong and how to overcome it. If necessary, make this the topic of this sessions problem-solving discussion rather than a new topic. Incorporate another try at implementation into the homework for this session.

- Review last session assessment video. Have family practice generating solution. Go through problem-solving steps. Have family members take turns generating examples.

- Choose a new, $1^{\text {st }}$ moderate intensity-level issue with the family from the IC for discussion at home. Or, re-assign last weeks problem for homework.

- Introduce general principles of communication.

- Introduce specific communication targets to be practiced family members during problemsolving discussion.

Pass out Communication Habits handout. Remind family of communication skills learned in earlier sessions. Refer them to the Communication Skills handout (Bloomquist, 1996) passed out in second session. Explain the following three rules of communication: 1) Listen when your teen/parent is in the mood to talk, but don't force him/her to open up; 2) Use active listening to encourage your teen/parent to express opinions and feelings; 3) Honestly express how you feel, good or bad, without being hurtful to your listeners. 
Discuss with the family the need to be aware of the specific communication habits that can make problem-solving discussions more difficult. Explain that each family member will need to work on these skills during discussions, especially when discussing the more sensitive issues.

Homework

- Go through problem-solving steps. Have family members take turns generating examples.

- Have the family tape record at home a $15 \mathrm{~min}$. problem-solving discussion of the agreed upon ${ }^{\text {st }}$ moderate intensity-level issue. Have them complete Problem-Solving Worksheet and follow along with the Steps for Better Problem Solving handout as they discuss the issue.

- Have family members monitor themselves for negative or positive communication styles throughout the discussion. Each member should be given a Communication Habits Worksheet to examine throughout the problem-solving discussion.

- GIVE NEW BE MONITOR SHEET. Continue to implement and record 10 min 1-to-1 time procedure on BE Monitoring Sheet.

******Therapist Complete Rating of Family Cooperation and place envelope and CSS Rating in Folder 
(Barkley et al., 1999; Steps 14 \& 15(p. 145-149))

NOTE: The therapist should review Family Belief Inventory (FBI) Scores prior to session. Mark on handouts unreasonable beliefs held by adolescent and parents.

$\underline{\text { Goals }}$

1. To review implementation of last weeks solution.

2. To give feedback on taped homework discussion.

3. To continue to practice new communication skills.

4. To introduce concept of irrational beliefs to both parent and adolescent.

$\underline{\text { Materials }}$

- Previous week's problem-solving assessment videotape

- Parent Handout: Unreasonable Beliefs Chart Unreasonable and Reasonable Beliefs Blank Problem-Solving Worksheet

- Adolescent Handout: Unreasonable and Reasonable Beliefs

- Blank Problem-Solving Worksheet

- BE Monitoring Sheet

- Cassette Tape

$\underline{\text { Session Outline }}$

- Review and provide feedback regarding the Problem-Solving Worksheet for the $1^{\text {st }}$ moderate intensity-level issue homework assignment. Collect the tape of the discussion and review next week in Session 8. Or review the implementation of the solution generated in the last session.

- Provide feedback regarding the low intensity-level issue home discussion audio tape.

The therapist should begin this session by asking the family to describe how the problemsolving discussion went. Have the family review the Problem-Solving Worksheet and help the family through each of the steps. Praise appropriate responses and correct steps in which the family has difficulty. Modify and correct solution if necessary. Also, compare and contrast last week's family discussion regarding a moderate conflict issue with the discussion the therapist listen to from two weeks ago concerning a low-level intensity conflict issue. Praise positives and correct inappropriate responses. Point out improvements. If no homework is completed, review last assessment session problem-solving discussion. Provide feedback.

- Review and identify communication targets family members should be focusing on improving.

Highlight communication negative and positive behaviors exhibited by each family member that were seen during the assessment video tape sessions or that the therapist 
heard listening to the audio tape of the problem solving discussion. Play the tape for the family to highlight both positive and negative behaviors. BE BRIEF! (5-10 min)

Praise and provide feedback. Encourage them to work on communication targets during problem-solving discussions, as well as throughout daily interactions.

- Choose a new $2^{\text {nd }}$ moderate issue with the family from the IC for discussion at home.

- Introduce the role of belief systems and expectations. Discuss how to challenge irrational beliefs.

The therapist should present the rationale for cognitive restructuring, review the most common unreasonable beliefs, identify which ones apply to the parents and adolescent (with the family's assistance), and help them begin to develop more reasonable beliefs and expectations.

You may want to discuss specific parent and adolescent beliefs individually. Have the parent wait outside while talking to the adolescent and vice versa.

Begin by providing the rationale that we will be learning a more positive coping attitude. Using Socratic discussion, help the family realize how extreme thinking evokes extreme affect, which makes it difficult to deal rationally and problem solve effectively. Pass out handouts to parents and adolescent. Review common unreasonable beliefs, asking parents and adolescents to rate how much they apply to them. Ask for examples of when they have activated this belief. Review reasonable beliefs and ask parents if they find it reasonable. If not, set up experiments for family to test if evidence exists for belief.

\section{Homework}

- Have family implement modified solutions generated from last week problem-solving discussion of $1^{\text {st }}$ moderate intensity-level issue.

- Have family tape record a problem-solving discussion of the $2^{\text {nd }}$ moderate intensitylevel issue agreed upon in session.

- Have family members try to monitor situations in which they adhere to unreasonable

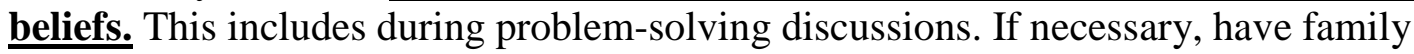
members conduct experiment to see if evidence exists for extreme belief.

- GIVE NEW BE MONITOR SHEET. Continue to implement and record 10 min 1-to-1 time procedure on BE Monitoring Sheet.

*****Therapist Complete Rating of Family Cooperation and place envelope and CSS Rating in Folder 
(Barkley et al., 1999; Step 16)

$\underline{\text { Goals }}$

1. To review family's reaction to last week's discussion of unreasonable beliefs.

2. To continue to practice new communication skills.

3. To examine if the family was able to successfully implement the solution generated from last weeks problem-solving discussion.

$\underline{\text { Materials }}$

- Previous week's problem-solving assessment videotape

- Blank Problem-Solving Worksheet

- BE Monitoring Sheet

- Cassette Tape

- OPTIONAL

\author{
Parent Handout: \\ Unreasonable Beliefs Chart \\ Unreasonable and Reasonable Beliefs Blank Problem-Solving \\ Worksheet \\ Adolescent Handout: \\ Unreasonable and Reasonable Beliefs
}

$\underline{\text { Session Outline }}$

- Discuss the problem-solving discussion and review the Problem-Solving Worksheet for the $2^{\text {nd }}$ moderate intensity-level issue homework assignment. Discuss how the implementation of the solution worked. Problem-solve and provide feedback.

- Review and provide feedback regarding the tape from the previous weeks moderate intensity-level issue problem-solving discussion (initially assigned in Session 6). Also, review assessment videotape from last assessment session. For both audio and video tapes: Compare and contrast with last week's discussion. Point out improvements and areas that could be improved. Spend some time highlighting communication targets.

The therapist should begin with a review of the homework. Spend time focusing on specifics (e.g., implementation and is it working?). Have family members critique their own performances. If no homework, begin reviewing video.

- Discuss and review how to challenge irrational beliefs. If possible, include examples found during videotaped discussions in assessment sessions and the taped discussions from home.

- Spend additional time, if necessary, on identifying and re-mediating negative communication patterns.

The therapist should revisit unreasonable beliefs and how to challenge them. Review the handouts from last week. Discuss what, if any, unreasonable beliefs the family identified over the last week. Discuss experiments. Provide feedback. Focus on how beliefs interact with communication patterns. 
- Choose a high intensity issue with the family from the IC for discussion at home.

- Discuss crisis management strategies to enhance problem-solving participation. Include role-plays.

The therapist should select an intense, highly conflictual topic for the problem-solving discussion from the Issues Checklist. Focus should be on teaching the family to "cool off" in order to avoid negative communication habits. Identify any possible unreasonable beliefs that may be fueling the conflict regarding this issue. Have the family role play what they will do if the problem-solving discussion falls apart and family members become angry. Help them identify ways to calm themselves (e.g., counting to ten, leaving the scene, calling for time out). Have the family commit to using at least one stop responses and have them roleplay a mock crisis in session.

Homework

- Have the family conduct a problem-solving discussion regarding the high-intensity issue, practicing all of the skills learned in the program

- Have the family tape record the problem-solving discussion of the high-intensity issue agreed upon in session. Have family complete Problem-Solving Worksheet.

- GIVE NEW BE MONITOR SHEET. Continue to implement and record 10 min 1-to-1 time procedure on BE Monitoring Sheet.

******Therapist Complete Rating of Family Cooperation and place envelope and CSS Rating in Folder 
(Barkley et al., 1999; Step 17)

$\underline{\text { Goals }}$

1. To review the family's performance during last week's problem-solving discussion regarding a high-intensity issue.

2. To have a problem-solving discussion of the most difficult issues.

$\underline{\text { Materials }}$

- Previous week's problem-solving assessment videotape (optional)

- Blank Problem-Solving Worksheet

- BE Monitoring Sheet

- Cassette Tape

$\underline{\text { Session Outline }}$

- Review and provide feedback on the high-intensity issue discussion and ProblemSolving Worksheet. Collect the audio tape of the home discussion.

- Review and provide feedback re: the $2^{\text {nd }}$ moderate-intensity issue audio tape (if available).

- Discuss how the implementation of the solution generated for the high-intensity issue worked. Problem-solve and provide feedback. Re-assign if necessary.

- Address the most intense, conflictual issue on the family's IC during session. Attempt to let the family handle most of the discussion. 
Homework

- If a solution is not generated in session, have the family continue to conduct a problemsolving discussion regarding the highest-intensity issue and implement the solution.

- If a solution is generated in session, choose another topic to be assigned for homework and implement solution. Have the family tape record the discussion and complete the Problem-Solving Worksheet.

- Remind family to bring back tape recorder.

- Consider scheduling final assessment next session. Family may be willing to attend for two hours.

- Have the family tape record the problem-solving discussion of the high-intensity issue agreed upon in session. Have family complete Problem-Solving Worksheet.

- GIVE NEW BE MONITOR SHEET. Continue to implement and record 10 min 1-to-1 time procedure on BE Monitoring Sheet.

*****Therapist Complete Rating of Family Cooperation and place envelope and CSS Rating in Folder 
Treatment Session 10: Concluding

(Barkley et al., 1999; Step 18)

$\underline{\text { Goals }}$

1. To review homework.

2. To review any problems that still need to be addressed.

3. To review the major elements of the program.

$\underline{\text { Materials }}$

- Video camera and instructions to conduct final generalization point.

- Final Assessment Measures (if time available)

Parent: FBI, IC, CBQ, PARQ, CBCL, CSS

Adolescent: FBI, IC, CBQ, PARQ, YSR, CSS

$\underline{\text { Session Outline }}$

- Review and provide feedback re: homework concerning the highest-intensity conflictual issue worked on last week.

- Review and provide feedback on any problems that remain. Address questions and concerns. Specify areas that have improved and those areas that still need improvement.

- Let family know the follow-up procedures. Let family know they can contact us in the future and crisis numbers in the community. Congratulate them for completing the program. Give the family time to express themselves regarding any concerns, questions, etc.

- Videotape generalization data point. Read the bold text in the instructions below and have family attempt to solve problem that was identified for the generalization point. This will be the same problem that they attempted to solve prior to beginning Treatment Session 1. Therapists may want to watch video tape of treatment session 1 to review procedure.

"We want to learn more about how you communicate and solve problems, and we have found that one way to do this is to ask you to discuss an issue. I've selected a discussion topic that is common to parents and adolescents.

I would like you to discuss this problem for ten minutes and try to resolve it as best as you can. When I leave the room, I would like for you to start. No interruptions - like talking about other topics, leaving the room, or talking to me - will be permitted during these discussions. Are there any questions? (pause)

The first problem will be (Researcher reads the example problem to both the parent(s) and adolescent). Even if this is no longer a problem for your family, I would like you to pretend that this still is a problem. Do you have any questions? (pause) Please discuss the problem of (brief label) as best as you can, trying to resolve it. Remember, there are to be no interruptions. If you finish early, please do not get up from your seats. Relax and I will return to tell you that the ten minutes are up." 
After providing the rationale, the researcher will start the video camera, instruct the participants to "Begin their discussion," start the stop watch, and leave the room. After ten minutes, the researcher will return to the room, turn off the video camera, and ask the participants to stop.

- If time, have family start to complete dependent measures. If family does not have time to complete assessment measures, schedule final assessment session.

$\underline{\text { Homework }}$

- Schedule final assessment session to occur as soon as possible after this session.

*****Therapist Complete Rating of Family Cooperation and place envelope and CSS Rating in Folder 
Dyad 1

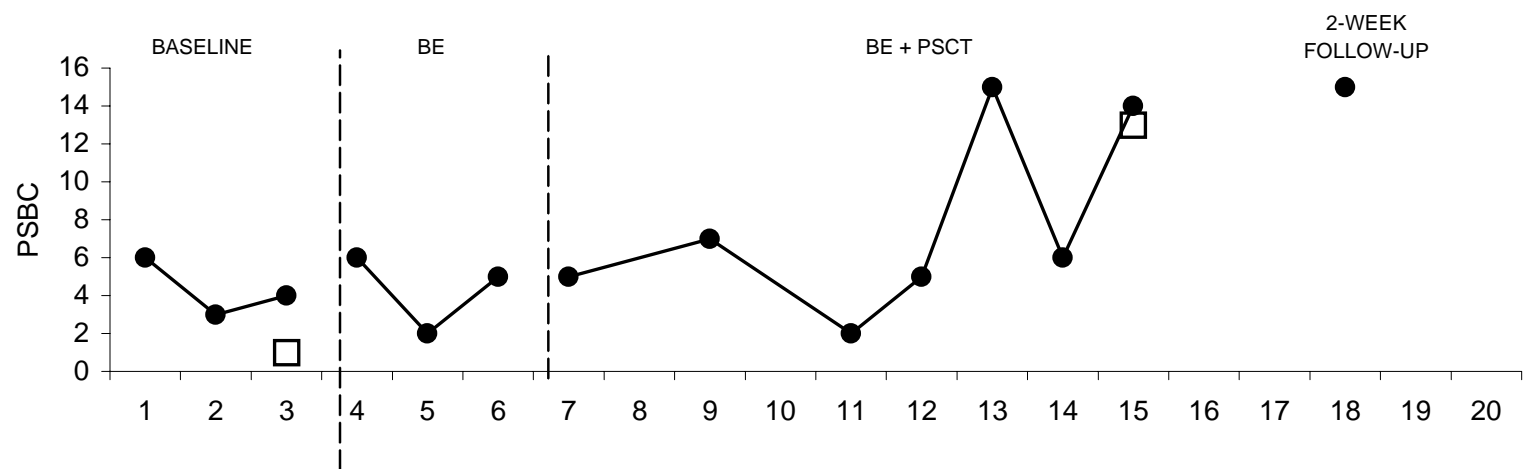

\section{Dyad 2}
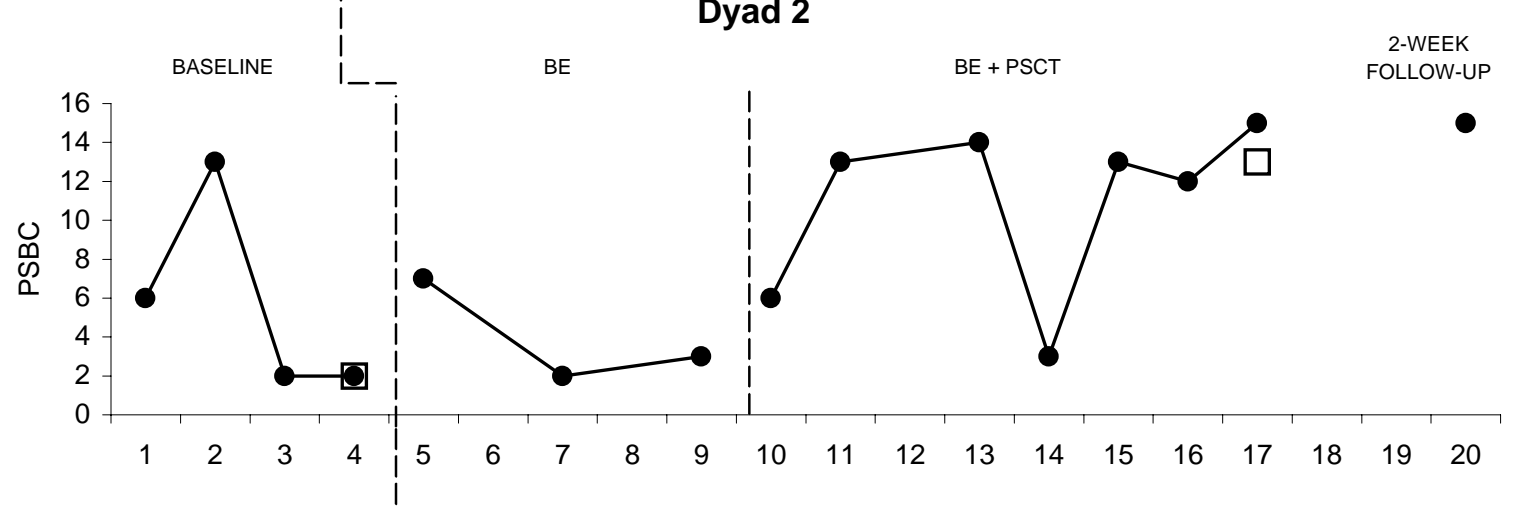

Dyad 3
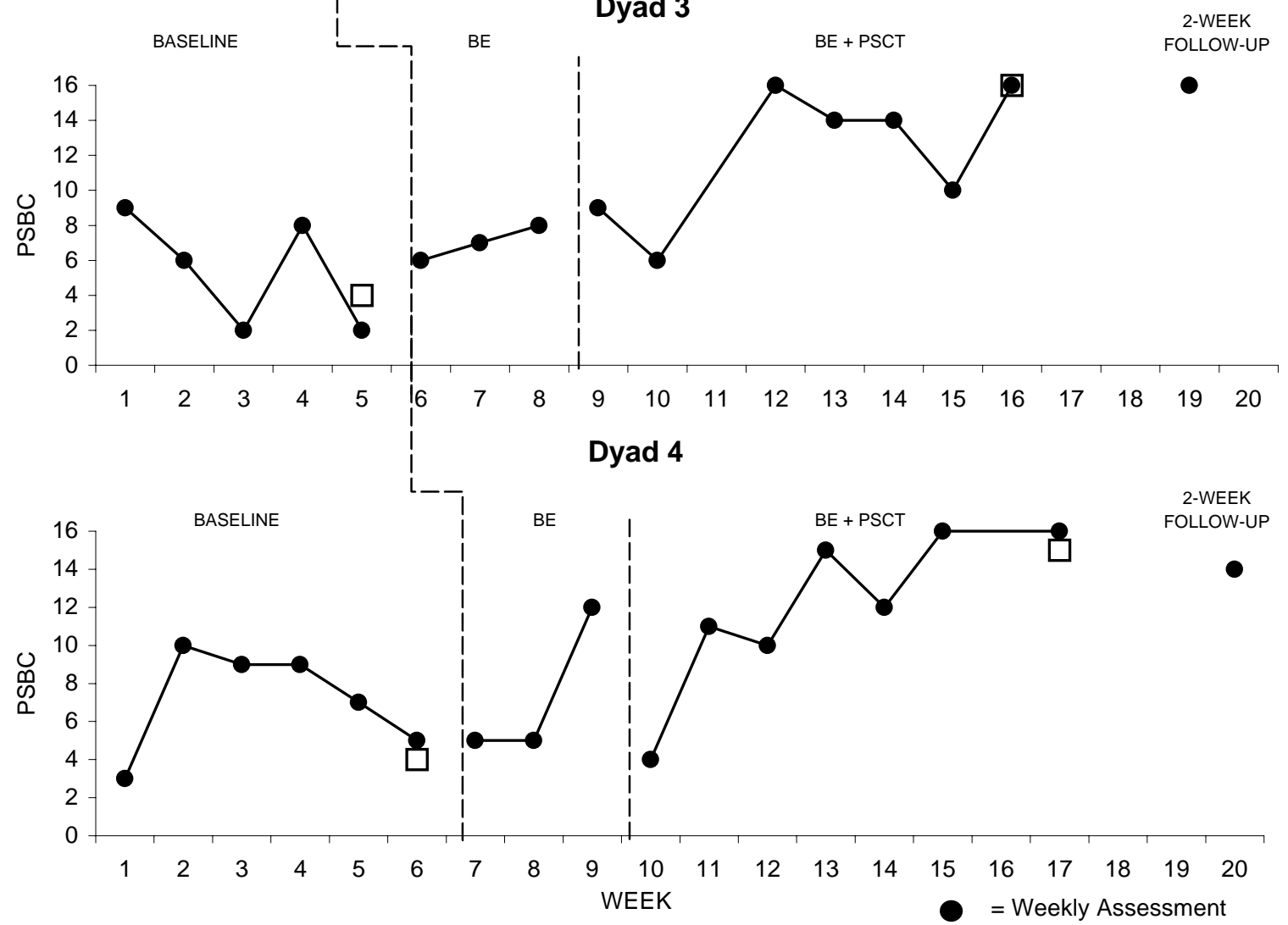

Figure 1. Problem-Solving Behavior Code Scores for Dyad 1 - 4. $\quad \square$ = Generalization Point 

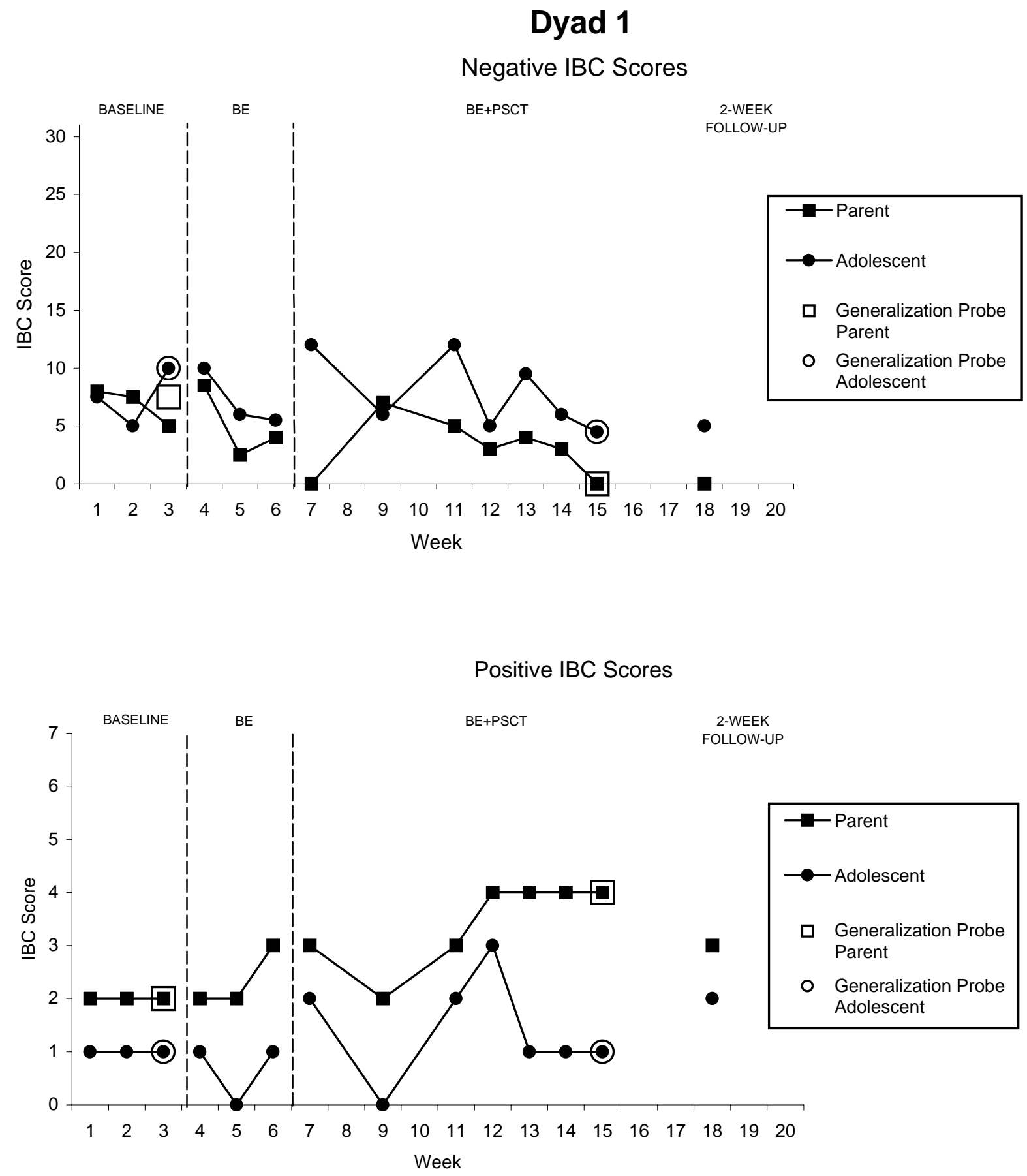

Figure 2. Interaction Behavior Code Scores for Dyad 1. 


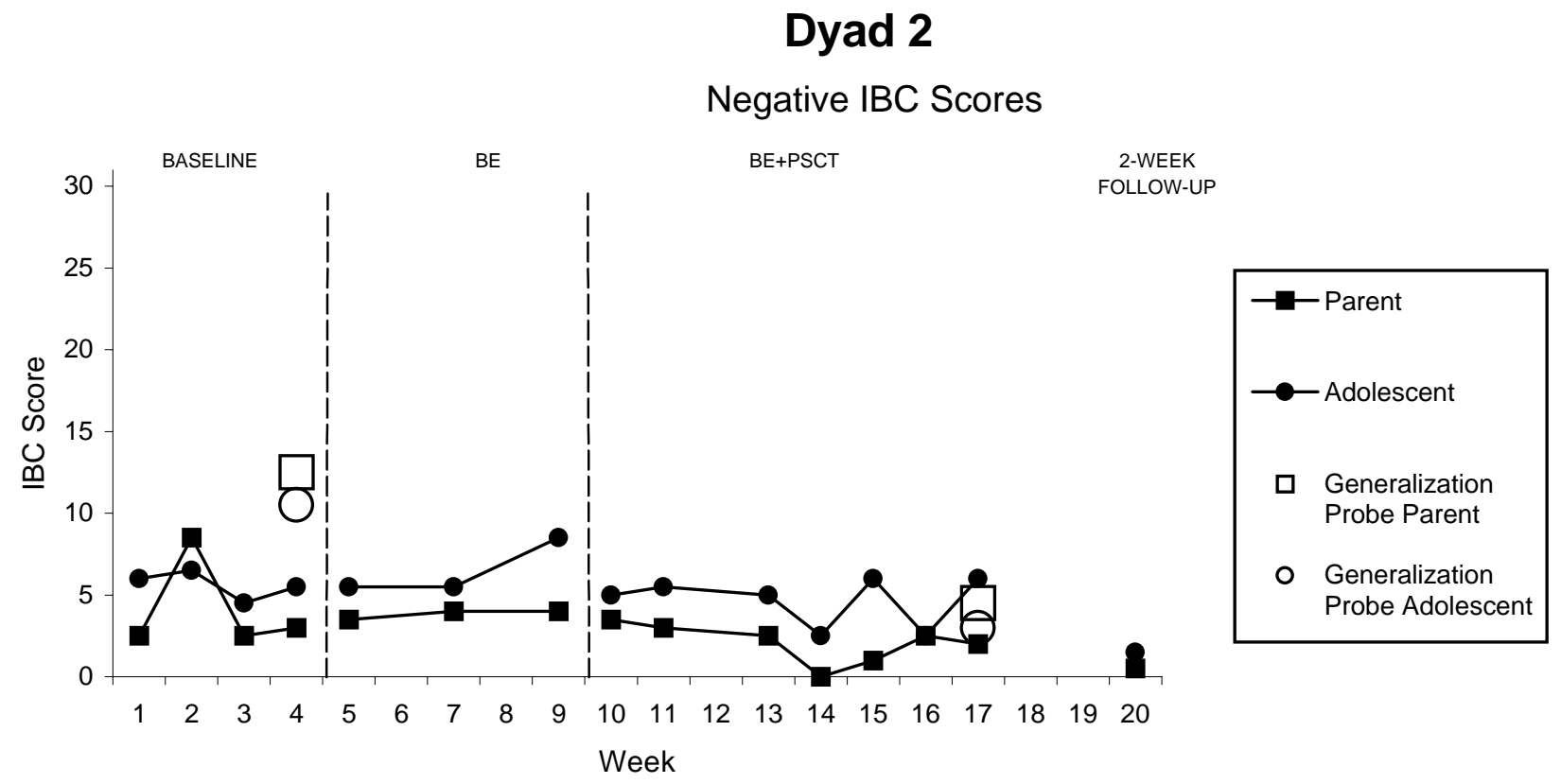

Positive IBC Scores

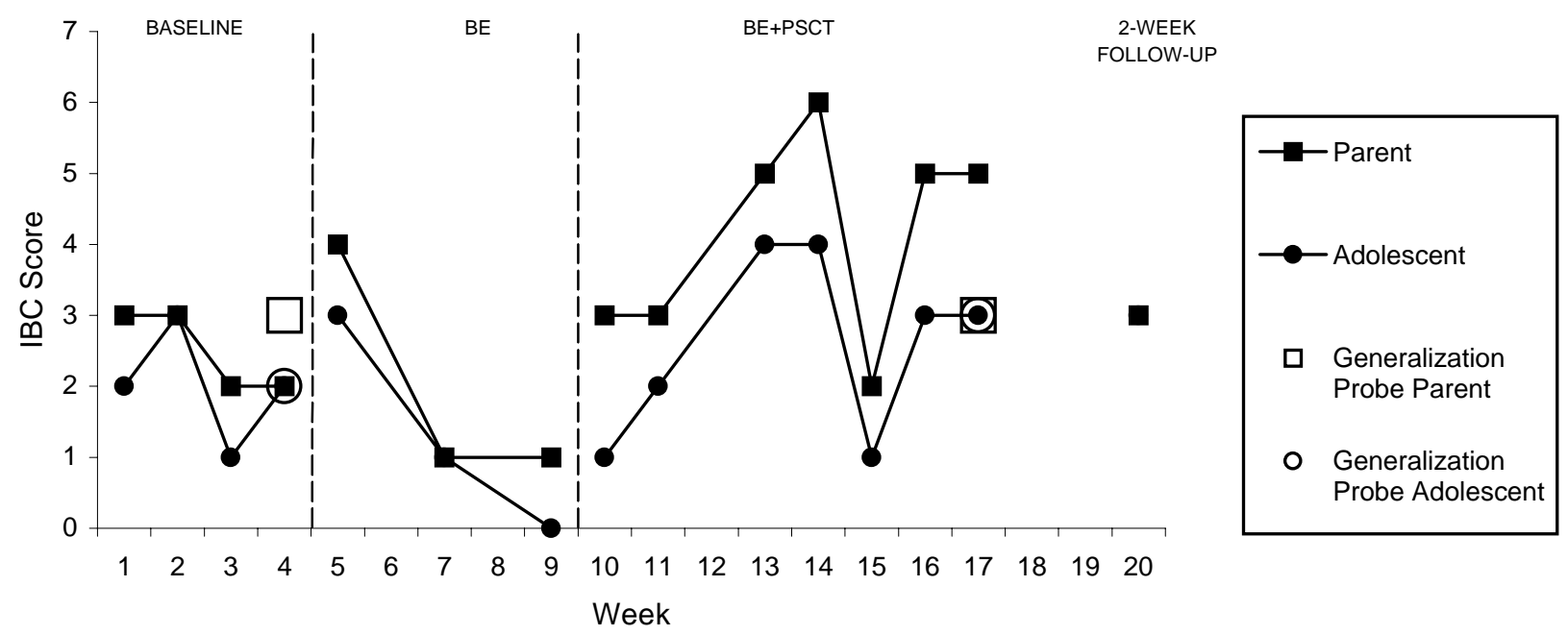

Figure 3. Interaction Behavior Code Scores for Dyad 2. 

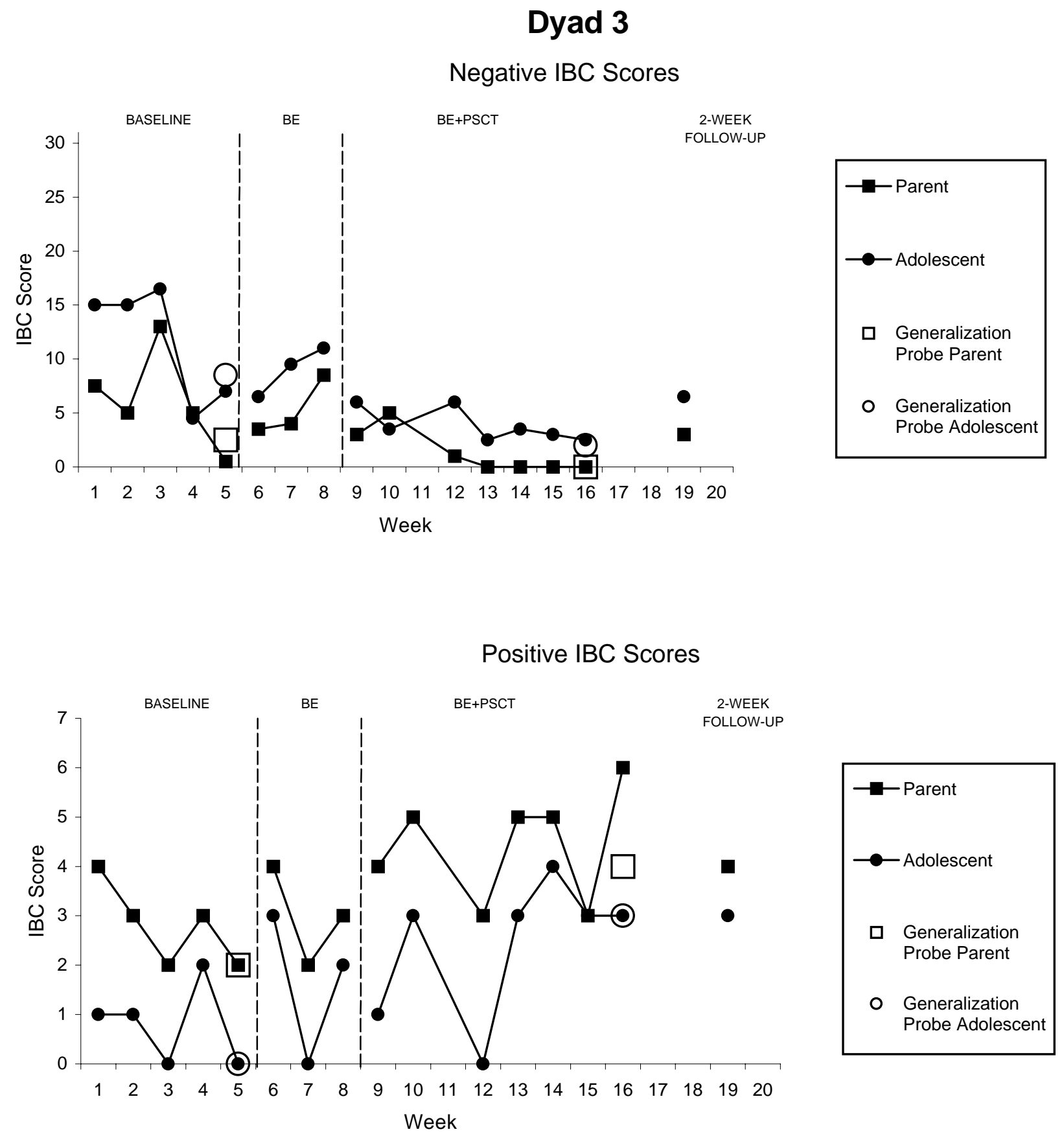

Figure 4. Interaction Behavior Code Scores for Dyad 3. 

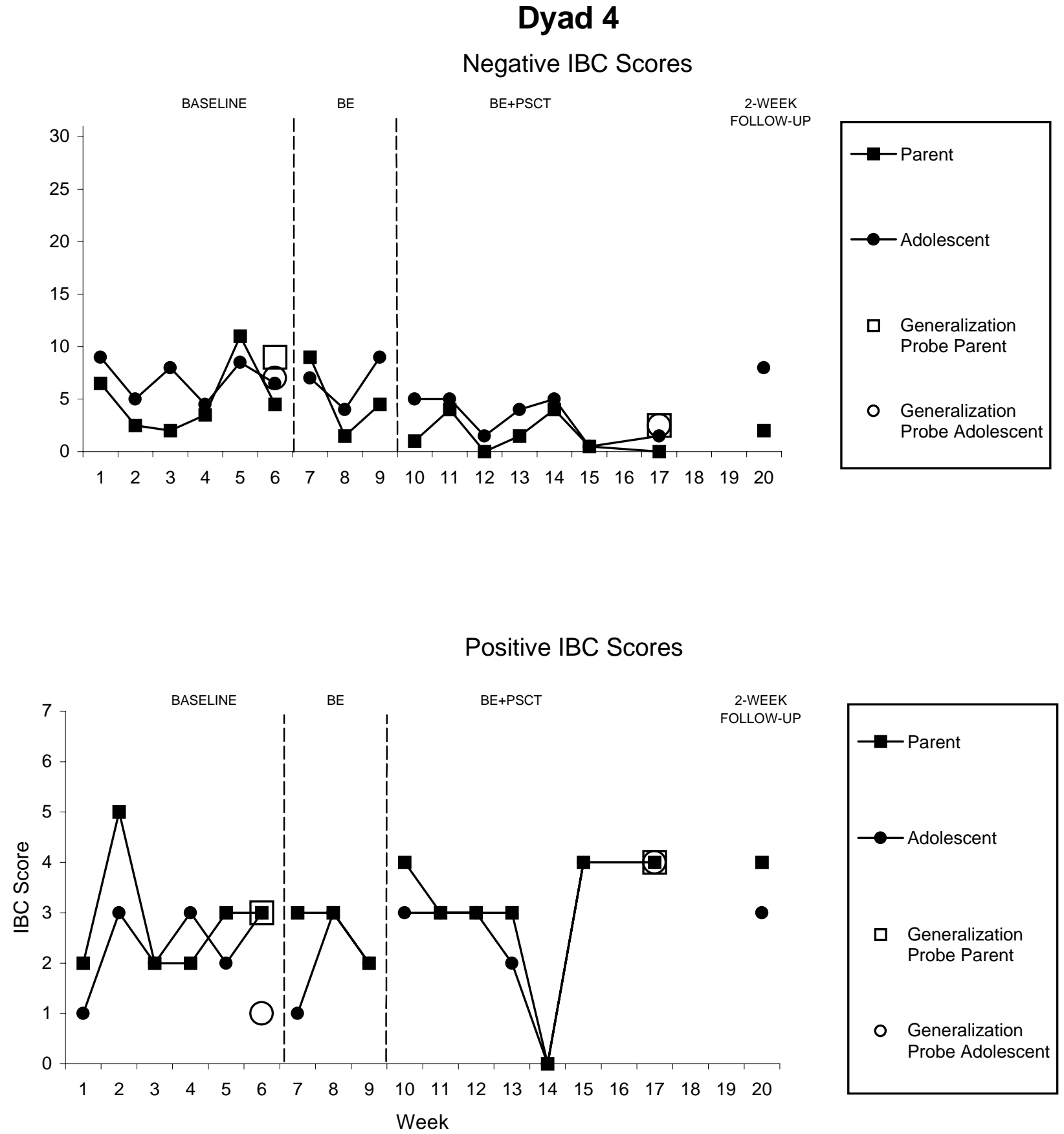

Figure 5. Interaction Behavior Code Scores for Dyad 4. 